\title{
WestVirginiaUniversity
}

THE RESEARCH REPOSITORY @ WVU

Graduate Theses, Dissertations, and Problem Reports

2010

\section{Religious and environmental values in PCUSA and UCC church camp programs}

\author{
Ross S. Bash \\ West Virginia University
}

Follow this and additional works at: https://researchrepository.wvu.edu/etd

\section{Recommended Citation}

Bash, Ross S., "Religious and environmental values in PCUSA and UCC church camp programs" (2010). Graduate Theses, Dissertations, and Problem Reports. 2949.

https://researchrepository.wvu.edu/etd/2949

This Thesis is protected by copyright and/or related rights. It has been brought to you by the The Research Repository @WVU with permission from the rights-holder(s). You are free to use this Thesis in any way that is permitted by the copyright and related rights legislation that applies to your use. For other uses you must obtain permission from the rights-holder(s) directly, unless additional rights are indicated by a Creative Commons license in the record and/ or on the work itself. This Thesis has been accepted for inclusion in WVU Graduate Theses, Dissertations, and Problem Reports collection by an authorized administrator of The Research Repository @ WVU. For more information, please contact researchrepository@mail.wvu.edu. 
Religious and Environmental Values in PCUSA and UCC Church Camp Programs

\author{
Ross S. Bash
}

\begin{abstract}
Thesis submitted to Davis College of Agriculture, Natural Resources and Design at West Virginia University in partial fulfillment of the requirements for the degree of

Master of Science in Recreation, Parks, and Tourism Resources
\end{abstract}

Chad D. Pierskalla, Ph.D., Chair

Steven W. Selin, Ph.D.

David A. Smaldone, Ph.D.

Department of Recreation, Parks, and Tourism Resources Division of Forestry and Natural Resources

\author{
Morgantown, West Virginia \\ 2010
}

Keywords: Environment, Nature, Environmental Values, Religious Values, Church Camps 


\section{ABSTRACT \\ Religious and Environmental Values in PCUSA and UCC Church Camp Programs}

Ross S. Bash

The association between denominational affiliation, as the independent variable, and (1) religious values, (2) environmental values, and (3) the integration of religious values and environmental values, as the dependent variables, in church camp programs of the Presbyterian Church (U.S.A.) (PCUSA) and the United Church of Christ (UCC) was examined through survey research of PCUSA and UCC church camps across the United States. The results indicated that there is a significant statistical relationship between PCUSA and UCC church camp programs by reference to denominational affiliation for all three dependent variables. 


\section{Acknowledgements}

I express my thanks to the following persons for their support and assistance in the course of my completion of this thesis and the requirements for the Master of Science degree at West Virginia University:

$\checkmark$ My committee comprised of Chad D. Pierskalla, Ph.D., Steven W. Selin, Ph.D., and David A. Smaldone, Ph.D.

$\checkmark$ Theresa G. Coble, Ph.D., of Stephen F. Austin State University, and Michael A. Schuett, Ph.D., of Texas A\&M University

$\checkmark$ Charles F. Melchert, Ph.D., Lee C. Barrett, III, Ph.D., and Anabel Proffitt, Ph.D., of Lancaster Theological Seminary.

$\checkmark$ The PCUSA and UCC camp directors and staff who participated in the survey that was part of this study.

$\checkmark$ My wife, Christiann, and our children, Sarah, Elizabeth and Nathan. 


\section{Table of Contents}

Chapter 1 - Introduction

Overview of the Topic and Study

Three Primary Dimensions of Church Camp Programs 2

Objectives of the Study $\quad 3$

Hypotheses

Denominational Context of the Study

Constituency Groups in Church Camping Programs $\quad 12$

The Historical Context of the Study 15

The Tradition of the Spiritual Retreat 15

The Tradition of Revival Movements and "Tent Camp Meetings"

$\begin{array}{lc}\text { The Tradition of Organized Camping } & 16\end{array}$

$\begin{array}{ll}\text { Significance of the Study } & 21\end{array}$

Chapter 2 - Literature Review 26

Outdoor Recreation Program Studies 26

Denominational Policy Papers and Statements 31

Denominational Surveys in the PCUSA 43

Church Camping Literature $\quad 53$

$\begin{array}{lr}\text { Chapter } 3 \text { - Methodology } & 82\end{array}$

Research Design $\quad 82$

$\begin{array}{lr}\text { Population } & 83\end{array}$

$\begin{array}{lr}\text { Instrumentation } & 85\end{array}$

$\begin{array}{lr}\text { Conditions of Testing } & 89\end{array}$

$\begin{array}{lr}\text { Data Analysis } & 90\end{array}$

Chapter 4 - Results $\quad 92$

Organizational and Descriptive Profiles 92

Religious Values $\quad 96$

$\begin{array}{lr}\text { Environmental Values } & 103\end{array}$

Integration of Religious Values and Environmental Values 110

$\begin{array}{ll}\text { Chapter 5 - Interpretation and Conclusions } & 117\end{array}$

Descriptive Profiles of PCUSA and UCC Camps 117

Three Aspects of PCUSA and UCC Camp Programs 119

$\begin{array}{ll}\text { Religious Values } & 119\end{array}$

Environmental Values 123

Integration of Religious Values and Environmental Values 126

$\begin{array}{ll}\text { Implications of the Study } & 130\end{array}$

Implications Related to the Literature 131

Outdoor Recreation Program Studies 133

Denominational Policy Papers and Statements $\quad 135$

Denominational Surveys in the PCUSA 135

Church Camping Literature 136 
Implications Related to the Practice of Church Camping 138

Implications Related to Limitations of the Study and Further Research 144 Limitations of the Study $\quad 144$

Potential for Further Research 147

Appendix: Survey Instrument 149

$\begin{array}{lr}\text { References } & 160\end{array}$ 


\section{Religious and Environmental Values in \\ PCUSA and UCC Camp Programs}

\section{Chapter 1 - Introduction}

\section{Overview of the Topic and Study}

Many religious groups in the United States that work with children, youth, and adults have a long tradition of church camp, conference and retreat programs that are carried out in outdoor settings. Among the religious groups in the United States providing such programs are two major Protestant denominations, the Presbyterian Church (U.S.A.) (PCUSA) and the United Church of Christ (UCC), and church camp programs of these two denominations serve as the focus of this study. The program facilities of such church camps, usually comprising residenttype facilities, are often located within a reasonable driving distance from where participants in the programs live, yet at sufficient distance from these more developed areas as to be (or seem to be) "set apart," thus fostering a sense of "living in the out-of-doors" or being in the midst of "God's creation."

While the term "church camping" is, perhaps, the most common name or term for these kinds of programs, they are also often described by other terms such as outdoor religious education, outdoor Christian education, and outdoor ministry. These various terms reflect subtle but significant differences in philosophy and practice, especially in terms of the value or benefit associated with the natural environment as a setting and as an actual element of the program. For example, if a program is described as "outdoor ministry," is it a program that actually does

outdoor ministry or is it a program that simply does ministry outdoors? If the latter, then it may actually be a form of religious proselytization carried out in an outdoor setting; in effect, it may simply represent a modern form of the proverbial "tent camp meeting" or a variation of the 
formalized "Sunday School class" transplanted outdoors. If it is the former, however, and actually involves outdoor ministry, then it will represent a program that is conceptually different in that its philosophy and practice will likely involve a synthesis or integration of both religious values and environmental values.

\section{Three Primary Dimensions of Church Camp Programs}

The fact that many religious groups in the United States sponsor church camps suggests that these kinds of programs play a significant role in the formation of beliefs and practices characteristic of these religious groups. However, many of the activities that take place in church camps (and virtually all of the activities in some church camps) do not require an outdoor setting. Moreover, the "outdoor" setting is not always "natural" as many of these activities are also carried out in community parks, playgrounds, or even in church buildings. While the "outdoors" may provide a pleasant and functional setting for church camp programs, what is its significance in terms of integrating religious and environmental values in these programs; that is, to what extent do these church camp programs contribute to the formation of religious beliefs and practices in ways that ground the relationship between God and God's creation, including humanity, more ecologically and holistically?

The philosophies and practices associated with church camp programs are diverse in that they reflect particular historical and cultural as well as ecclesiastical influences. Several church camping philosophies and practices are examined in this introduction and in the literature review. For purposes of this study, however, the various philosophies and practices in church camping are considered here primarily in terms of three dimensions that help define the field and characterize its practice: 
(1) Theological: It is a form of the church's ministry that tends to reflect beliefs and practices characteristic of particular faith traditions such as the faith traditions of the two religious groups that provide the denominational context of this study;

(2) Pedagogical: It is a form of ministry that, philosophically and in practice, is primarily educational with methodologies that tend to be non-formal and experiential; and

(3) Environmental: It is a form of educational ministry that not only takes place primarily in outdoor settings, but in which the outdoor setting contributes to a more ecological and holistic understanding of the relationship between God, humanity and the natural order.

All three dimensions are essential to the field and characterize its practice. Moreover, it is the synthesis or integration of all three dimensions that enables church camp programs to better contribute to a more informed understanding of, and responsibility for, the natural environment by grounding the relationship between God and God's creation, including humanity, more ecologically and holistically.

\section{Objectives of the Study}

The objectives of the study comprise the following:

(1) To examine and summarize philosophies and practices in the church camping field from a review of:

(a) Its denominational context in relation to the PCUSA and the UCC;

(b) Church camping constituency groups within the PCUSA and the UCC;

(c) The historical context of church camping and retreat programs; and

(d) Extant literature, but particularly program and curriculum material. 
(2) Through a nationwide survey of church camps affiliated with the PCUSA and the UCC to examine and compare:

(a) The organizational profiles of church camps in each denomination;

(b) The extent to which religious values are emphasized in church camp programs in each denomination;

(c) The extent to which environmental values are emphasized in church camp programs in each denomination;

(d) The extent to which religious values and environmental values are integrated in church camp programs in each denomination; and

(e) Whether the association between denominational affiliation and (1) religious values, (2) environmental values, and (3) the integration of religious values and environmental values values, in church camp programs in each denomination is statistically significant.

\section{Hypotheses}

Three hypotheses are advanced in this study:

$\mathrm{H}_{1}$ : Religious values in PCUSA and UCC church camp programs are independent of denominational affiliation and the association between them is not statistically significant.

$\mathrm{H}_{2}$ : Environmental values in PCUSA and UCC church camp programs are independent of denominational affiliation and the association between them is not statistically significant.

$\mathrm{H}_{3}$ : Integration of religious and environmental values in PCUSA and UCC church camp programs is independent of denominational affiliation and the association between them is not statistically significant. 


\section{The Denominational Context of the Study}

As noted above, this study examined church camp programs affiliated with the PCUSA and the UCC, two major Protestant religious groups or denominations in the United States. These two denominations reflect both convergence and divergence in their respective polity (forms of government), historical and socio-cultural origins, denominational development, geographical dispersion, and religious beliefs and practices.

Regional associations of local congregations in the PCUSA are called presbyteries. Presbyteries function collectively in synods, and both the national association and annual meeting of the denomination is called the General Assembly (Angell, 1984: Bonnell, 1975; Gray \& Tucker, 1986; Mead \& Hill, 1985; PCUSA Book of Order, 2001).

Regional associations of local congregations in the UCC are called conferences and its national association and biannual meeting is called the General Synod (Sheares, 1990; UCC About Us: A Family of Faith for a Global Community, n.d.; UCC About Us: The Constitution of the United Church of Christ, n.d.; UCC About Us: Frequently Asked Questions (FAQs) about the United Church of Christ, n.d.; UCC About Us: What is the United Church of Christ?, n.d.; Zikmund, 1990).

The PCUSA follows a representative form of government in which each level of church government functions through both clergy and laity as church officers. The lowest governing body, called the session, makes virtually all of the major decisions for the local congregation. Members of the session are ordained lay persons called elders (presbyteros from the Greek translates as elder or "old man"), and the session is moderated by a clergy member. The higher governing bodies, comprising presbyteries, synods, and the General Assembly, also function 
through elders and clergy as the elected representatives (Angell, 1984; Bonnell, 1975; Gray \& Tucker, 1986; Mead \& Hill, 1985; PCUSA Book of Order, 2001).

The UCC form of government is a Congregationalist model. A local congregation elects a consistory comprised of members of the congregation, but who are not ordained, and all major decisions are ultimately made by the congregation. Clergy may participate in both consistory and congregational meetings, but only to the extent that the consistory and congregation permit.

Higher governing bodies comprise associations, conferences, and General Synod which function through clergy and laity as elected representatives, although clergy tend to exercise greater degree of influence at these higher governing levels (Sheares, 1990; UCC About Us: A Family of Faith for a Global Community, n.d.; UCC About Us: The Constitution of the United Church of Christ, n.d.; UCC About Us: Frequently Asked Questions (FAQs) about the United Church of Christ, n.d.; UCC About Us: What Is the United Church of Christ?, n.d.; Zikmund, 1990). Both denominations share an ecclesiastical and historical affinity in terms of their identification with the Reformed tradition, a major theological tradition in Protestant Christianity. Both denominations are also considered to be "mainline denominations" in the United States. In terms of historical and cultural origins, Presbyterian emigrants tended to be from Scotland, Northern Ireland and Switzerland. Patterns of Presbyterian settlement tended to be in the middle and southern colonies, although there was some Presbyterian presence in New England. The Scotch-Irish in particular tended to move into the frontier areas of the colonies and there still exist strong patterns of Scotch-Irish Presbyterian tradition along the length of the Appalachian Mountains from Pennsylvania to Georgia (Angell, 1984; Dillenberger \& Welch, 1954; Leith, 1977, 1981; Leyburn, 1962; Mead \& Hill, 1985; Rian, 1940). 
Three constituent religious groups characterized emigration patterns of the several faith traditions that comprise the UCC. The two earliest groups were Puritans and Congregationalists, including the Pilgrims of Plymouth, Massachusetts and the Puritans of Salem, Massachusetts; in fact, Congregationalist faith tradition became dominant in New England. The third constituent group comprised the strong immigrant tradition of German Reformed, Lutheran, and other German Evangelical adherents who initially settled in Pennsylvania and subsequently throughout the Midwest (Bass, 1987; Dillenberger \& Welch, 1954; Dunn, Crusius, Friedli, Menzel, Schneider, \& Toth, 1990; Leith, 1977, 1981; Mead \& Hill, 1986; Nordbeck, 1990; Quellhorst, 1990; Schroeder, 1987; Taylor, 1990; UCC Short Course: Congregationalism, n.d.; UCC Short Course: German Evangelical Churches, n.d.; UCC Short Course: German Evangelical Synod, n.d.; UCC Short Course: German Reformed Church, n.d.; UCC Short Course: Moves Toward Unity, n.d.; UCC Confirmation: A Guide for Confirmation Instruction, 1994; UCC Short Course: Not the Final Chapter, n.d.; UCC Short Course: Reformation in England, n.d.; UCC Short Course: Reformation Roots, n.d.; UCC Short Course: The Christian Churches, n.d.; UCC Short Course: The Congregational Christian Churches, n.d.; UCC Short Course: The Evangelical and Reformed Church, n.d.; UCC Short Course: The First Centuries, n.d.; UCC Short Course: Westward Expansion and Social Vision, n.d.; UCC What is the United Church of Christ?, 1975).

Presbyterianism in North America has been marked by both schisms and mergers too numerous and complex to do more than mention. Most of the schisms have involved theological disputes, although a major split occurred over slavery in 1860 . There may be as many as eight or nine distinct denominations in the United States at present that call themselves "Presbyterian," of which the PCUSA is the largest. The PCUSA resulted from the merger in 1983 of the northern 
and southern branches of Presbyterianism that divided over slavery at the outbreak of the Civil War and only reunited after some 120 years. This merger, however, resulted in another schism in the southern branch of Presbyterianism among those who opposed the 1983 merger because they viewed the northern branch of Presbyterianism as too "liberal." An earlier merger, in 1958, reunited two branches of the northern church that split in the $19^{\text {th }}$ century over theological issues. Ironically, there is again a substantial risk of schism in the PCUSA over several theological issues that involve the same sort of liberal/conservative or modernist/traditionalist disputes that have been the cause of past schisms (Coalter, Multer, \& Weeks, 1990; Daly, 2000; Farley, 1990; Mead \& Hill, 1985; Rian, 1940; Rogers, 1995; Wuthnow, 1990).

In contrast, the United Church of Christ represents a number of mergers and few, if any, schisms over a period of some 250 years. In the early $17^{\text {th }}$ century, various Puritan groups in New England joined together as North American Congregationalism. This loosely-connected association was joined in 1892 by the Congregational Methodists; in 1925 by the Evangelical Protestants; and in 1927 by the German Congregationalists. In 1931, the Congregational Christian Churches were formed when the Congregationalists merged with the Christian Church, a religious group that was itself the result of a merger in 1922 of the First Free Christian Church and the Southern Christian Convention, both established in the mid- $19^{\text {th }}$ century. In 1934 , the Evangelical and Reformed Church was formed by the merger of the German Reformed Church of the U.S., and the Evangelical Synod in North America, both established in the $19^{\text {th }}$ century. In 1957, the UCC was established by merger of the Congregational Christian Churches and the Evangelical and Reformed Church (Bass, 1987; Dillenberger \& Welch, 1954; Dunn et al., 1990;

\footnotetext{
${ }^{1}$ A major point of the theological dispute that gave rise in part to this particular schism was the ordination of women. Those Presbyterians who left the southern branch of Presbyterianism and formed the Presbyterian Church in America (PCA) opposed the ordination of women, although there were other theological issues that also contributed to the schism.
} 
Gunnemann, 1987; Leith, 1977, 1981; Mead \& Hill, 1986; Nordbeck, 1990; Quellhorst, 1990;

Schroeder, 1987; Taylor, 1990; UCC Short Course: Congregationalism, n.d.; UCC Short

Course: German Evangelical Churches, n.d.; UCC Short Course: German Evangelical Synod, n.d.; UCC Short Course: German Reformed Church, n.d.; UCC Short Course: Moves Toward Unity, n.d.; UCC My Confirmation: A Guide for Confirmation Instruction, 1994; UCC Short Course: Not the Final Chapter, n.d.; UCC Short Course: Reformation in England, n.d.; UCC Short Course: Reformation Roots, n.d.; UCC Short Course: The Christian Churches, n.d.; UCC Short Course: The Congregational Christian Churches, n.d.; UCC Short Course: The Evangelical and Reformed Church, n.d.; UCC Short Course: The First Centuries, n.d.; UCC Short Course: Westward Expansion and Social Vision, n.d.; UCC What is the United Church of Christ?, 1975).

Consistent with their common roots in the Protestant Reformation, the PCUSA and the UCC share many theological beliefs and practices. Both denominations share similar views as to sacraments and forms of worship. Both denominations are Trinitarian and adhere to other major themes of the Reformed tradition (e.g., the sovereignty of God, the sinful nature of humanity, the redemptive nature of Jesus Christ, the authority of scripture, the priesthood of all believers, and the doctrines of vocation, election, and salvation by grace through faith) (Alston, 1984; Angell, 1984; Bass, 1987; Bonnell, 1975; Dillenberger \& Welch, 1954; Fackre, 1990; Farley, 1990; Johnson \& Hambrick-Stowe, 1990; Leith, 1977, 1981; Marheine, 1995; Mead \& Hill, 1985; Schroeder, 1987; Trost, 1990; UCC My Confirmation: A Guide for Confirmation Instruction, 1994; UCC What is the United Church of Christ?, 1975; Zikmund, 1990).

Presbyterians, however, have tended to be much stricter in adherence to many doctrinal standards, especially on the part of ordained persons, while the UCC has tended to allow more 
doctrinal freedom and interpretation among its adherents and constituent congregations. For example, while both denominations adhere to the doctrine of election (i.e., who will be "saved"), Presbyterians have tended historically toward a much narrower and stricter interpretation of this doctrine. As their history of schisms illustrates, Presbyterians also tend to be more divided in their understanding of the authority of scripture. For example, the term "fundamentalism" (but not the tradition itself which was earlier) grew out of a controversy that divided Presbyterians in the 1920s over what constituted the "essentials" (or "fundamentals") of faith and belief to which all candidates for ordination as well as ordained persons must vow to adhere. This controversy has never been fully resolved and remains a potential source of further schism (Bonnell, 1975; Coalter et al., 1990; Daly, 2000; Farley, 1990; Mead \& Hill, 1985; Rian, 1940; Rogers, 1995; Wuthnow, 1990).

Both denominations are also "confessional" churches (i.e., making use of formal and historic statements or "confessions" of religious belief). Presbyterians, however, have tended to make greater and stricter use of confessions of faith. For example, the PCUSA has adopted 11 different confessions as a Book of Confessions (1999) and all candidates for ordination and ordained persons must promise to be "instructed" by these confessions. While the UCC also uses confessional statements, they are treated more as "testimonies of faith" rather than "tests of faith" (Angell, 1984; Bonnell, 1975; Farley, 1990; Marheine, 1995; Mead \& Hill, 1985; PCUSA, Book of Confessions, 1999; PCUSA Book of Order, 2001; Rogers, 1995; UCC About Us: What is the United Church of Christ?, n.d.; UCC What is the United Church of Christ?,1975; Wuthnow, 1990).

Both denominations also strongly emphasize religious education as an integral aspect of their understanding and practice of ministry. This emphasis on educational ministry includes not 
only traditional church school programs (i.e., "Sunday School") for different age groups, but also programs that are not classroom-based such as youth groups and other fellowship groups intended to serve different age or interest groups within local congregations. In addition to educational programs in local congregations, groups of churches work collectively within presbyteries (PCUSA) and conferences (UCC) to provide programs for children, youth and adults. While these programs tend to be regional, some are national in scope. Church camps represent an important aspect or form of each denomination's educational ministry through presbyteries and conferences that primarily serve local congregations within their geographical regions. The PCUSA and the UCC also have constituency groups that focus on church camping as an integral aspect of each denomination's educational ministry. Some presbyteries and conferences also sponsor conference and retreat centers, although these centers do not usually provide outdoor programs. The PCUSA also has national conference centers in New York, North Carolina and New Mexico, but these centers generally do not provide outdoor programs (Bonnell, 1985; Burgess, 1975; Harris, 1989; Leith, 1981; Little, 1995; Marheine, 1995; Monkres \& Ostermiller, 1995; PCUSA Association of Presbyterian Church Educators, n.d.; PCUSA Book of Confessions, 1999;; PCUSA Book of Order, 2001; PCUSA Christian Education in the Presbyterian Church (U.S.A.), n.d.; PCUSA Presbyterian Church Camp and Conference Associates, n.d.; Smart, 1954; UCC My Confirmation: A Guide for Confirmation Instruction, 1994; UCC About Us: What is the United Church of Christ?, n.d.; UCC Outdoor Ministries Association - United Church of Christ, n.d.; UCC The Association of United Church Educators, n.d.; UCC The Educational Mission of the United Church of Christ, n.d.).

Both denominations have also taken strong advocacy positions at the national level on issues related to the environment and environmental concerns. The respective positions of each 
denomination are discussed in the literature review. Both the PCUSA and the UCC also have affiliated "interest groups" that function to develop increased cognizance of environmental issues through newsletters, conferences, resource materials, cooperative efforts with other religious and secular groups, and various forms of political advocacy and "grassroots" organizing (e.g., PCUSA Presbyterians for Restoring Creation, n.d.; UCC Network for Environmental and Economic Responsibility, n.d.). This focus conforms to long tradition in each denomination pertaining to a significant moral, cultural, economic, and even political role in the history and social ordering of the nation. Although the influence and strength of both denominations, like "mainlines" generally, has declined in the United States over the last quarter century, they still play a significant role in American society and remain strongly representative of the "Protestant ethic" in some regions that so dominated much of our nation's history (Angell, 1984; Bonnell, 1975; PCUSA Book of Order, 2001; PCUSA Environmental Justice Office, n.d.; PCUSA Social Justice Ministries, n.d.; UCC About Us: What is the United Church of Christ?, n.d.; UCC Justice and Peace, n.d.; UCC Justice and Peace: Biblical Foundations, n.d.; UCC Justice and Peace: Take Action, n.d.; UCC Neighbors in Need: It's About Justice!, n.d.; UCC What is the United Church of Christ?, 1975).

\section{Constituency Camping Groups in the PCUSA and UCC}

Constituency groups play a significant role in church camping by: (1) Providing a means for representing camp leaders, staff and participants involved in particular kinds of programs; (2) Providing a means of identification and support within sponsoring groups and organizations; and (3) Reflecting philosophies and practices in church camping characteristic of particular kinds of programs. Constituency groups affiliated with the PCUSA, Presbyterian Church Camp and 
Conference Associates (PCCCA), and the UCC, the Outdoors Ministries Association - United Church of Christ (OMA), are examined here.

PCCCA is a group representing approximately 150 camping, retreat, and conference facilities affiliated with the PCUSA (PCUSA Presbyterian Church Camp and Conference Associates, n.d.). It previously functioned as a more informal group, but has become more structured by reason of the changing nature of the camping industry (e.g., funding and liability concerns) and a denomination-wide restructuring of the PCUSA. As a result, PCCCA has assumed many camp and conference-related functions that were formerly handled by denominational staff. Its membership generally comprises PCCCA camp directors and other camp staff. It holds an annual conference and other events that include workshops, speakers in the camping field, focus on common issues facing PCUSA church camps and conferences (e.g., food service, funding, and staffing), and opportunities for social interaction and spiritual renewal among camp directors and staff of PCUSA church camps.

While the "care of Creation" is described as part of its mission, its primary focus is serving as resource for its member camps, conference and retreat facilities, providing training opportunities and benefits to individual members, providing consulting services, and serving as the "programmatic arm" of camp and conference ministry in the PCUSA:

The mission of PCCCA is to equip leaders for ministries of discipleship, community building and the care of Creation. It seeks to provide a common voice and shared vision for Presbyterian camp and conference ministry... (PCUSA Presbyterian Church Camp and Conference Associates, n.d.; PCCCA Vision Statement, 2009). 
The Outdoor Ministries Association - United Church of Christ (OMA) is a group representing approximately 65 church camping, retreat, and conference facilities. Its overarching purpose is to promote and provide support for outdoor ministry in the UCC. Like PCCCA, its membership generally comprises camp directors and other camp staff. Its purposes similarly involve serving as a resource for UCC camps, providing education and training opportunities, and holding an annual conference and other events that include workshops, speakers in the camping field, focus on common issues facing UCC church camps (e.g., food service, funding, and staffing), and opportunities for social interaction and spiritual renewal among camp directors and staff of UCC church camps.

However, OMA seems to provide more of an emphasis on both the environmental dimension and the integration of the environmental and religious dimensions in terms of outdoor educational ministry than does PCCCA. For example, its name not only incorporates "outdoor ministry," but it also includes among its stated purposes: “[to] discover and deepen...faith through encounters with God in creation and Christian community...to promote outdoor ministries in all areas of the church; and to celebrate the many wonders of God's nature!" (UCC Outdoor Ministries Association, n.d.). Moreover, its Mission Statement (n.d.) emphasizes the interdependence both between UCC camps and the denomination and between the church and “God's creation:"

Recognizing and affirming Outdoor Ministries as a significant partner in the ministry and future of the Church, the purpose of the Outdoor Ministries Association United Church of Christ is to advise, connect and advocate on behalf of the network of persons responsible for outdoor ministries in the United Church of Christ, so that we may work together to meet the needs and find common 
solutions, deepening and broadening the understanding of the interdependence of the whole of God's creation on behalf of the whole church (UCC Outdoor Ministries Association Mission Statement, n.d. ).

\section{The Historical Context of the Study}

Church camping and retreat programs have their primary historical origin in three traditions: (1) Spiritual retreats; (2) Revival movements and "tent camp meetings;" and (3) Organized camping.

\section{The Tradition of the Spiritual Retreat}

While the relationship between the tradition of church camps and retreats and other historical traditions of the church is significant, it has not always been sufficiently recognized. For example, the spiritual practice of religious contemplation, prayer and study in a natural setting - one that is "set apart" from "everyday life" - has its roots in the ancient monastic tradition of a spiritual retreat, for example, in a desert or mountain setting. This tradition was exemplified by Jesus in the biblical tradition of going into the wilderness, up on a mountain or to some other lonely place to fast, pray or be alone with his disciples. ${ }^{2}$ The religious "retreat" thus represents both a time and a place "set apart" for spiritual preparation, transition or renewal (Klopfenstein, Klopfenstein, \& Williams, 1984; Louth, 1991; Paetkau, Harder, \& Sawatzky, 1978).

\section{The Tradition of Revival Movements and "Tent Camp Meetings"}

A parallel tradition of both socio-cultural and religious significance in the $18^{\text {th }}$ and $19^{\text {th }}$ centuries in the United States, from which the tradition of church camping also arose in part, was that of religious revival movements and the proverbial "tent camp meeting." Some of these revival meetings lasted for days and involved thousands of people gathered in an outdoor setting.

\footnotetext{
${ }^{2}$ See, for example, Matthew 4:1-11, 14:23; Mark 1:12-13, 6:31-32; Luke 4:1-13, 9:28; John 6:15, 11:54.
} 
In the late $19^{\text {th }}$ century, this religious tradition began to evolve into religious "institutes" and large religious conferences of which the Chataqua Movement is, perhaps, the best known (Graendorf \& Mattson, 1979; Klopfenstein et al., 1984; Mackay, 1984; Mattson, 1998; Mitchell, Robberson, \& Obley, 1977).

\section{The Tradition of Organized Camping}

The origins and history of church camping are even more evident in the historical context and larger tradition of the organized camping movement (Eells, 1986; Graendorf \& Mattson, 1979; Klopfenstein et al., 1984). Organized camping has been defined by the American Camping Association (ACA), probably the largest organized camping group in the field, as:

A sustained experience which provides a creative, recreational, and educational opportunity in group living out-of-doors. It utilizes trained leadership and the resources of natural surroundings to contribute to each camper's mental, physical, social and spiritual growth (ACA Accreditation Standards, 1998).

Writers in the field have similarly identified the "characteristic elements, blended together in the right proportion, of an organized camp [as]: (1) persons, (2) outdoor life, (3) living in groups, (4) a camp community, and (5) leadership and conditions designed to satisfy personal needs and interests and to stimulate wholesome personal, social and spiritual development" (Ball \& Ball, 1995, citing Dimock, 1948). The camp experience [should be] "indigenous to group living in the out-of-door setting" (Ball \& Ball, 1995, citing Dimock, 1948).

The adaptation and application of these definitions or perspectives of organized camping to church camping emphasizes the same "elements," but from a more specific and overtly religious orientation: 
- A short-term residential experience in a natural setting.

- A non-formal educational experience in the outdoors.

- A temporary and dynamic interaction of people and environment designed for purposeful outcomes.

- A social unit with many of the characteristics of a family interacting in an outdoor setting.

- A temporary community in the context of a permanent modeling community.

- A leadership laboratory using the temporary community in the out-of-doors.

- The Church ministering out-of-doors.

- A short-term period of withdrawal from the normal setting and activities of life for the purposes of renewal and growth (Klopfenstein et al., 1984).

It has been stated in this regard that while the camping experience is unique, its "ultimate effectiveness [within the church camping tradition] lies not in its uniqueness, but in terms of uniquely fulfilling its established purpose" (Klopfenstein et al., 1984). The church camping experience is thus intended to be related to "the Church's total ministry:"

The uniqueness of camp is implicit to its natural environment; the uniqueness of the Christian camp is evidenced in the personal relationship of its leaders to the Creator of the environment (Klopfenstein et al., 1984).

The historical origins of the organized camping movement have been attributed to the legendary traditions and narrative accounts of frontiersmen, pioneers and Native Americans (Eells, 1986; Graendorf \& Mattson, 1979; Mackay, 1984; Mitchell et al., 1977). Its more recent origins, however, are attributed to a shift in social and cultural perspectives that arose in the United States in the late $19^{\text {th }}$ century when the American frontier was declared to be "closed" as 
primitive natural areas and "wilderness" throughout the nation were being populated and developed (especially by extractive or resource-intensive industries such as mining and timbering). Attitudes about nature and the natural world in this period began to shift from fear to hostility to a more romantic and even benign tradition hearkening back to Rousseau and later Thoreau (Eells, 1986).

Many of the early organized camps also grew out of two significant social welfare movements in the United States in the late $19^{\text {th }}$ century and early $20^{\text {th }}$ century. The first, the Fresh Air Movement, reflected a concern for children's health and morals, especially children living in crowded urban areas. It was believed that the fresh air of the country and mountains would have a curative and restorative effect on young people. Attention was also given to providing camping opportunities for physically handicapped children. The second movement, the Settlement Movement, was inspired by the work of the Rev. Samuel Barnett in London and Jane Addams in Chicago amidst the extraordinary waves of new immigrants to the United States between 1889 and 1912. It reflected a concern for the welfare of families living in crowded and unsanitary tenements, ameliorating conflicted social interaction among different classes and ethnic groups in the United States, and promoting enjoyment and conservation of the natural environment (Ball \& Ball, 1995; Eells, 1986).

Development of organized camping has also been divided into three different eras or stages: (1) The recreational stage from 1861 to 1920; (2) The educational stage from 1920 to 1930; and (3) The social orientation and responsibility stage from 1930 through the present (Klopfenstein et al., 1984; Kraus \& Scanlin, 1983; Mitchell et al., 1977). The organized camping field has also been examined in terms of social, cultural, and historical trends reflecting the nature of camping programs, the particular focus of agencies or groups sponsoring the programs, 
and the philosophical and social factors that have tended to cause camping programs to evolve differently over different periods of time. For example, a long-term historical trend can be identified in which the camping movement moved from an ignorance and even hostility about outdoor recreation and programs, to one of indifference, to one of increasing interest, and ultimately to what approximates a virtual institutionalization of organized camping. The involvement of quasi-public agencies, especially those serving children and youth, is another related long-term trend in organized camping, reflected by organizations such as the Salvation Army, the YMCA, the YWCA, 4-H, the Boy Scouts of America, the Girl Scouts of America, and the Camp Fire Girls. Another long-term trend that accelerated in the late 1940s and early 1950s is the significant and increasing significance of religious education as an important element in organized camps established by religious groups and denominations (Eells, 1986; Graendorf \& Mattson, 1979; Klopfenstein et al., 1984; Mackay, 1984; Van Slyck, 2006). It has been suggested by one writer, however, that religious camps (or at least those of an evangelical orientation) have tended to change more slowly in response to these kinds of long-term trends than secular camps (Mackay, 1984).

An increasingly significant involvement of government at all levels can also be observed in organized camping, although this involvement has tended to wax and wane according to political, social, and cultural trends characteristic of particular time periods. For example, the era of large land "set asides" by government at both federal and state levels in the late $19^{\text {th }}$ century and early $20^{\text {th }}$ century coincided with the growth of social movements that were supportive of organized camping. This included the formation at the federal level of the United States Forest Service, the National Park Service and, to a lesser extent, the Bureau of Land Management, as well as the development of parks and recreation areas by both states and cities during the same 
period. Federal work assistance programs such as the Works Progress Administration and the Civilian Conservation Corp in the Great Depression era of the 1930s also contributed significantly to the development of campgrounds and recreation areas (Ball \& Ball, 1995 Eells, 1986; Graendorf \& Mattson, 1979). A significant shift in the philosophy of organized camping can also be noted as, for example, from health and recreation characteristic of the late $19^{\text {th }}$ century and early $20^{\text {th }}$ century, to outdoor education programs characteristic of the 1940 s, to specialized camps, environmental education programs and experiential education programs increasingly characteristic of the organized camping field today (Ball \& Ball, 1995; Kraus \& Scanlin, 1983; Mackay, 1984; Van Slyck, 2006;Venable \& Joy, 1998).

Professional organizations have also increasingly affected development of the organized camping field. This reflects a trend toward trained leadership in the field and can be dated from the Conference of Boy Workers established in 1902 by the YMCA. This trend is also reflected by organizations such as the American Camping Association (ACA) and its predecessor, the Camp Directors Association (CDA), founded in 1924. CDA published the first professional journal in the field, Camping, which is still being published by ACA. CDA was succeeded by ACA in 1935, and ACA is now considered to be the leading professional organization in the field (Eells, 1986). This increased emphasis on professional development is also viewed as contributing to three particular values in the organized camping field: (1) Outdoor education; (2) Relationships and associations among participants; and (3) The camping program itself in terms of skills, mental and physical health, appreciation for outdoor living, recreation, selfgrowth, contact with diverse opinions and values, and group interaction (Shivers, 1989). To better achieve these values, ACA has developed and promoted professional standards and 
resources in organized camping through leadership training, research and publications in the field, and accreditation of camps (Mitchell et al., 1977; Shivers, 1989).

\section{Significance of the Study}

There is a growing awareness - an awareness that is scientific, economic, social, cultural, political and even spiritual ${ }^{3}$ in nature - that the earth and its life forms are in the midst of an environmental crisis. The evidence and effects of the crisis are not uniform in that it affects different regions of the earth - and different peoples as well as other life forms on earth - in different ways and to different degrees. It arises from a number of factors that are not uniform, but rather are variable and diffuse. It also affects both developed nations and developing nations, although adverse environmental conditions tend to affect developing nations and the poor of the earth more severely than developed nations and the more affluent of the earth. ${ }^{4}$ The title of a book by Wackernagel and Rees (1996), Our Ecological Footprint: Reducing Human Impact on the Earth, provides an excellent metaphor to describe this crisis. It is the "tread" of humanity's "footprint" on the earth's ecosystems that represents the primary cause of this crisis; that is, the factors giving rise to this crisis can be attributed primarily to humanity's impact on the natural world and not, conversely, to the natural world's impact on humanity. This perspective is also reflected in the increasing body of literature, supported by research in a variety of disciplines,

\footnotetext{
${ }^{3}$ See, for example, Rasmussen (1996), Sharper (1997), Tucker and Grim (2000), and World Council of Churches (1990) for discussion of the spiritual nature of the environmental crisis.

${ }^{4}$ The environmental crisis includes concerns such as increased pollution of air, soil and water, especially by toxins; loss of habitat and increased risk of species extinction in terms of both plant and animal life; adverse effects on genetic diversity and viability, including commercial control, manipulation, dilution, and even elimination of genetic varieties, especially in relation to food production; reemergence of diseases in more virulent forms once thought to be controlled or even eradicated; increased resistance of bacteria and viruses to medicines and medical treatment; changes in global conditions, including sea levels, ocean currents, weather patterns and climate; gross inequities in the allocation and use of natural resources, including rampant depletion of resources, some of which (e.g., rainforests) may be vital to sustaining conditions essential to life on a global scale; and a potential, and often actual, decline in the viability of both humans and non-human life forms.
} 
that considers and attempts to address the environmental crisis in terms of its effect on both human and non-human life forms. ${ }^{5}$

It has also been argued by a number of writers that Christianity has contributed to, and may have actually caused, much of the environmental crisis. For example, developed nations having Christianity as their dominant religious tradition historically engaged in rampant colonialism characterized by exploitative practices toward both natural resources and indigenous peoples in undeveloped or less developed nations (including European exploration and development of the American continents). In addition to their economic purpose, such practices often had an evangelical or missionary purpose in terms of converting "heathen" peoples, by force if necessary, to Christianity. While the extent to which environmental harm and destruction can be attributed to Christianity in terms of cause and effect is problematic, it is certainly the case that, with only a few exceptions (e.g., Francis of Assisi and Patrick of Ireland), Christianity has not been characterized historically by a strong tradition of environmentalism (Berry, 1973; Bouma-Prediger, 2001; Cobb, 1992; Gustafson, 1994; Johnson, 2000; McFague, 1993, 1997; Nash, 1997; Oelschlaeger, 1994; Rasmussen, 1996; Rolston, 1992; Santmire, 1985; White, 1967; White, 1973). However, as the policy papers and statements of the PCUSA and the UCC on the

\footnotetext{
${ }^{5}$ See, for example, the AAAS Atlas of Population and Environment (Harrison and Pearce, 2000) of the American Association for the Advancement of Science; The Biodiversity Crisis: Losing What Counts (Novacek, 2001) of the American Museum of Natural History; Our Living Resources: A Report on the Distribution, Abundance, and Health of U.S. Plants, Animals, and Ecosystems (LaRoe, Farris, Puckett, Doran, \& Mac, 1995) of the National Biological Services of the U.S. Department of the Interior; State of the World 2002: A Worldwatch Institute Report on Progress Toward a Sustainable Society (Starke, 2002) of the Worldwatch Institute; World Resources 2000-2001: People and Ecosystems, The Fraying Web of Life, (The World Resources Institute, 2000) of the United Nations Development Programme, the United Nations Environment Programme, the World Bank, and the World Resources Institute. However, this is not to ignore contrary views as to the causes, nature, extent, and potential means of resolving the environmental crisis. For example, an excellent critique of some of the claims, and especially much of the rhetoric, of the environmental movement is provided by Lomborg (2001) in The Skeptical Environmentalist: Measuring the Real State of the World. Lomborg is a statistician by profession and he examines many of the claims made in the environmental field on the basis of actual statistical data. His position is that the scientific data in the environmental field tends to be accurate and reliable, but that many of the claims made in purported reliance on this data, often in non-scientific and even apocalyptic terms (what he calls the environmental "litany"), are not supported by the data. Lomborg's book is, therefore, intended to be a corrective in the environmental field to the sort of claims that either are overstated or are simply inaccurate.
} 
environment and environmental concerns summarized in the literature review in Chapter 2 indicate, this aspect of Christian tradition is gradually shifting from one of environmental ignorance, apathy and even hostility to one characterized by increased environmental concern, responsibility and even activism (e.g., environmental stewardship and environmental justice).

Notwithstanding the fact that the very nature of the outdoor setting of church camps provides effective opportunities for both environmental education and religious education, it is unclear as to how or even whether these kinds of environmental concerns are being effectively addressed in church camps. For example, much of the literature in the church camping field does not emphasize or integrate nature, the natural environment or an environmental dimension in church camp materials. As this study proposes to examine and compare in terms of PCUSA and UCC church camps, to what extent do church camps in each of these two denominations focus, primarily if not exclusively, on traditional religious concerns such as evangelism? To what extent do PCUSA and UCC church camps treat nature and the natural environment, primarily if not exclusively, as simply a setting for camp programs? Conversely, to what extent do PCUSA and UCC church camps - whether in response to the environmental crisis or simply in accord with the strong environmental policy positions of their respective denominations - treat nature and the natural environment as a critical concern that requires an effective integration - environmentally, pedagogically, and theologically - of religious values and environmental values in their camp programs? The possible reasons for the persistence of an emphasis, primary if not exclusive, on traditional religious concerns such as evangelism are not readily apparent (and this study does not attempt to articulate such reasons except indirectly). However, "tradition" itself seems to be central to the primary focus of church camps; that is, the long-established religious beliefs and practices under which church camps were organized and have developed reflect strong historical 
and theological traditions. These traditions, thoroughly grounded in the Reformation, did not (at least until recently) include an environmental emphasis as a primary focus; in fact, significant aspects of the Reformed tradition (e.g., Barthian) reflect an antipathy or even hostility toward nature and the natural environment as a legitimate source of theological inquiry or Christian belief and practice (e.g., natural theology or a theology of nature) (Barr, 1993; Fraenkel, 1946; Grenz, Guretzki, \& Nordling, 1999; Haldane, 2000; Harvey, 1964; Hauerwas, 2001; Hendry, 1980; McFague, 1993; Sittler, 1972).

This traditional focus of church camp programs, including PCUSA and UCC church camps, is also in marked contrast to significant parts of the origins and historical tradition of the organized camping movement as well as the work of environmentalists both within and outside organized religion. While the enjoyment of nature and the natural environment represents an important aspect of the church camp experience, the church's ministry in the context of the environmental crisis could reasonably be expected to result in a stronger and more integrated environmental dimension being incorporated in church camp programs. For example, is the moral and ethical significance of nature and the natural environment emphasized and integrated in church camp programs, including PCUSA and UCC church camps, or is this significance largely neglected or ignored? In terms of moral and ethical significance, do nature and the natural environment have intrinsic value (i.e., value in and of themselves), representing an ecocentric or biocentric perspective, or do they have only instrumental value (i.e., value only in terms of the benefit they provide to humans), representing an anthropocentric perspective?

The significance of this study, therefore, goes first to the question of the extent to which PCUSA and UCC church camps tend to focus, primarily if not exclusively, on traditional religious values and concerns such as evangelism. A second, but related, question is the extent to 
which nature and the natural environment, in terms of environmental values, are emphasized in church camp programs rather than being treated more or simply as a program setting.

Lastly, the significance of the study is that it examines and compares the extent to which PCUSA and UCC church camps effectively integrate - environmentally, pedagogically and theologically - religious values and environmental values. This last focus can, at least potentially, provide a more integrated approach to church camping programs that will serve the educational objectives of both religious and environmental purposes, while also contributing to the formation - and the reformation - of Christian beliefs and practices in ways that can ground the relationship between God and God's creation, including humanity, more ecologically and holistically. 


\section{Chapter 2 - Literature Review}

The literature reviewed comprises four areas: (1) Studies related to environmental education and/or youth development and other benefits of outdoor recreation programs, including residential and day camp programs. ${ }^{6}$ (2) Denominational policy papers or statements adopted by the Presbyterian Church (U.S.A.) (PCUSA) and the United Church of Christ (UCC) having reference to the environment or environmental concerns; (3) Denominational surveys in the PCUSA having reference to the environment or environmental concerns; and (4) Church camping literature.

\section{Outdoor Recreation Program Studies}

While the literature reporting research related to outdoor recreation programs, including residential and day camp programs, is extensive, there is virtually no literature specifically related to church camps, especially in relation to either environmental values in church camping or the integration of religious and environmental values in church camp programs. The focus here is therefore on studies that, by analogy or implication, can be used to examine the potential for emphasis of religious and environmental values, and their integration, in PCUSA and UCC church camp programs.

Hungerford and Volk (1990), noting that the "ultimate aim of education is shaping human behavior" (p. 8), state that, in relation to environmental education, there is a progression that can be observed regarding behavioral change that moves from knowledge to awareness and attitudes to action. This progression is summarized by five objectives: ${ }^{7}$

\footnotetext{
${ }^{6}$ This section includes discussion of the study by Negra and Manning (1997) from which the instrument used in the present study was developed in significant part.

${ }^{7}$ Negra and Manning (1997) use a model or framework of seven environmental indicators that is based on these five objectives developed by Hungerford and Volk (1990).
} 
(1) Developing an "awareness" (p. 8) of the natural environment and problems or issues associated with human impact on it;

(2) Developing "sensitivity" to and a "basic understanding" (p. 9) of the natural environment and problems or issues associated with human impact on it;

(3) Developing "attitudes," reflected in acquisition of a "set of values and feelings of concerns" about the natural environment, that will motivate "active [participation] in environmental improvement and protection" (p. 9);

(4) “[Acquiring] skills for identifying and solving" (p. 9) problems and issues related to the natural environment associated with human impact on it; and

(5) Providing opportunities for "participation... and [active involvement] in working toward resolution" (p. 9) of problems and issues related to the natural environment associated with human impact on it.

Negra and Manning (1997), in considering potential design of environmental education programs in parks, examine environmental behaviors, values, and ethics of park visitors using a framework of seven environmental indicators based on Hungerford and Volk (1997) and a typology of environmental ethics statements. The typology has as its purpose:

... empirical measurement of environmental ethics drawn from the theoretical, historical and empirical literature (DeVall \& Sessions, 1985; Graber, 1976; Hargrove, 1989; Kellert, 1980; Kellert \& Berry, 1979; Leopold, 1949; Nash, 1989; Rolston, 1989; Stone, 1972; Valliere, 1994; White, 1967) (p. 12).

It also measures "three key concepts" (p. 12) in relation to environmental behavior, values, and ethics: 
(1) An "anthropocentric-biocentric continuum" under which anthropocentric ethics will tend to determine "moral relationships" between humans and nature more on the basis of "human needs" while biocentric ethics will tend to determine these "moral relationships" more on the basis of "the intrinsic rights of both humans and nonhumans" (p. 12);

(2) "Ethical extensionism and egalitarian ethics" under which "ethical extensionism" identifies an "expansion of moral consideration and extension of intrinsic rights over time to an ever-widening spectrum of human and nonhuman communities" and "egalitarian ethics" that morally equates humans and nonhumans (p. 13); and

(3) "Secular, religious and spiritual beliefs" in terms of convergence and divergence of "secular environmental ethics [that are] based in rational thought," "religiously based ethics [that] draw on institutional religious teachings," and "spiritually based ethics [that] draw on beliefs regarding spiritual qualities of nature" (p. 13).

The typology utilized by Negra and Manning (1997) comprises 16 environmental ethics statements divided into five categories: ${ }^{8}$

(1) Anti-environment: "Aggressively anthropocentric ethics that espouse active engagement in controlling nature and accord negative moral status to non-human entities" (p. 15). This category comprises of two statements:

(a) "Nature can be dangerous to human survival" (p. 15); and

(b) "Nature is sometimes evil" (p. 15);

(2) Benign indifference: "Definitively anthropocentric ethics that dictate that humans have no moral relationship with nature and translate into unlimited use of natural resources" (p. 15). This category comprises three statements:

\footnotetext{
${ }^{8}$ Negra and Manning (1997) indicate 17 "environmental ethics" statements in the typology (13), but there are only 16 statements actually listed in the table by which they summarize the typology (15-16).
} 
(a) "Nature is a valuable storehouse of raw materials" (p. 15);

(b) "Humans were created as fundamentally different from other living things" (p. 15); and

(c) "The ability to think makes humans fundamentally different from other living things" (p. 15);

(3) Utilitarian conservation: "Anthropocentric ethics that direct humans to exercise caution in their use of nature because of acknowledged limits in nature's ability to produce goods and services" (p. 15). This category comprises four statements:

(a) "Cruelty toward animals makes people less human" (p. 15);

(b) "The supply of goods and services provided by nature is limited" (p. 15);

(c) "Nature adds to the quality of our lives" (p. 15); and

(d) "Human survival depends on nature and natural processes" (p. 15);

(4) Stewardship: "Ethics that bridge the gap between anthropocentrism and biocentrism by recognizing the moral status or spirituality of nonhuman entities" (pp. 15-16). This category comprises four statements:

(a) "It is our religious/spiritual duty to take care of nature" (p. 15);

(b) "Nature will be important to future generations" (p. 16);

(c) "Nature is God's creation" (p. 16); and

(d) "All living things have a spirit" (p. 16); and

(5) Radical environmentalism: "Biocentric ethics, grounded in science or spirituality, that extend moral considerability to nonhumans and reject ethical hierarchy" (p. 16). This category comprises three statements:

(a) "Animals should be free from needless pain and suffering" (p. 16); 
(b) "All living things are sacred" (p. 16); and

(c) "Humans are related to other living things through evolution" (p. 16).

Environmental education in outdoor programs has also been examined in relation to the effect of outdoor activities (e.g., camps and adventure activities) on environmental attitudes and behaviors and as a basis for developing environmental responsibility (Palmberg \& Kuru, 2000; Thapa, 2010), fostering positive attitudes toward wildlife on the part of students in residential programs (Dettman-Easler \& Pease, 1999), building self-esteem and increasing environmental awareness and naturalist skills in campers at nature camps (Dresner \& Gill, 1994), developing more positive attitudes toward the outdoors and increasing understanding of ecological principles and the interconnectedness of humans and the environment on the part of staff in residential camps (Strickland, 1991), and developing a view of nature as a sacred symbol on the part of campers in religiously-oriented camps (Clampit, 1970).

Studies have also focused on development of environmental attitudes and knowledge and perceiving the benefits of environmental education in school or other educational settings through children's activities (Eagles \& Demare, 1999), using natural settings for educational purposes (Simmons, 1998), using science to help students become better environmental decisionmakers (Arvai, Campbell, Baird, \& Rivers, 2004), using a “multiple perspectives approach" to environmental issues (Christenson, 2004), the effect of pre-trip and post-trip activities in a residential environmental education program (Smith-Sebasto \& Cavern, 2006), and the use of particular environmental education programs such as NatureScope (Armstrong \& Impara, 1991).

Youth development and other benefits associated with the camp experience, but not related specifically to environmental education, have also been a focus of the research related to residential and day camp programs. These benefits include such things as building self-esteem 
and developing positive self-identity, developing social and leadership skills, making friends and healthy peer relationships, developing mental and physical skills, increasing self-confidence through adventure and challenge activities, developing positive values, and increasing environmental awareness (Henderson, Powell, \& Scanlin, 2005; Henderson, Scanlin, Whitaker, Thurber, Marsh, Burkhardt, \& Bialeschki, 2005; Ross \& Driver, 1988; Sekine, 1994). Spiritual growth has also been examined, either as a specific and distinct benefit or in combination with other benefits, in relation to both non-religious and religious camp programs (Henderson \& Bialeschki, 2008; Henderson, Powell, \& Scanlin, 2005; Schnell, 1996).

\section{Denominational Policy Papers or Statements}

The PCUSA General Assembly and the UCC General Synod have adopted a number of socio-theological policy papers and statements related to the environment or environmental concerns. The PCUSA policy papers and statements are reviewed first.

In relation to its mission and ministry, especially educational ministry, PCUSA policy papers and statements over the last 25 years indicate a strong commitment to environmental protection and restoration both within the larger Church and within society. These policy papers provide the denominational context for what Presbyterian church camps are doing (or not doing) in terms of the inclusion of environmental values and the integration of environmental values and religious values in church camp programs. In 1982, the United Presbyterian Church in the U.S.A. (UPCUSA), one of two predecessor denominations of the present PCUSA, adopted a policy paper entitled The Theology of Stewardship that focuses on the church's responsibility to practice stewardship of the natural environment in relation to God's covenant in creation of the natural order. It posits a parallel between environmental stewardship and the traditional concern for funding the mission of the church in terms of a strong connection between covenant and 
stewardship; that is, in "following God's example as the creator and sustainer of life," the church acknowledges that "God's covenant requires that the church work toward the protection of the earth and its resources" (p. 338). It also draws on a denominational survey regarding stewardship discussed later in this literature review.

In 1984, the UPCUSA adopted a policy paper entitled Christian Faith and Economic Justice that again focuses on God's covenant in creation of the natural order. In terms of this covenant, four things are stated about God's creation: (1) It is good because it is created by God; (2) The material things of creation (e.g., natural resources) are given by God for the benefit of all of humankind, including future generations; (3) Because it is God's creation, human dominion over material things (e.g., natural resources) is limited; and (4) Because humanity is created in God's image, humans are to be treated with dignity, including development of economic systems that are protective of all of humanity (pp. 370-371). This policy paper thus focuses specifically on the relationship between economic systems and the ecological crisis in terms of social and environmental justice as it involves six primary concerns: (1) Rapid population growth, especially in poorer nations; (2) Exploitation of natural resources by richer nations; (3) The rampant poverty of poorer nations, especially as conditions of poverty are related to inequality in the consumption of natural resources; (4) Massive transformation of the global economy by multinational corporations; (5) Dwindling natural resources and the ultimate limits to economic growth in relation to the ecological crisis; and (6) The role of capitalistic systems, especially in the United States, in addressing (or failing to address) these concerns (pp. 376-383).

In 1990, after the merger that formed the PCUSA, a policy paper entitled Restoring Creation for Ecology and Justice was adopted by the PCUSA that directly addressed 
environmental and ecological concerns. In addition to examining biblical grounds for the protection and restoration of creation, this statement addresses the need for "eco-justice" (ecology and justice) in terms of combining ecological health and wholeness with social and economic justice (pp. 647-648). The need for eco-justice is described by reference to the major components of the ecological crisis: depletion of resources, lack of sanitary water, disposal of solid and hazardous waste, population growth, threats to plant and wildlife, global warming, and ozone depletion (pp. 648-651). Specific responses are proposed toward earth-keeping and the healing of creation that include advocacy for policies that preserve the environment, promote sustainability, conserve energy, relieve hunger and famine, work for economic justice, promote sustainable agriculture, protect water quality, preserve wildlife and wild lands, eliminate hazardous waste and toxic threats, and reduce atmospheric instability, global warming and ozone depletion (pp. 652-670). The policy paper also calls upon the PCUSA to work for environmental preservation and restoration through mission initiatives, education and leadership development, public policy advocacy, citizen participation and organization, and corporate responsibility (pp. 671-676).

In 1996, the PCUSA adopted another policy paper entitled Hope for a Global Future: Toward Just and Sustainable Human Development. It draws on the Presbyterian Confession of 1967 in which "enslaving poverty," whether arising from unjust social conditions or exploitation of the natural world, is deemed "an intolerable violation of God's good creation" (p. 250). In contrast to the adverse effects of economic policies of the United States on the world's poorest nations and peoples, it views creation as an "antidote" to idolatry arising in "economic forms:"

Our treasures are indicators of our ultimate values, and wherever these values are incompatible with the values created by God, there is idolatry. We are 
devoted to false gods when we lavish confidence in technology to save us from our ecological follies; we seek plenty obsessively; we engage in compulsive and competitive consumption; and we commit ourselves to Economic Fate - that makes prosperity for some and poverty for others inevitable (p. 253).

The 1996 policy paper also identifies some of the ways in which we either affirm or deny moral and Christian duty toward "biophysical realities [that] have great moral significance" (p. 254):

- We affirm our moral duty when we "image" God and justly and benevolently exercise dominion for "the entire stewardship of nature." We deny our moral duty when we treat dominion as "a license for [its] destruction" or "a divine grant to prey on [it] without restraints" (pp. 254-255).

- We affirm our moral duty when we exercise dominion as "responsible representatives" of God and treat creation "in accord with the values of God's dominion. We deny our moral duty when we "oppress" creation, "distort" God's image, and "usurp" God's sovereignty (p. 255).

- We affirm our moral duty when we practice "social and ecological responsibility." We deny our moral duty when we fail to be "faithful stewards... on behalf of the interest of both human and non-human kind" (p. 255).

- We affirm our moral duty when we acknowledge and abide by the "ecological covenant" of justice intended by God that recognizes "the interdependence of all creatures [that] share the earth together." We deny our moral duty when we act unjustly in terms of "economic depredations and ecological plunderings all over the world" (pp. 256-258). 
- We affirm our moral duty when we recognize the perils as well as the promise of technology in relation to the earth and its peoples. We deny our moral duty when we fail to address harmful, albeit unintended, consequences of technology or treat technology as a panacea for social and ecological irresponsibility (pp. 258-260).

- We affirm our moral duty when we acknowledge that the "moral ordering of the planet requires that biological limits be respected, that just rules of relationship be observed, and that our interdependence in culture and with nature be honored." We deny our moral duty when we are "disdainful of these limits and disruptive of these rules" (p. 260).

As the 1996 policy paper states in conclusion: "Christians can discern the dynamics of sin by searching constantly for the causal relationship between environmental abuse and ecological collapse, and between human injustices and social disorders...For the church to represent God's values, it must witness on behalf of social and ecological justice and call out for repentance and reconciliation" (p. 260). ${ }^{9}$

The policy papers and statements adopted by the UCC related to the natural environment or environmentally-related concerns have been more numerous, numbering 27 , than those adopted by the PCUSA. They have also been more targeted than those of the PCUSA as the UCC policy positions have tended to be stated more in the form of pronouncements or resolutions. ${ }^{10}$ The UCC policy positions reviewed were adopted over a period of 40 years, from 1959 through 1999. While the PCUSA policy papers were reviewed chronologically as an entire

\footnotetext{
${ }^{9}$ The work of the task force that drafted the 1996 policy paper was extended by an entire issue of Church and Society magazine. This issue included articles such as "Ethical Imperatives" by Abival Pires de Silva, "Forests Are Not Forever" by Edna J. Orteza, "Moral Norms for Just and Sustainable Development" by Larry Rasmussen, and :Sizing the Earth: Understanding 'Caring Capacity"” by James W. Kuhn.

${ }^{10}$ The UCC denominational policy positions discussed here are indexed in The Prophetic Statement: Social Policy Statements of the United Church of Christ, 1957-1992 and Social Policy Statements of the United Church of Christ, 1993-2000.
} 
group, the UCC policy statements are reviewed within 10 focus areas, beginning with those focus areas most closely related to this thesis.

The UCC has adopted six policy papers or statements directly related to the care and protection of the natural environment. In its Statement on a Decent Environment, adopted in 1970, the UCC calls for stricter pollution controls at all levels of government by reason of the need for a "new ecological ethic which would redirect the allocation of our natural resources such as air, water, soil, wild life and minerals" (p. 1) In 1975, a policy paper was adopted entitled Report on Christian Life Style and Ecology also addresses pollution, but views it more broadly by reference to patterns of growth and development and the level of consumption characteristic of life styles in the United States as compared to other nations in five areas: food, recycling, energy, population (i.e., family size) and land use (pp. 46-49). A second report having the same title was adopted in 1977 and focuses on the impact of industrialization on the biosphere, the limits of energy resources and the need for conservation of natural resources generally, the risk of placing undue reliance on technology as an environmental remedy, and the ethical and theological questions posed by the ecological crisis. (pp. 45-47). A Resolution on Christian Environmental Stewardship adopted in 1983 calls for promotion of environmental protection with particular emphasis on the issue of hazardous wastes (pp. 87-88), as does a Resolution on Environment, Solid Waste and Ecologically Sound Lifestyle adopted in 1989 (p. 64). Lastly, in 1991, the UCC adopted a Resolution in Support of UCC Delegates to the Earth Summit that emphasizes the inter-faith nature of efforts to address environmental degradation and destruction that crosses ethnic and cultural as well as national boundaries.

The UCC has also adopted separate policy papers or statements as to climate change, care for animals, and leisure. The UCC adopted a Resolution on Global Warming in 1999 that raises 
the environmental and climate-related dangers posed by global warming in terms of the biblical mandate to practice stewardship of God's creation. Moreover, it challenges industrial nations, and especially the United States, to reduce greenhouse gases that contribute to global warming and calls on government to enact legislation to reduce dependence on fossil fuels and development alternative energy sources (pp. 125-126). In 1993, the UCC adopted a Resolution of Respect for Animals that acknowledges the relationship within creation that humans share with animals; that is, the relationship creatures have with their Creator. It also notes the biblical mandate that humans should act with compassion and care toward animals rather than cruelty. While humans can thus properly use animals for food and other purposes, all living creatures, as fellow creatures of God with humans, are deserving of humane and respectful treatment (pp. 5354). Finally, the UCC adopted a Resolution on Leisure in 1967 that addresses economic changes in society that often allow people more time and possibilities for leisure. It also views this development as an opportunity for educational growth, although not referencing camps and camp programs explicitly in this regard, while also noting this growing emphasis on leisure raises new questions as to people's worth and dignity that are distinct from their economic worth in terms of work and productivity (p. 83).

Environmental justice has also been a strong focus of environmental concern in the UCC by way of its adoption of four policy papers or statements. In 1975, it adopted an Overture on the Bicentennial with an Affirmation of Human Interdependence that emphasizes recognition not only of the interdependence of the earth's inhabitants, but also their unity as a global community (pp. 90-92). Environmental justice is also included as one of several issues requiring social and political action in a Resolution and Report on Racial and Economic Justice adopted in 1977 (pp. 90-91). The UCC adopted a statement in 1989 entitled Integrity of Creation, Justice and Peace 
that, while emphasizing the interrelationship of these three concepts, argues that injustice - in terms of war, hunger, poverty, and economic and environmental exploitation - is the impediment to "full and equal human development with protection of the ecosystem" (p. 32). In 1991, the UCC adopted a Resolution on Justice in the Maquiladoras as a response to a specific case of the interrelationship between economic exploitation and environmental injustice in terms of environmental, working and living conditions of Mexican nationals employed by U.S.-based transnational corporations in the border area between Mexico and the United States (p. 90).

The relationship between environmental protection and economic development has also been an important concern for the UCC in terms of seven policy papers or statements. In 1959, the UCC issued a Call to Christian Action in Society which, more than a decade before the advent of the environmental movement in the United States, argues that realization of goals such as freedom, world peace, human welfare, and social justice requires recognition and inclusion of the need for "conservation and development of the earth's resources for the benefit of mankind now and in the future" (p. 173). While acknowledging the human tendency and temptation "to love things and use people when we should love people and use things" (p. 173), it also asserts the need for a recognition of the interdependency that is not only characteristic of the human condition, but that would also move Americans to remedy socio-political conditions such as concentrations of economic power, inequality and injustice, inequitable and unsustainable levels of consumption, and the misuse of leisure time that adversely affects both their own wellbeing and that of people in other nations (pp. 171-175). While not described explicitly in terms of environmental protection or the conservation of natural resources, this is also the theme of Justice and International Development adopted by the UCC in 1967, in which the affluence, 
wellbeing, and economic advantage of developed nations, particularly the United States, is starkly contrasted with that of less developed nations.

The same theme is advanced in Hunger, Population and World Development adopted by the UCC in 1969, but it emphasizes that the need to recognize that the problem of inadequate sources and distribution of food in some parts of the world, especially conditions of malnutrition and famine, also requires addressing related problems such as burgeoning population growth in less developed nations, the lack or denial of access to family planning resources in many nations, the gross inequity of trade policies between nations, and the misuse of aid by developed nations to obtain or enhance their economic, political, or military hegemony over less developed nations (pp. 54-55). The same theme is raised in Overture on the Bicentennial with an Affirmation of Human Interdependence adopted by the UCC in 1975 and discussed above in terms of its focus on environmental justice (pp. 90-92). The same theme is raised in a Resolution for Support of the United Nations Conference on Environment and Development adopted by the UCC in 1991 that not only notes the need to address the environmental crisis, but also the fact that less developed nations are adversely affected by this crisis more than developed nations. It also cites the policy paper entitled Integrity of Creation, Justice and Peace discussed above in terms of the spiritual as well as the social dimension of environmental concerns (p. 43). Finally, the UCC adopted a Resolution in Support of International Fair Trade in 1993 that advocates development of more sustainable relationships between the environment and economic development, especially in terms of trade policies and treaties (e.g., the North American Free Trade Agreement), enactment of new laws and more effective enforcement of existing laws affecting the environment and working conditions, and development and promotion of more sustainable manufacturing and agricultural practices (pp. 20-22). 
Four policy papers or statements adopted by the UCC focus on concerns related to development and the environment, specifically population and hunger. In 1967, the UCC adopted a Resolution on Population Control expressing support for increasing efforts on the part of government and the United Nations to deal with the problem of burgeoning population growth (p. 70). The UCC also adopted a Resolution in Support of the United Nations Conference on Population and Development in 1993 that makes reference again to the Integrity of Creation, Justice and Peace discussed above and also emphasizes the sort of linkages increasingly evident between "poverty, environmental destruction and unlimited population growth" (p. 53). As also discussed above, the UCC adopted a policy paper entitled Hunger, Population and World Development in1969 that emphasizes the need to recognize similar linkages between inadequate sources and distribution of food in many world regions, especially under conditions of malnutrition and famine, problems such as burgeoning population growth in less developed nations, the lack or denial of family planning resources in many nations, gross inequities in trade policies between nations, and the misuse of aid by developed nations to obtain or enhance their economic, political, and military hegemony over less developed nations (pp. 54-55). Lastly, the UCC adopted a policy paper in 1975 entitled Pronouncement on the World Food Crisis that notes that the causes of world hunger are "complex and interrelated;" population growth, particularly in developing nations; exploitation of agricultural and forest lands causing soil erosion, floods and pollution; large concentrations of land ownership by the rich that result in exploitation of the poor and landless; patterns of trade and foreign aid that give economic advantage to developed nations over less developed nations; the increasing cost of oil amidst an increasing dependence on oil in developed and developing nations; and the effect of drought, soil depletion and like conditions on food production (pp. 54-55). Among the recommendations made 
to remedy these conditions, the policy paper advocates a "respect for the environment" that includes increased effort by government to "end abuse, misuse and overuse [of] the earth and its resources [that violates] the fragile, ecological fabric of the planet" (pp. 55-56).

Another environmental concern on which the UCC has focused involves the relationship between hazardous waste and the environment. Two policy papers or statements on hazardous waste have been adopted by the UCC. The first, adopted in 1983, is entitled Pronouncement on Toxic and Hazardous Waste. It is grounded in the biblical imperative of stewardship of creation whereby the wellbeing of the earth and its diverse life forms compels the conclusion that toxic pollution should not be tolerated. Moreover, as the storage and disposal of toxic and hazardous waste most has tended to impact areas inhabited by persons of color and the poor, resolution of this issue is also a matter of environmental justice (pp. 48-50). The second statement, entitled Pronouncement on National Toxic Injustice, was adopted in 1985. In extending and further developing the theme of the first statement, it notes that toxic pollution has approached crisis proportions and now adversely affects thousands of communities just in the United States. In addition to health and safety concerns, toxic pollution has also created severe, adverse and longterm environmental effects. The statement also addresses the environmental injustice aspect of toxic pollution in that, again, it impacts persons of color and the poor far more than any other racial or economic group (pp. 51-53).

The last focus area involves the relationship between energy and the environment. Four policy papers or statements adopted by the UCC address this concern. The first was adopted in 1974 and is entitled Resolution on the Energy Crisis. Set in the context of the oil embargo of the mid-1970s, it notes that while the United States has only six per cent of the world's population, it consumes over one-third of the world's total energy production. It characterizes the dependence 
of the United States on foreign energy sources, and particularly Middle Eastern oil, as "poor stewardship" that is only exacerbated by its failure to develop alternative and non-polluting forms of energy that would better protect the environment. In 1977, the UCC adopted an Overture on the Domestic Impact of Energy Resource Development. It notes the severe impact of energy development, particularly coal mining and processing, on rural areas of the United States, especially the Great Plains. It addresses issues of reclamation and the sustainability of land subjected to mining. It also characterizes the failure to consider the risk that can be imposed by energy development on long-established ecosystems for the short-term gain as poor stewardship, stating that "each generation is charged with continuing stewardship of all our resources to guarantee s legacy of productive land, pure air, clean water and a just society" (pp. 48-50).

In 1979, the UCC adopted a Pronouncement on Energy: Policy and Program that again addresses energy issues in terms of the effect of energy development on the environment as well as people. It further develops the theme of the prior statement adopted in 1977 by noting the need to recognize the important relationship that exists between energy issues and social justice. Lastly, it advocates energy conservation, development of alternative and non-polluting energy resources, and a drastic reduction in, if not an end to, reliance on imported oil and other forms of energy (pp. 32-34). The final policy paper or statement reviewed here was adopted by the UCC in 1980 and is entitled Religion and Energy in the 80s. Set again within the context of the energy crisis, it advocates energy conservation, protection of the poor from price and other forms of exploitation related to energy, and development of renewable energy resources. However, it also notes that such efforts cannot be accomplished simply by individuals, but will require political action to accomplish the "institutional transformation" necessary if further environmental harm is to be ended or at least minimized. 


\section{Denominational Surveys in the PCUSA}

The PCUSA policy papers and statements adopted in 1982, 1984 and 1990 were followed by two denominational surveys focusing on the environment and environmental concerns, a survey focusing on science, technology and faith, and a survey focusing on church camps and retreats. The first survey, in 1991, and was entitled The Environment. Among the major findings of the survey are the following:

- A majority of the Presbyterians surveyed under every sample label identified themselves as "environmentalists" and more than a third in each sample identified themselves as "strong environmentalists."

- Presbyterians strongly support recycling efforts and $75 \%$ of the persons in every sample regularly recycled and took other steps to reduce household waste generated.

- Most of the Presbyterians surveyed expressed a willingness to make small sacrifices to clean up and protect the environment, including higher taxes and higher prices for goods made from recycled material.

- $\quad 90 \%$ of the clergy surveyed agreed that "environmental issues are appropriate social concerns for the church" and just under $90 \%$ of Presbyterian clergy agreed that "the Presbyterian Church (U.S.A.) should become more involved in environmental issues."

- Majorities of the Presbyterians surveyed in every sample agreed that "to improve everyone's standard of living, those of us in wealthy countries need to simplify our lifestyles." 
- Most of the Presbyterians surveyed anticipated either no change or only minor change in the quality of the environment during the 1990s. Laypersons tended to foresee positive change, while clergy tended to foresee negative change.

- Compared to Americans generally, the Presbyterians surveyed were less likely to label environmental concerns such as acid rain, nuclear waste and air pollution as serious problems, although they were more likely than other Americans to be involved in recycling programs.

The work of the task force that produced the 1996 policy paper entitled Hope for a Global Future: Toward Just and Sustainable Human Development was followed by another denominational survey in 1997 entitled Nature and The Environment. Among the major findings of this survey are the following:

- A majority of the Presbyterians surveyed were in agreement as to the sacredness of nature, and most attributed this sacredness to God's role as Creator.

- Most of the Presbyterians surveyed agreed with the statement that they "often feel the presence of God when...out in nature."

- Approximately $90 \%$ of the Presbyterians surveyed in each sample agreed that the one thing they "enjoy most in life is going someplace in the woods, the mountains, or the ocean to be surrounded by nature."

- More than two-thirds of laypersons and majorities of clergy surveyed agreed with the statement that "nature is far more beautiful than things made by humankind."

- In terms of evolution, approximately one-third of laypersons surveyed agreed with the statement that "human beings developed from earlier species of animals" while approximately one-half disagreed. 
- Attitudes about scripture had a strong relation to opinions about human origins. Among those who held a literal view of scripture (i.e., that the Bible was "the inspired Word of God... without error) more than $75 \%$ of the Presbyterians surveyed disagreed or strongly disagreed with evolution. Among Presbyterians surveyed who viewed scripture as "a useful guide for Christians," only $22 \%$ percent disagreed with evolution.

- The results indicated a very high involvement of both laypersons and clergy in various kinds of outdoor activities, although the percentage of clergy participating in such activities was significantly lower than that of laypersons.

- The "most serious" environmental problems reported by a majority of Presbyterians surveyed in each sample comprised air pollution, destruction of rain forest, destruction of natural areas and destruction of the ozone layer.

- Other problems indicated as "most serious" by a majority of Presbyterians surveyed in at least one of the samples included agricultural runoff, material consumption demands, consumption of nonrenewable resources, destruction of swamps and wetlands, environmental contamination from chemical toxins and nuclear waste, oil spillage in bodies of water, rapid population growth, and water pollution.

- Large majorities of both laypersons and clergy surveyed agreed with the statement that "animals... as creatures made by God...have inherent value in God's sight," but smaller percentages agreed with the statement that "animals should have the same moral rights as human beings..." 
- Support for animal rights appeared strongest among those Presbyterians surveyed who described themselves as theologically liberal, see other religions as having comparable truth to Christianity, believe that salvation is possible apart from Jesus, reject the label "born again," are female, are either under age 40 or over age 50, have had either fewer children or no children, and are Democrats. However, supporters of animal rights also showed no significant differences in terms of percentages on the basis of belief in heaven or life after death, source of religious belief independent of the church, or level of family income.

- Clergy surveyed who believed in the existence of Hell were less likely than other clergy to treat global warming as a serious environmental problem, while clergy who rejected the idea of Hell were more likely to view global warming as a serious environmental threat.

- Most of the Presbyterians surveyed agreed with the statement that "we believe too often in science and technology" and at least a majority of Presbyterians surveyed in each sample agreed that excessive reliance on science and technology can be to the detriment of faith." A plurality of laypersons and a majority of clergy disagreed with the statement that "New technologies will surely come along to solve environmental problems before they get out of hand."

- At least $84 \%$ of Presbyterians surveyed in every sample indicated that they recycle on a regular basis, but only about half of Presbyterians reported that they try to reduce the amount of their household waste on a regular basis. 
- Utilization of alternatives to motor vehicles (e.g., public transportation, car pooling and bicycling) was not reported by the Presbyterians surveyed as a widespread practice.

- Approximately one-half of Presbyterians surveyed indicated that their political views, including election of candidates to public office, were sometimes based on environmental issues, but a smaller percentage reported that they actually engage in any form of public advocacy as to environmental issues.

- Approximately one-fifth of clergy and a slightly smaller percentage of laypersons surveyed held membership in environmentally-related organizations, and the largest share of membership in every sample was membership in the Nature Conservancy.

- Over half of the Presbyterians surveyed in every sample identified themselves as "stewards of God's creation," "conservationists," "preservationists," and "environmentalists," although few called themselves "environmental activists" or "eco-feminists." However, there was a wide disparity as to any sort of crossreferencing identification between these kinds of environmental "labels" and the highest percentages tended to favor either "stewards of God's creation" or "conservationists."

- More clergy than laypersons surveyed, and more Presbyterians who identified themselves as Democrats and Independents than Republicans, indicated a willingness to make personal sacrifices in terms of financial and consumptive practices to "protect the environment." 
- A majority of Presbyterians surveyed in every sample agreed that "environmental issues are appropriate social concerns for the church," although the percentage was higher among clergy than laypersons.

- Very few laypersons surveyed expressed awareness of environmental programs or initiatives in which the Presbyterian Church (U.S.A.) was involved, and this lack of awareness extended to environmental policy papers and statements adopted by the denomination.

- Two-thirds of clergy surveyed reported that their congregations had participated in environmental programs in the past year, primarily community recycling programs and efforts to reduce energy consumption in church buildings.

- Less than one-third of congregations reported having held worship services in the past year having an environmental theme, but more clergy than laypersons reported at least one sermon emphasizing environmental issues in the past year.

- More Presbyterian clergy than laypersons surveyed expressed concern about material consumption as a source of environmental problems, especially as it affects efforts to improve living standards of people in poorer countries. Another denominational survey in 1998, entitled Science, Technology, and Faith, also had findings relevant to the focus of this study:

- Majorities of both laypersons and clergy surveyed in every sample believe that "science and technology will eventually solve" some problems like pollution, but that they will not solve all such problems. Majorities in every sample also disagreed with the statement that "one of the effects of science is that it breaks down people's ideas of right and wrong." 
- Most of the Presbyterians surveyed gave "scientifically correct responses" to several generalizations drawn from different branches of science. However, there was division as to the truth or falsehood of both the "Big Bang Theory" and human evolution from earlier species with more clergy than laypersons holding both of these theories to be true.

- Few Presbyterians surveyed could "guess" the age of the universe within the scientific consensus of 10-20 billion years and most responded that they either did not know or estimated it only in terms of "billions" of years. However, the creationist position that the universe is only 10,000 or fewer years old was not strong among the Presbyterians surveyed.

- There was a comparable uncertainty about defining "DNA" according to a "textbook" definition and most responses on this question were partially accurate, although incomplete.

- Few Presbyterians surveyed reported a "thorough understanding" of scientific theories such as evolution, natural selection, the "Anthropic Principle," and the "Second Law of Thermodynamics." There was greater agreement noted as to these theories when the Presbyterians surveyed reported a greater understanding of them. Clergy also tended to express more understanding of these theories than laypersons, and there was a strong correlation between such understanding and the level of formal education.

- Less than one-third of Presbyterians surveyed in every sample reported that they subscribed to a "science-related" magazine (e.g., Smithsonian and Psychology Today) and relatively few Presbyterians reported reading any scientific books 
within the past year. However, most of the Presbyterians surveyed reported watching science programs on television (e.g., "National Geographic Specials," "Nature," and "Nova").

- Majorities of Presbyterians surveyed in every sample reported having taken at least one college-level science course, but relatively few had taken more than one such course. Relatively few Presbyterians surveyed reported having a college degree in a scientific field, and most of these comprised a bachelor's degree. The highest percentage among laypersons was in engineering (4\%), followed by biology (3\%) and nursing (2\%). The highest percentage among clergy was in biology (2\%).

- Majorities of all Presbyterians surveyed in all samples agreed that:

(1) Theology and science address fundamentally different types of knowledge;

(2) Theology and science use fundamentally different methods and languages;

(3) Theology and science use similar methods, but focus on different objects;

(4) Theology and science influence one another constructively; and

(5) Theology and science can be integrated to form a single unified system of understanding.

- Majorities of Presbyterians surveyed in three out of four samples agreed that "science provides support for specific theological doctrines" and disagreed that "theology can be derived from science or can be a science."

- A majority of laypersons surveyed agreed, while a majority of clergy surveyed disagreed, that:

(1) Theology and science address fundamentally different realms; and 
(2) Theology and science have fundamentally different objects of concern.

- A majority of clergy surveyed agreed, while laypersons surveyed were evenly divided, that "theology and science depend upon one another." However, majorities in all samples disagreed that:

(1) Theology and science adopt similar approaches to the same aspects of reality; and

(2) Theology and science are inevitably in conflict with one another.

- Majorities of Presbyterians surveyed in all samples agreed that:

(1) "My personal faith in God has been strengthened by some of the discoveries of science;"

(2) "To be a faithful Christian, I need to keep up with developments in science and technology;

(3) "To be a faithful Christian, I need to actively engage in theological discussion and reflection on developments in science and technology."

- Majorities of Presbyterians surveyed in every sample strongly agreed that "the universe was created by God." Few believed that "the world runs pretty much by itself." However, $90 \%$ of those persons expressing an opinion as to this statement also agreed with the statement that "God controls the fate of the universe."

- Majorities of Presbyterians surveyed in every sample agreed that it is possible for "God [to] suspend the laws of the universe to intervene in human affairs," although one-quarter to one-third of the persons surveyed disagreed with this statement. 
- Majorities of Presbyterians surveyed in every sample agreed that "evolutionary theory is compatible with the idea of God as Creator," although majorities in every sample also agreed that "life is so complex that it has to be the deliberate outcome of an intelligent design."

- A plurality of Presbyterians surveyed in every sample agreed that "humans usurp God's role as Creator when we try to clone a human being." While sizable minorities were unsure of their position on gene therapy, most of those who expressed an opinion believed gene therapy to be appropriate, although many would restrict it to "cells that are not involved in producing the next generation."

- Majorities of Presbyterians surveyed in every sample agreed that "each human being has an eternal soul created by God.” Majorities in every sample also disagreed that "our minds can be understood entirely through biochemistry and other science, without reference to a soul" and that "human consciousness will one day be utterly explained by science as the workings of natural processes."

The final denominational survey reviewed here was done in 2002 and, although it is entitled Church Camps and Retreats, its focus is primarily on congregational retreats and conference centers. As a result, it has only a couple of findings relevant to the focus of this study:

- A majority of clergy (64\%), but not of laypersons (40\%), reported that camps and retreats contributed "a very great extent or great extent" to their faith understanding.

- The most common setting for a "singular spiritual growth experience" was a camp for $27 \%$ of clergy, $17 \%$ of elders, and $20 \%$ of members.

- In terms of features of a retreat facility, a majority of clergy included the following as "essential or important:" 
(1) Indoor sleeping accommodations (no camping) (85\%).

(2) Motel-like sleeping facility (versus dorm-like) (52\%).

(3) Meals provided by the host facility (77\%).

(4) Private group kitchen facilities (53\%).

(5) Central heating (73\%).

(6) Air conditioning (56\%).

(7) Separate accommodations from other groups (71\%).

(8) Recreation activities (69\%).

(9) Rural setting (56\%).

- In terms of features of a retreat facility, a majority of members included the following as "essential or important:"

(1) Indoor sleeping accommodations (no camping) (79\%).

(2) Meals provided by the host facility $(71 \%)$.

(3) Central heating (80\%).

(4) Air conditioning (70\%).

(5) Private baths (59\%).

(6) Recreation activities (55\%).

(7) Walking trails $(68 \%)$.

(8) Rural setting (54\%).

\section{Church Camping Literature}

The literature reviewed in the first area of this section, particularly as it relates to the church camping field, represents something of a continuum or spectrum insofar as the integration of environmental values and religious values in outdoor educational ministry. At one end of the 
spectrum, the literature contains little if any reference either to nature or the natural environment in terms of either philosophy or activities in church camp programs. The focus here is primarily religious and any environmental focus is secondary and developed only in terms of activities in church camping programs. The literature at this end of the spectrum also reflects little if any attempt to integrate environmental values and religious values. The sources at this end of the spectrum are therefore simply noted. At the other end of the spectrum, the literature reflects either a stronger emphasis on nature and the natural environment or a more intentional attempt to integrate to a greater or lesser degree religious values and environmental values in terms of both philosophy and activities in church camp programs. Consequently, the sources in this latter part of the spectrum are more fully discussed here.

As noted above, the literature at one end of the spectrum contains little if any reference either to nature or the natural environment in terms of either philosophy or activities in church camp programs, even when particular outdoor activities require use of the natural environment (Badke, 1998; Bowman, C., 1954; Church Camping for Junior Highs, 1960; Clark, 1990; Cobric, 1983; Gehris, Resources for Outdoor Ministry: Community: Guide for Older Children, 1985; Martin-Adkins, Resources for Outdoor Ministry: Community: Guide for Older Youth, 1985; Martin-Adkins, Resources for Outdoor Ministry: Lifestyles of Faithfulness: Guide for Older Youth, 1983; Messinger, Simpson, \& Ulrich, 1983; Venable \& Joy, 1998). This is also the case with much of the periodical literature at this end of the spectrum (Andre, 1961; Ballinger, 1972; Balmer, 1989; Chandler, 1971; Genné, 1961; Peters, 1979; Schreckhise, 1979; Tully, 1979) and some of the organized camping literature (Ball and Ball, 1995; Rodney \& Ford, 1971; Wilkinson, 1981). 
Any environmental references in the literature at this end of the spectrum also tend to be confined to nature-type activities or specific chapters on topics such as ecology and conservation (Anderson, 1985; Celebrate: Resources for Camping Families, 1970; Clyde, 1934;Cues for Church Camping for Counselors of Juniors and Junior Highs, 1962; Davis, 1954; Ensign \& Ensign, 1958; Fauver, 1995; Genné \& Genné, 1962; Gieschen, 1971; Graendorf \& Mattson, 1979; Guideposts to Junior High Camping in Westminster Fellowship, 1958; Junior Camping Cues for Churches, 1957; Kamm, Resources for Outdoor Ministry: Community: Guide for Younger Youth, 1985; Kamm, Resources for Outdoor Ministry: Lifestyles of Faithfulness: Guide for Younger Youth, 1983; Kemper, Caring for God's World, 1991; Kemper, Co-Workers in Creation, 199; Kemper, Co-Workers in Creation: First Steps in Ecology, 1991; MacInnes, 1962; Mackay, J., 1984; Malone, 1979; Mattson, Build Your Church Through Camping, 1984; Mattson, Christian Camping Today, 1998; Milton, 1935; Rice, 1935; Venable, 1955; Witt, 1979). This is also the case with the periodical literature in which the primary focus is religious such that any environmental references are limited to nature-type activities on specific topics (Bowman, W., 1979; Clampit, 1970; Cruger, 1973; Gingrich, 1979; Glasscock, 1961; Long, 1961; Messinger, 1975; Mitchell, 1979). A similar approach is taken in the organized camping literature, albeit without any sort of religious orientation (Goodrich, 1959; Kraus \& Scanlin, 1983; Meier \& Mitchell, 1993; Shivers, 1989).

As also noted above, the literature at the other end of the spectrum reflects either a stronger emphasis on nature and the natural environment or a more intentional attempt to integrate religious values and environmental values in both philosophy and activities in church camp programs. God's Good Earth: Christian Values in Outdoor Education, edited by Mattson (1985), is primarily a series of essays by Mattson and other writers in a number of environment- 
related fields that include church camping. This book had its origins in a task force study sponsored by Christian Camping International (CCI) in the mid-1980s regarding outdoor educational ministry in church camps and private religious schools. In the introductory chapter, Mattson makes an important observation from the work of this task force that appears to be supported by the results of the present study:

As the task force study progressed, it became evident that enthusiasm for outdoor education was measurably greater among camps than schools. In camps where nature study and wilderness programming flourished, the potential for serving schools with a resident outdoor education ministry mounted. From these observations an obvious conclusion followed: a prior concern for the creation had to exist in the hearts of camp leaders or significant nature-related programming would not occur. Program follows philosophy, almost always. We do what is important to us (p. 14).

Or as another writer, Peterson (1985), states in a subsequent essay entitled "Gaining A Mountain-Top Perspective:"

Only after one has become sensitized to the natural will one yearn to learn more about that environment and, equipped with that knowledge, rally to protect it. Sensitivity and knowledge are, therefore, two keys to environmental education (EE) and to a quality environment. If it's this simple, why haven't all youths been given mountain-top perspectives?

Part of the reason may be, as Matthew Brennan, a stalwart of EE observes, "So we have failed to develop a program of environmental education for the same reason that we do not have an energy program, or a land use policy, or an 
environmental policy - we do not have the will. Conservation is a philosophy that runs counter to our American way of life" (p. 110).

God's Good Earth is divided into six sections: (1) Four essays on biblical, theological and spiritual perspectives related to church camping with a strong emphasis on creation and stewardship; (2) Four essays on care of the earth, outdoor education, and programming in camps and retreat facilities that focus on nature and the natural world; (3) Five essays describing some actual examples as well as theoretical models of church camping programs; (4) Six readings or reflection pieces regarding church camping from various perspectives such as significant life experiences in the outdoors, process thought and theology, environmental education, literary and philosophical approaches to nature, and ethical issues associated with the natural environment; (5) Lists of church camping resources; and (6) A directory of camps, conferences, environmental centers, and schools having environmentally-related programs, particularly in church camping and outdoor education. Three of these essays are reviewed here.

Mattson (1985) suggests in an essay entitled "Beyond the Nature Trail" that when church camp leaders consider the "environment" in relation to church camps, they tend to think more in terms of three "environments:"

(1) The spiritual environment that involves religious belief and practice;

(2) The social environment that involves attitudes and behaviors conducive to community living; and

(3) The physical environments that comprise the site and facilities where camp programs and activities take place. 
As Mattson notes, however, "the greater environment" - of creation itself - is too often ignored:

Nature must not be viewed as a pleasant option, or even as a valuable program feature. Nature is us! God established the rules for man and nature, assigning man to manage creation. Our Christian society would shrink from stealing the financial resources of future generations as outright sin. But practically no thought is given to the depletion of environmental treasures on which tomorrow's very survival depends.

While we applaud concern for the spiritual, social, and physical environments of life, we often ignore the call to environmental responsibility. Pollution and soil depletion are real and deadly. Overpopulation is a moral as well as an economic issue. America's profligate use of the world's resources is not mere ranting by liberal humanists.

Is pollution a Christian issue? If an open sewer ran down the gutter in front of the church, who would consider it spiritually compromising to march on city hall?

Dare we hope that a beginning might be made through camps toward environmental awareness among Christians? If not camps, where? Who is in a position to feel the peril more keenly, or appreciate nature more deeply than camp leaders? (p. 54).

Yaple (1985), in a subsequent essay entitled "Merging at the Crossroads: New Vehicles for Environmental Education," discusses his research into the influence of Christian faith on human behavior as it relates to the natural environment. This has also been the subject of survey 
research by the PCUSA as discussed earlier in this literature review. In introducing his research, Yaple cites three aims of environmental education:

(1) [Knowledge] about the complex interrelationships of the biophysical and sociocultural environments;

(2) [Awareness] of both the associated environmental problems and alternatives for solving those problems; and

(3) [Motivation or commitment toward] working toward solving environmental problems in such a way as to create environments that are optimal for living (p. 115).

Yaple then describes the purposes of his own research in terms of these aims:

The main thesis tendered for the research effort was that the Christian Church, a shaper of human behavior, can and should play an important role in promoting motivation and commitment for the resolution of environmental problems and the evolution of creative environments that are optimal for living. And if it attends in a serious, vigorous and systematic fashion to the implications of its central symbols and the findings of environmental science, the Church may significantly assist in bringing about the aims of environmental education...(p. 115).

Keener (1985), in a subsequent essay entitled "Toward a Holistic View of Nature: A Process Perspective," argues that the resolution of adverse environmental conditions, especially as the conditions are related to science and technology, requires "a new vision, a reconstructed metaphysics [i.e., one dealing with both ontology and epistemology], a reformulation of values, a species perspective" (p. 133). He proposes that this new vision be grounded in process thought and theology. Through this new vision, nature would no longer be viewed dualistically or 
mechanistically, but rather holistically and ecologically. We would recognize and accept limitations on humanity's capacity to manipulate and reshape the natural environment. We would develop new or reformulate existing religious concepts, particularly as they relate to God, in terms of a "new cosmic theism" (p. 135) that emphasizes the immanence of God within the universe. We would also tend to reconceive human life and its value more in terms of relationships rather than material things.

Although religious experiences are secondary to environmental experiences in his approach, Van Matre is among the strongest proponents of the conceptual approach to the kind of environmental emphasis or dimension posited in this thesis. In Acclimatization: A Sensory and Conceptual Approach to Ecological Involvement (1972), he presents a program, also entitled "Acclimatization," that was first developed in the 1960s under his leadership at Camp Towering Pines in Wisconsin. He describes the program as both a sensory and conceptual approach in which experiential activities are emphasized and participants are actually immersed in the natural environment. Utilizing a small group process, participants conceptually study ecosystems through sensory experiences to achieve not only an understanding of, but also an empathy with, certain "ecological objectives" associated with "The Web of Life:"

- Light, air, water and soil are the elements of life.

- Life is divided into producers, consumers, and decomposers.

- Everything is becoming something else.

- Everything has a home.

- Homes in a defined area form a community.

- Inhabitants of these communities live together in competition, cooperation, or neutrality. 
- Man is the chief predator (p. 18).

The remainder of the book consists of daily lessons and activities intended to implement the "Acclimatization" philosophy.

The introductory chapter of Acclimatization also contains an important caveat regarding the camping experience; that is, the "uniqueness" of the camping experience does not rest on the natural environment insofar as simply providing an outdoor setting for camp programs:

And do not be fooled by those who would lead you to believe that summer camps are unique only in their setting - that kind of sophistry cannot even be graced by the description of the pragmatic. There is much more to the camping idea than environment - group living, skill building, self-identification, fellowship - all are important elements of the experience. It is true that most of these factors can be judged important in other institutions with other facilities and perhaps aided just as well. But the simple and rather obvious point is that they are not. Furthermore, the attempt to equate our objectives, and thus our positive values, with our geographical location is tantamount to an irrevocable association of purpose with position...(p. 10).

The significance of the point made in this caveat is that the benefits associated with the camping experience, including the church camping experience, depend more on what actually takes place in the outdoor setting than on the outdoor setting alone. It is not the case that every aspect of the church camping experience must involve an environmental emphasis, just as it is not the case the every aspect of the experience must also involve a theological or pedagogical emphasis. It is rather the lack of an environmental emphasis, and the lack of integration of environmental values and religious values, that tends to diminish or even eliminate particularly benefits associated with 
the church camping experience that: (1) are available, primarily and immediately if not uniquely, in an outdoor setting; (2) better serve the educational purposes of both environmental values and religious values through their integration; and (3) contribute to the formation, and reformation, of Christian beliefs and practices in ways that ground the relationship between God and God's creation, including humanity, more ecologically and holistically.

Two subsequent books by Van Matre (1974, 1979), Acclimatization: A Personal and Reflective Approach to a Natural Relationship, and Sunship Earth: An Acclimatizing Program for Outdoor Learning, build on his "Acclimatization" approach. Given that Van Matre intended Acclimatization to introduce the approach, Acclimatizing provides more of an emphasis on environmental concerns and "personalizes' the process through what he describes as "a life-long approach to a personal way of relating with the natural world" (p. 13). It thus comprises a series of reflections based on sensory experiences of the natural world, conceptualizations of nature that are grounded more in natural as opposed to human dimensions, and various techniques by which participants' experiences of the conceptualizations of nature are enhanced. Sunship Earth represents a restatement or refinement of the "Acclimatization" process in terms of a five-day outdoor program through which participants increase their conceptual under-standing of how ecosystems function, again utilizing sensory experiences that yield empathy and understanding with the natural world.

God Man Land: Interrelationship Programs for Camps by Paetkau, Harder, and Sawatzky (1978), is introduced through an essay by Harder (1978) entitled "A Theology for Christian Camping" which he describes as "rooted in scripture, branching in the outdoors" (p. 10): 
The church camp has the unique opportunity of utilizing its setting, the out-of-doors, in such a way that one particular theme in our biblical faith is highlighted and communicated. Briefly stated, I refer to the inter-relationship of God, persons, and land...Because we are speaking of a church camp, reference to God is essential to the camp programming. For the same reason, the interrelationship of persons influences our programming, since the church is a community of believers. While these two factors are normative ingredients in any church program, the camp setting includes a third and distinctive element, namely land. When this third factor is combined with the first two - God and persons - a unique but important aspect of the church's ministry of proclamation and nurture is provided in the camp setting (pp. 9-10).

As Harder emphasizes, this ministry has as its purpose the communication of a biblical understanding of creation, development of a relationship with God as creator, repentance and redemption from humanity's sin, development of a more responsible and harmonious relationship with the created world, and the provision of a context within which Christian relationships can be learned and experienced. The remainder of the book is comprised of developmentally graded programs that involve experiential activities which are focused on the natural world and are introduced by scriptural or spiritual reflection pieces.

Mason's (1962) Let the Bible Speak Outdoors, published by the National Council of the Churches of Christ in the U.S.A. (NCC) for use by parents and church leaders of children (ages six to 12), provides an excellent example of integrating environmental values and religious values. It emphasizes that scripture records God's action both in creation and in history such that both humanity and nature reflect God's purposes. The overarching theme is creation which is 
considered in the context of the relationship of God and humanity within the created order, interrelationships and interdependence within the created order, scriptural references reflecting humanity's response to the created order and its relationship with it (e.g., the Hebrews in the wilderness or the psalmist praising the glory of God in creation), Jesus' use of natural imagery and outdoor experiences in his teaching, suggested activities and examples of comparable experiences children have with nature in their own life situations [e.g., in camping and other outdoor experiences], and sensory experiences [the "hearing ear" and the "seeing eye"] that not only enhance children's experience of God's creation, but also their own response to and relationship with creation. Mason states that her aim is to make scripture relevant and meaningful to children in camping and other kinds of outdoor experiences:

The outdoors offers man a distinctive opportunity to discover evidence of God's creative power in the natural world which he has created, and which he sustains. Meaningful use of biblical material will enable leaders to guide boys and girls toward a Christian interpretation of the universe and toward seeing God as the Creator who has worked, is working, and will continue to work in his world (pp. 5-6).

She also notes that the "convictions" underlying "the church's use of the outdoors as a resource in Christian education" comprise the following:

- More time than the Sunday church school hour is needed for Christian education.

- Christian guidance is most helpful and most enduring when it is given in life situations.

- Boys and girls enjoy being outdoors and it is therefore a natural place to work with them. 
- Boys and girls need opportunity to express their natural feelings of wonder and awe.

- Boys and girls need to develop feelings of at-homeness in God's world.

- Small groups in the out-of-doors can learn Christian values and relationships.

- The natural world provides a setting in which boys and girls may recognize God's continuing action as Creator and Sustainer of life (p. 7).

The National Council of Churches (NCC) $(1983,1984,1985)$ also published three series of developmentally graded curriculum in the 1980s. The three series are part of the Sow Seeds: Trust the Promise outdoor ministry resource material published by the NCC and reviewed below. Each series comprises a basic resource guide, a guide for older children (ages eight to 11), a guide for younger youth (ages 12 to 14), and a guide for older youth (ages 15 to 18). The first series is entitled Lifestyles of Faithfulness: Resources for Outdoor Ministry (1983). The second series is entitled Stewardship of Creation: Resources for Outdoor Ministry (1984). As noted above, the third series, entitled Community: Resources for Outdoor Ministry (1985), does not have a strong environmental emphasis, notwithstanding that the basic resource guides in the Lifestyles of Faithfulness and the Stewardship of Creation series do provide some environmental emphasis and integration of environmental values and religious values as do each of the children and youth guides in the Stewardship of Creation series.

The basic resource guide in the Lifestyles of Faithfulness series, by McCollough and McCollough (1983), introduces the series by noting that while many outdoor living and recreational themes traditionally associated with church camping are included, particular emphasis is given to being "recreated by nature" (p. 6) in terms of "lifestyles of wholeness that live in interdependence with nature and all people" (p. 6). The authors state five objectives: 
- Help campers experience the rich meaning of the biblical teachings about people and their relationship with nature and God.

- Organize camp life around the gentle use of nature in contrast to the conquest and exploitation of nature.

- Organize camp activities that teach the skills of friendship, caring, and cooperation in contrast to the extreme competition found in the lifestyle of conquest and defeat.

- Become acquainted with some of the tools that are appropriate for the gentle use of nature.

- Experience this theme in the supportive context of an intergenerational setting. They describe this "lifestyle of faithfulness" in terms of a creation model that involves stewardship and responsibility for care of the earth. The authors propose a continuum or spectrum of attitudes toward nature comparable to the environmental typology developed by Negra and Manning (1997) and adapted for use in the present study:

(1) Nature is to be conquered.

(2) Nature is neutral, an inert reflector.

(3) Nature is to be used gently.

(4) Nature reveals God.

(5) Nature is to be worshipped (p. 16).

The authors' view is that the middle portion of the spectrum, "Nature is to be used gently," represents the biblical view of nature. Church camps should therefore develop programs in which “people will learn lifestyles which gently use the natural gifts of God's creation, both at camp and back home" (p. 17). The latter half of the book also provides a number of programs and 
activities that integrate this "gentle use of nature" theme through elements of the natural world such as fire and sun, earth, water, air, plants and animals, food and drink, and shelter.

As suggested by its title, the overarching theme in the basic resource guide by Crouser (1984) for the Stewardship of Creation series is stewardship of God's creation. One of the first programming sections in the book comprises a series of daily scripture readings focusing on stewardship-related themes. This section is followed by one that summarizes what Crouser characterizes as "The Original Agreement" (p. 27) between God and humanity regarding stewardship on the basis of the creation accounts in Genesis. The "breaking" of this "agreement" (p. 29) is examined in subsequent sections in terms of stewardship as it relates to population growth, economic growth, hunger myths, food production and distribution, loss of agricultural land, the energy crisis, water and the atmosphere, species extinction, and nuclear destruction. The theological and ethical implications of stewardship are examined in terms of the "root causes" (p. 40) [e.g., theological, social, political and economic] of the environmental crisis, theological traditions characterized by persons like Benedict of Nursia and Francis of Assisi that provide a model for Christian stewardship of creation, and recognition of the need for a "new environmental ethic" (p. 44) of stewardship summarized by Crouser in five points:

(1) Everything belongs to God; we merely use it while we are here. God has given us control over the earth but did not intend for us to misuse air, soil, or water. God gave us control, but also gave us the responsibility to take care of the gift.

(2) We should use no more than our share. Earth provides enough to satisfy every person's needs, but not every person's greed!

(3) We should try to see that everyone gets a fair share.

(4) We should keep things in balance, putting back as well as taking. 
(5) We should leave the world in good shape for those who will come after us (p. 45). Crouser's concluding section comprises learning activities that integrate the stewardship theme and scripture references with responsible use of land and water, food production and distribution, healthy [holistic] living, energy conservation and production, and peace and justice issues as they affect both human and non-human life.

Gehris (1984), in the guide for older children (ages eight to 11) in the Stewardship of Creation series, suggests the following purposes for older children in the church camp experience:

- To enjoy one another as children of God and practice relating to one another as interdependent human beings.

- To be guided into a deepening relationship with God through appreciation of God's creation and God's order and purpose as seen in nature.

- To interpret life in terms of a relationship with Jesus Christ as Lord and Savior.

- To develop a sense of belonging to a larger Christian family or community.

- To adopt a sense of responsibility for all of God's creation: self, other people, and all living things.

- To develop and strengthen living skills that enable them to be faithful stewards of creation as they seek to fulfill God's purposes for their lives (pp. 5-6).

Gehris then develops the stewardship of creation theme according to the program outline in the basic resource guide summarized above.

Kamm (1984), in the guide for younger youth (ages 12 to 14), in the Stewardship of Creation series, follows the same program outline summarized above in developing the stewardship theme in terms of 10 goals: 
- To guide persons into a deepening relationship with God, through an appreciation of God's creation and a sense of God's order, purpose, and plan.

- To be aware of God's purpose and plan even in the midst of tension.

- To help campers interpret life in terms of a relationship with Jesus Christ.

- To help campers develop a sense of interdependence with others in a Christian community and fellowship.

- To have fun and delight in the complexity of God's creation.

- To foster a concern and care for God's creation and people, both in the camp setting and all around the world.

- $[\mathrm{To}]$ help people experience the rich meaning of the biblical teaching of the original agreement with God as stewards of creation.

- [To] organize camp life around the idea of stewardship of creation in contrast to the conquest and exploitation of creation.

- $\quad[\mathrm{To}]$ organize camp activities that teach the skills of friendship, caring, and cooperation in contrast to the extreme competition that characterizes conventional modern life-styles.

- $[\mathrm{To}]$ become acquainted with and experience some actions that are appropriate for the stewardship of creation (pp. 25-26).

Martin-Adkins (1984), in the guide for older youth (ages 15 to 18) in the Stewardship of Creation series, also follows the same program outline of the basic resource guide summarized above and develops the theme of stewardship of God's creation through six goals:

- Help older youth see that Biblical concepts of stewardship need to be rediscovered in our time. 
- Encourage and involve older youth in the service aspect of stewardship.

- Promote activities that experientially teach older youth to revere and respect creation.

- Promote an appreciation of salvation as wholeness.

- Help older youth discover the value and need of loving the world.

- Provide experiences with people their own age (pp. 3-4).

A second NCC resource in the Sow Seeds: Trust the Promise material, edited by Kerr (1983), is entitled Leadership Development Notebook for Outdoor Ministries. This resource comprises 28 sections or modules of which four modules contain some material relating to the natural environment. The worship module by Simpson (1983) suggests some ways in which worship in camp setting can incorporate an outdoor emphasis and also includes a short essay on the biblical view of nature entitled "Do You Worship Nature?" (“Worship” at pp. 7-8).

The music module by Manley (1983) has a strong focus on the relationship between nature, people and God, reflected not only in traditional hymns, but also in contemporary hymns and songs (e.g., camp songs). Manley also incorporates a form of the five-part continuum or spectrum utilized by McCollough and McCollough (1983) in the Lifestyles of Faithfulness basic resource guide as a standard for evaluating whether particular hymns and songs conform to the biblical view of nature:

(1) Nature is to be exploited and conquered.

(2) Creation is neutral and may reflect God.

(3) God's creation involves gentle use of nature for human need.

(4) Creation is beautiful and reveals God from within.

(5) Creation is divine and is to be worshipped ("Music" at pp. 11-14). 
The stewardship module by Cramer (1983) addresses environment, food, safety, time, and body as elements of God's "gifts of creation" ("Stewardship" at p. 1). It also includes and "Matrix of Christian Stewardship in a Camp Setting" ("Stewardship" at p. 10) that integrates biblical concepts, stewardship of food [as an example of a stewardship concern], and other "teachable examples" of stewardship in camp settings. The matrix also sets up a hierarchy of "ethical maturity" as stewardship concerns move from "self" to "others" to "non-human portions of creation" (p. 10).

The environmental education module by Allen (1983), which also contains material on adventure and survival experiences, focuses on stewardship. It is introduced through a number of games and activities. This section is followed by a brief section summarizing several theologies and biblical "connections" ("Environmental Education" at p. 14) focusing on creation and stewardship themes.

A subsequent NCC publication, entitled the Outdoor Ministries Program Leadership Manual and edited by Ferguson (2000), comprises 22 sections or modules of which three modules contain some material relating to the natural environment. Six guidelines are listed for the development and use of the manual as a resource in outdoor ministries:

(1) That it be biblically grounded;

(2) That it be theologically informed;

(3) That it be environmentally responsible;

(4) That it be culturally aware;

(5) That it be experientially based; and

(6) That it be developmentally appropriate and inclusive (pp. 2-3). The guideline for environmental responsibility (\#3 above) states: 
God called all creation good and calls humanity to care for all its resources. Such a holistic understanding of creation reminds us that we have no right to abuse or misuse creation. Instead we are responsible for discovering ways to preserve the earth's resources. Such an understanding of creation invites us to explore the wonder of creation and to give thanks to God for all we experience (p. 3).

The stewardship module by Borko (2000) notes first that the Christian concept of stewardship has broadened over the last several decades to now include responsibility for “creation, people, and institutions" (p. 82) as well as money. He notes that our "recognition and proclamation of God as creator" (p. 82) and God's providence in creation are the primary "biblical/theological principles" (p. 82) underlying stewardship. He also suggests that camp settings provide an excellent opportunity and a "safe environment" for "staff and campers [to] experiment with the lifestyle of a faithful steward" (p. 83), particularly in contrast to the "consumption-oriented lifestyle [that is characteristic] of North-American culture" (p. 83).

The environmental education module by Allen (2000) introduces its theme through the creation accounts in Genesis, Paul's several references in 1 Corinthians, Ephesians and Colossians to the church as a body having interdependent parts as well as our connection to God, and creation as "witness to the Creator" (194) in the Psalms and Romans. In an observation comparable to that of Mattson (1985) quoted earlier, Allen states:

Environmental education at camp is as much a lifestyle as it is a part of the camp curriculum. If the camp doesn't walk the talk, the talk will fall on deaf ears and opportunities to teach will be wasted. Environmental education at church camp increases compassion for all life; stimulates the desire to learn about the 
earth, its inhabitants and inter-relationships; [and] provides the skills and motivation needed for living carefully on the earth and celebrates God as Creator (p. 194).

Allen (2000) also notes the adverse effects to both human and non-human life caused by environmental irresponsibility, in part because people are increasingly separated from the natural environment. He notes the tension that arises when traditional beliefs, doctrines and biblical interpretations are challenged by scientific discoveries that increase our understanding and knowledge of the natural order. He also cautions against thinking of camp settings as "holy ground" where God is somehow more "present" than elsewhere, and instead to recognize a camp setting as a place where people are more open to God's "presence" because of their own sense of “spiritual pilgrimage" (p. 195).

Allen follows this introduction with a series of games and activities intended to provide opportunities to engage in theological reflection about the natural environment, to become familiar with environmental concepts and with environmental policies in camp settings, to become more observant of and sensitized to the natural environment, and to develop leadership skills and lesson plans for teaching environmental education. He also includes a six-part summary of important environmental concepts:

- Everything is connected to everything else.

- Everything gives and everything takes.

- Everything has a home.

- Nothing goes away.

- Natural resources are limited.

- Nature has a remarkable ability to heal (p. 197). 
The trip and travel camping module by Chamberlain (2000) notes that these kinds of trips provide a "unique occasion of living in the midst of God's natural world...(in which) campers can rejoice in the beauty of creation and ponder their responsibility to care for it" (p. 207). He quotes a passage from a sermon on the Genesis creation accounts in this regard by Kevin Witt, National Director of Camping Ministries for the United Methodist Church:

It seems to me that one of the great needs today in modern society is to reclaim the utter sacredness of the created community made by God and to recognize the deep interdependence human beings have with each other and the whole community of creation (p. 207).

Another developmentally graded curriculum series, entitled God Is In Our Midst: Resources for Outdoor Ministry $(1990,1998)$, is an example of an effective integration of religious values and environmental values in terms of both philosophy and activities in church camp programs. The series, presently published in a revised edition, consists of three leaders' guides and corresponding campers' resource booklets:

(1) Leader's Guide for Children by Grabher and Rose-Heim (1990, 1998), Camper's Resource Guide for Primary Children by Grabher (1990, 1998), and Camper's Resource Guide for Older Children by Grabher (1990, 1998);

(2) Leader's Guide for Younger Youth by Miller and Rose-Heim (1990, 1998) and Camper's Resource for Younger Youth by Miller (1990, 1998); and

(3) Leader's Guide for Older Youth and Camper's Resource for Older Youth, both by Suess and Ferguson $(1990,1998)$.

Each of the leader's guides contains an introductory section by Moore $(1990,1998)$ entitled "God Is In Our Midst" that focuses on the sacredness of God's creation, the dilemmas that have 
arisen for humanity because of its environmental irresponsibility and desecration of creation, the affirmation that the Christian witness is intended to provide about creation, and the challenges that these dilemmas and this affirmation present to Christians. Moore emphasizes that we not only need to recognize God's presence in creation, but also that the gift of creation represents a form of God's grace as an alternative to humanity's sin. This focus provides the philosophical context for the activities summarized in the remaining portions of each of the leaders' guides as well as in each of the campers' resource booklets. While most of the activities appear to involve a focus on nature and the natural environment, usually in the context of some aspect of creation, some of the activities do not have this distinct focus. However, all of the activities appear to focus on the relationship between God and some aspect of God's creation in relation to natural settings such as developing an awareness of God's presence, experiencing God's creative work in different kinds of communities [i.e., human and non-human communities], and practicing stewardship of God's gift in creation.

Bogardus (1955), in Planning the Church Camp for Juniors, similarly emphasizes the importance of relationships in her "philosophy of program" (p. 22) in church camping. These relationships are significant not only in terms of persons sharing the experience of the camp community, but also in the camper's experience of actually relating to nature. The first two among 10 criteria by which Bogardus evaluates the validity of church camp programs are: (1) "Is the activity in line with the idea of simple outdoor living?" and (2) "Is it an activity that can be done better in a camp environment than in the camper's home church?' (p. 24). For example, she relates the story of a teacher teaching a lesson about conservation to a class of elementary students. The teacher pulled down the shades of the classroom windows so that the 
students would not be distracted by the sights of nature beyond the classroom walls. Bogardus analogizes the story to the church camp setting as follows:

Often camp leaders have done as poorly. They have taken boys and girls to camp, only to post an hour-by-hour schedule of activities wholly unrelated to the outdoor environment. And all the time the environment was full of things to be explored and appreciated in ways which would push boys and girls to seek answers to some all important questions about the nature of God and man's part in his plans (p. 47).

Bogardus (1961) builds on her "philosophy of program" in Living and Learning in God's World: A Guide for Leaders in Junior Camps and Other Outdoor Activities of the Church with Juniors. The first part of the book focuses on the program planning process that she describes as "planning for" the program rather than simply planning the program (pp. 34-35). The second part comprises a number of "program ingredients" that emphasize both nature and religious concerns through small group discussions, creative activities, Bible study and worship. A concluding section provides additional resources such as poems, games and stories. Outdoor Living: A Guide for Camping and Other Outdoor Activities of the Church with Older Elementary Students by Bogardus (1971) comprises a revised and expanded version of Living and Learning in God's World that emphasizes the interconnectedness of environmentalism and ministry in "planning for" the program. As Bogardus notes:

Living in the outdoors offers a distinctive opportunity to grow in an understanding of God as Creator, to discover some of the wonders of God's creation: things that are beautiful to see and hear, the inter-relatedness running 
like a thread throughout creation, and dependability evident in the coming and going of the seasons and of day and night (p. 8).

Come Yourselves Apart: Christian Leadership in the Temporary Community by

Klopfenstein, Klopfenstein and Williams (1993), provides an excellent discussion of a program philosophy emphasizing the integration of religious values and environmental values in church camp and retreat programs. While it contains very few actual program activities and also focuses primarily on retreats, it emphasizes that integration of religious values and environmental values, intended to be reflected in experiences in the natural world, has a significant relationship to spiritual development. For example, the authors cite the camping and retreat movement; the witness to nature in scripture with particular attention to Jesus' use of experiential learning and natural metaphors; the desire and need of the Church to recover the holistic relationship with God characteristic of creation; the importance of developing leadership within the Church that reflects and models both the order and the grace of God characteristic of creation; the nature of church camp and retreat settings as examples of "temporary communities" (pp. 10-11, 71-72); and an approach described as "closed/open systems" (pp. 72-74) involving relationships that, while set "apart" (pp. 10-11, 88-89) from normal life experiences, are intended to foster profound changes in faith beliefs and practices within normal life experiences. These various approaches are intended to develop an understanding of these changes as dynamic and developmental, rather than static, thus reflecting the natural world itself.

There is also periodical literature at this end of the spectrum emphasizing nature and the natural environment or an integration of religious values and environmental values in church camp programs. Miller (1979) suggests in "The Biblical Basis for Ecology" that the relationship between scripture and the camping movement "has been at best an uneasy one" (p. 12). He 
argues that biblical accounts used in camping programs, often limited to the creation accounts or passages involving natural imagery, sometimes "raise more problems than they answer" (p. 12). For example, natural metaphors occurring in scripture are often treated non-metaphorically and, when contrasted with scientific knowledge about the natural order, give rise to serious interpretive problems. Miller also contends that the environmental dimension of scripture is often downplayed or even deliberately avoided because of the often reactive approach of the church to scientific knowledge about the natural order; in effect, scientific discoveries that seem to refute biblical "facts" about nature are de-emphasized or even repudiated, thus leaving only a moralistic approach to scripture as a means of accommodating science with traditional church doctrines. He suggests a symbolic approach in which allusions to nature in scripture are treated as having a theological and social significance that enables us to be more open to and knowledgeable about the relationship between humanity and the natural order. Under this approach, nature provides opportunities in the church camp experience to gain "a new appreciation of the environment" (p. 17), especially in terms of stewardship and an increased appreciation of how traditional concepts such as justice and peace in scripture have profound implications for the church's ministry in relation to the natural order.

Snyder (1979), in "The Impact of Camping on the Life-Style of the Faith Community," intends to relate local faith communities to nature and the natural order through camping. In contrast to other religious traditions that idolatrize nature, Christian tradition seeks to discern and model the relationship of God as Creator with the created order. While there have been significant developments and changes in this discernment process over the centuries, the sovereignty and centrality of God in relation to the created order has been a constant theme in Christian understanding and application of this process. Church camp experiences represent 
educational opportunities within this discernment process and serve a dual function for the church: (1) They relate us "to God's creation in a responsible way" (p. 23); and (2) They help develop the kinds of relationships that better integrate faith values within faith communities.

In "God's Voice in the Out-of-Doors," Spotts (1963) suggests that the church's ministry in the outdoor setting of a temporary faith community models the ministry of Jesus and his disciples. It also provides a biblical and theological context supportive of the local church's program of Christian nurture. He emphasizes the doctrine of creation as an indication of God's nature and sovereignty while describing the church camp experience, like the unity and interdependence of creation, as a reflection or model of Christian life; that is, it is holistic rather than fragmented. As form of church mission, church camping also represents an important aspect of mission in terms of relational living that enables "the church to be the people of God in the whole of life" (p. 7).

Brown (1963), in “Outdoor Experiences Are Not 'Extras,"” asserts the potential for profound religious experiences in outdoor programming, stating that the church is involved in outdoor ministry because every person is part of the whole creation that is itself inter-related. She contrasts these kinds of relational experiences with secular life and suggests that the church can use outdoor experiences to restore "the lost sense of oneness with the natural order" (p. 10). She describes the integration of environmental values and religious values as ecological and religious experiences that provide "a sense of interrelationship or interdependence among all living things" (p. 11). The experiences associated with outdoor programs are thus not "extras" in ministry, but rather serve to enrich and reinforce what local churches are doing in terms of their own programs. 
In "Is Nature Study Christian Education?," Woodgates (1963) reports on an NCC project in the late 1950s to provide an outdoor program for primary age children. The project had two primary purposes: (1) To discover what children understood about God as "Creator" and “Sustainer;" and (2) To discover how children's understanding of God was enhanced and expanded through a Christian education program emphasizing outdoor experiences. The program was designed to avoid a day camp or vacation church school approach and "to use the outdoors as the medium and primary resource for teaching rather than only as the setting" (p. 5). No prepared curriculum was used and children were instead given the opportunity to discover, explore and use the natural habitat for activities and program resource materials. As importantly, program leaders made intentional use of the natural habitat as a "frame of reference" (p. 5) to help the children grow in their understanding of God, creation, and humanity's place within creation. Particular attention was given to the religious context of the children's experiences and this consideration itself reinforced the leaders' own sensed need for increased theological understanding of the natural world and God's relationship to it. The project resulted in strong recommendations for further study of the theology of "creation and redemption in relation to the natural world" (p. 19) and further "exploration of the basic question about the extent to which nature study can become Christian education in a very meaningful sense" (p. 19).

Finally, "Your Wetlands Are Not A Wasteland: Developing Natural Areas for Program Use," by Astle and Boss (2000), describes Camp Henry, a Presbyterian camp in Michigan surrounded by wetlands that, historically, were unused except for occasional "bog walks" or "bullfrog hunts," but were restored as an environmental resource for camp programs. The authors recommend greater attention to land management practices and they outline a process for greater program use of natural habitats in effective and ecologically protective ways. For 
example, Camp Henry has undertaken reforestation programs to add wildlife cover, established food plots for upland game and clear cuts for grouse and deer, and built nesting structures for birds, waterfowl, bats and squirrels. The authors note that these types of land management practices provide opportunities to use natural resources both for educational purposes as well as demonstrating a commitment to "protect the natural world and appreciate the wonders of creation" (p. 37). 


\section{Chapter 3 - Methodology}

\section{Research Design}

As the second of the two objectives of the study indicates, the research design of the study was descriptive in terms of a nationwide survey of church camps affiliated with the PCUSA and the UCC to examine and compare:

(a) The organizational and descriptive profiles of church camps in each denomination;

(b) The extent to which religious values are emphasized in church camp programs in each denomination;

(c) The extent to which environmental values are emphasized in church camp programs in each denomination;

(d) The extent to which religious values and environmental values are integrated in church camp programs in each denomination; and

(e) Whether the association between denominational affiliation and (1) religious values, (2) environmental values, and (3) the integration of religious values and environmental values, in church camp programs in each denomination is statistically significant.

As also previously noted, three hypotheses are advanced for the study:

$\mathrm{H}_{1}$ : Religious values in PCUSA and UCC church camp programs are independent of denominational affiliation and the association between them is not statistically significant.

$\mathrm{H}_{2}$ : Environmental values in PCUSA and UCC church camp programs are independent of denominational affiliation and the association between them is not statistically significant.

$\mathrm{H}_{3}$ : Integration of religious and environmental values in PCUSA and UCC church camp programs is independent of denominational affiliation and the association between them is not statistically significant. 


\section{Population}

The study comprised two populations of church camps: (1) church camps affiliated with the PCUSA; and (2) church camps affiliated with the UCC. Church camps affiliated with these two denominations were chosen for this study for six reasons. First, both denominations have a strong tradition of involvement in both church camping and educational ministry. Second, both denominations have a strong tradition of socio-theological involvement, including the environment and environmental concerns. Third, both denominations share a historical and theological affinity in the Reformed faith tradition in terms of their origins, development, beliefs and practices. Fourth, both denominations are characterized as "mainline denominations" among the numerous and diverse faith traditions in the United States. Fifth, both denominations reflect a strong denominational affinity or identity (characterized as "connectional" in the PCUSA and "covenantal" in the UCC) such that church camps in each denomination represent both a "network" (making a survey of each church camp population less problematic) and a common (but not homogenous) religious tradition. Finally, the author has extensive experience with the religious tradition generally, and the church camping tradition particularly, characteristic of each denomination.

The actual population of PCUSA church camps surveyed was calculated from a potential population of 152 church camp, conference, and retreat facilities in the United States listed in the 1999-2000 PCUSA Camp, Conference and Retreat Centers Directory. The actual population of UCC church camps was calculated from a potential population of 69 church camp, conference, and retreat facilities listed in the Directory of UCC Outdoor Ministry Sites and Programs. As the focus of this study was on actual church camp programs, some of the facilities were deleted from the potential populations in each denomination. Facilities that were exclusively conference or 
retreat facilities, and thus did not offer church camping programs, were deleted from the potential population in each of the denominations in the course of questionnaires being returned. Additional facilities were also deleted from the potential population in each denomination in the course of questionnaires being returned because the facilities were closed, had been sold, were no longer offering church camp programs, now offered only athletic programs, were not yet open, were no longer affiliated with the denomination, or represented combined facilities offering a single church camp program.

The actual population of church camps in each denomination was, therefore, calculated as follows:

\section{PCUSA UCC}

Potential population determined from total number of church camp, conference and retreat facilities

Centers that were exclusively conference and retreat facilities and did not offer church camp programs

Church camps closed, sold, no longer offering camp programs, offering only athletic programs, not yet open, or no longer affiliated with the denomination

Combined facilities offering a single camp program Actual church camp population

$\begin{array}{ll}(8) & (8) \\ \frac{(1)}{126} & \frac{(1)}{54}\end{array}$

No measures were taken to control non-response error. ${ }^{11}$ Consequently, although the return rates were high for both PCUSA church camps (92.86\%) and UCC church camps (87.04\%), the results are generalizable only to the responding church camps in each population.

\footnotetext{
${ }^{11}$ Among possible measures that could have been used to control non-response error are "doubledipping," comparing early to late respondents, comparing respondents to non-respondents on known characteristics, and comparing non-respondents to the population on known characteristics. However, only the first two measures would likely have been useable in this study.
} 


\section{Instrumentation}

A questionnaire comprising 24 questions was developed as the instrument for the study. A copy of the questionnaire is appended to this thesis. Fourteen of the questions focus on organizational or descriptive profiles of church camps. Ten questions form the core focus of the study in relation to church camp programs. Four of the questions focus on religious values, three of the questions focus on environmental values, and three of the questions focus on the integration of religious values and environmental values. The questions as to organizational and descriptive profiles cover general information about the church camps and church camp programs such as location (by state), topography, use of public lands, number of participants, age groups served, "home" areas of participants, staffing, sources of financial support, and strength of management and ecclesiastical relationships with religious or other groups with which the camps are affiliated.

The first of the four questions under religious values involved selecting the source of program/curriculum in camp programs. The second question involved selecting the category which best described the philosophy/theology of outdoor religious education in camp programs. The third question, which is the primary question as to religious values, focused on 13 philosophical/theological purposes in camp programs. Twelve of these purposes were developed by the author from beliefs and doctrines characteristic of the two religious groups and purposes of church camping articulated in the literature (Allen, 2000; Crouse, 1984; Ferguson, 2000; Gehris, 1984; Graabher and Rose-Heim, 1990, 1998; Kamm, 1984; Kerr, 1983; Klopfenstein et al., 1993; Martin-Adkins, 1984; Mason, 1962; Mattson, 1985; McCollogh \& McCollough, 1983; Miller and Rose-Heim, 1990, 1998; Moore, 1990, 1998; Paetkau, Harder, \& Sawatzky, 1978; Suess \& Ferguson, 1990, 1998; Van Matre. 1972), purposes of organized camping articulated in 
the literature (Ball \& Ball, 1995; Kraus \& Scanlin, 1983; Meier \& Mitchell, 1983; Shivers, 1989), and personal experience of the author in the church camping and organized camping fields. A final philosophical/theological purpose of "Other" was also included, with space provided for the "other" purpose to be entered by the respondent. This third question used a Likert-type scale $(1=$ very important to $5=$ not important $)$ to assess the importance of each of the 13 philosophical/ theological purposes.

The last question under religious values involved ranking (in terms of priority) the three most important philosophical/ theological purposes from the second question.

The first of the three questions relative to environmental values focused on the level of importance of environmental/ecological activities in camp programs. It used a Likert-type scale ( 1 = very important to $5=$ not important). The second question, which is the primary question assessing environmental values, focused on the importance of seven environmental/ecological indicators in camp programs. It used a Likert-type scale $(1=$ very important to $5=$ not important). This second question follows one of two models or frameworks used by Negra and Manning (1997) and represents a model adapted by them from Hungerford and Volk (1990). According to Negra and Manning (1997), the first model utilizes seven "key indicator variables" divided into three categories "to predict level of environmental behavior" (p. 12).

The first of five categories of environmental indicators is "entry level," defined by Negra and Manning as "variables [that] function as prerequisites for environmentally responsible behavior by providing the foundation for proenvironmental ( $\mathrm{sic}$ ) attitudes and decision making" (pp. 12,14). They posit one variable in the first category. The second category is "ownership" indicators defined by Negra and Manning as "variables [that] personalize environmental issues through expanded understanding and investment" (pp. 12, 14). They posit two variables in the 
second category. The third category is "empowerment" variables defined by Negra and Manning as "variables [that] represent environmental problem-solving skills" (pp. 12, 14). They posit four variables in the third category.

The third question under environmental values involved ranking the three most important environmental/ecological indicators from the second question.

The first of the three questions related to the integration of religious values and environmental values focused on the strength of the relationship between religious values and environmental values in camp programs. It used a Likert-type scale ( 1 = very strong relationship to $5=$ very weak relationship). The second question, which is the primary question assessing the integration of religious values and environmental values, focused on the likelihood of 16 "environmental ethics" statements, having reference to the relationship between environmental/ ecological aspects and philosophical/theological aspects, being taught in camp programs. It used a Likert-type scale $(1=$ more likely to be taught to $5=$ less likely to be taught $)$.

This second question, comprising a typology of 16 environmental ethics statements in five categories, follows the second of two models or frameworks developed by Negra and Manning (1997). The first category of statements is defined by Negra and Manning as "antienvironment" and comprises two statements (pp. 13, 15-16). The second category is defined as "benign indifference" and comprises three statements (pp. 13, 15-16). The third category is defined as "utilitarian conservation" and comprises four statements (pp. 13,15-16). The fourth category is defined as "stewardship" and comprises four statements (pp. 13,15-16). The fifth category is defined as "radical environmentalism" and comprises three statements (pp. 13, 15$16)$. 
The third question under the integration of religious values and environmental values involved ranking the three most important statements likely to be taught in camp programs from the second question.

Face validity of the instrument as to the primary question relating to religious values was based on the philosophical/theological purposes comprising the question being adapted from the church camping literature (Allen, 2000; Crouse, 1984; Ferguson, 2000; Gehris, 1984; Grabher and Rose-Heim, 1990, 1998; Kamm, 1984; Kerr, 1983; Klopfenstein et al., 1993; Martin-Adkins, 1984; Mason, 1962; Mattson, 1985; McCollough \& McCollough, 1983; Miller \& Rose-Heim, 1990, 1998; Moore, 1990, 1998; Paetkau et al., 1978; Suess \& Ferguson, 1990, 1998; Van Matre, 1972). Face validity of the instrument in relation to the primary question relating to environmental values was based on the seven environmental/ ecological indicators comprising the question being modeled on the seven environmental indicators used by Negra and Manning (1997). Face validity of the instrument as to the primary question relating to the integration of religious values and environmental values was based on the 16 statements comprising the question being modeled on the 16 environmental ethics developed by Negra and Manning as well as being adapted from the church camping literature noted above.

Content validity of the instrument was based on review of the instrument by a panel of "experts" comprising two camp directors having long experience in the church camping field who are also affiliated with the ACA, another ACA representative, and a professor in the Recreation, Parks, and Tourism program, Division of Forestry and Natural Resources, West Virginia University. No measures were taken to establish the reliability of the instrument. ${ }^{12}$

\footnotetext{
${ }^{12}$ The possible measures that could have been used to establish the reliability of the instrument include those yielding a coefficient of internal consistency (split-half, odd-even, Kuder-Richardson, and Cronbach's Alpha), testretest, and a pilot test. However, none of these measures were used given that they would have been applied "after the fact."
} 


\section{Conditions of Testing}

The questionnaire was initially sent to a random sample of PCUSA church camps as a research project in a course at West Virginia University. The course, which was entitled "Human Dimensions of Natural Resources \& Tourism: A Social/Psychological Perspective," was taught by the professor noted above who also reviewed the instrument. As part of a research project at Lancaster Theological Seminary focusing on PCUSA church camps, the questionnaire was then sent to all of the remaining PCUSA church camp, conference and retreat facilities in order to cover the entire and actual population of PCUSA church camps. For purposes of this study and thesis, the questionnaire was also mailed to all of the UCC church camp, conference and retreat facilities in order to cover the entire and actual population of UCC church camps.

As noted above, the actual population of church camps in each denomination was determined in the course of the questionnaires being returned. This resulted in the deletion of facilities from the potential population in each denomination that were exclusively conference and retreat facilities and did not offer church camp programs. As also noted above, additional facilities were deleted in the potential population of each denomination because the facilities were closed, had been sold, were no longer offering church camp programs, offered only athletic programs, were not yet open, were no longer affiliated with the denomination, or represented combined facilities that offered a single church camp program.

The initial contact and provision of questionnaires to each church camp was by mail. The questionnaires were coded and accompanied by a cover letter describing the nature and purpose of the study. It was also requested in this letter (and in follow-up letters) that facilities advise if they were exclusively conference and retreat facilities and did not offer church camp programs. Each mailing was addressed to the camp director or manager by name, if known, and otherwise 
was addressed to "Camp Director or Manager." A stamped, self-addressed envelope was also enclosed in every mailing for return of the questionnaire. Follow-up telephone calls were made to church camps that did not initially respond, another letter was sent to follow-up the telephone call, and a final follow-up letter was sent that included a duplicate copy of the questionnaire. Additional follow-up was conducted by telephone with church camps that still did not respond to the follow-up telephone calls and letters, as well as in cases where it appeared that any follow-up communication needed to be directed to a different contact person or address for a particular church camp. Confirmation was also made through written replies and by telephone as to those facilities that were exclusively conference and retreat facilities and/or did not offer church camp programs, as well as with camp or church officials regarding church camps that were closed, had been sold, were no longer offering church camp programs, offered only athletic programs, were not yet open, were no longer affiliated with the denomination, or represented combined facilities that offered a single church camp program.

\section{Data Analysis}

The completed questionnaires returned were entered in a personal computer and analyzed using the Statistical Package for the Social Sciences (SPSS 11.0). Descriptive statistics as to measures of central tendency and strength of association were computed to describe the populations and the responses to each question. Inferential statistics in terms of cross-tabulations and the chi-square test for independence were also computed as to the 10 questions that form the core focus of the study. The results as to the first 14 questions permit examination, assessment, and comparison of the organizational and descriptive profiles of church camps within and between the PCUSA and the UCC [Objective (2)(a)]. The results as to the remaining 10 questions having reference to religious values, environmental values, and the integration of 
religious values and environmental values permit examination, assessment, and comparison of the emphasis placed on these three aspects of church camping programs within and between the PCUSA and the UCC [Objectives (2)(b-d)]. The results also permit examination, assessment and comparison as to: (1) the strength of association between denominational affiliation and religious values, environmental values, and the integration of religious values and environmental values in church camp programs; and (2) whether the association between denominational affiliation and these three aspects of church camp programs are statistically significant [Objectives (2)(e)]. 


\section{Chapter 4 - Results}

\section{Organizational and Descriptive Profiles}

While organizational and descriptive-type information was examined by 14 questions in the survey instrument, only the results germane to the hypotheses are presented here. Table 1 summarizes the number of respondent camps in each denomination by states. There is a broad geographical range of camps in each denomination and this range conforms generally to the demographics (e.g., constituent churches and membership) of each denomination noted in Chapter 1. The number of camps in each state and their geographical range also tends to conform to the relative strength, numerical size (e.g., number of constituent churches), and socio-cultural dispersion of each denomination.

Given the significance of outdoor settings for church camp programs noted in Chapters 1 and 2, outdoor settings were examined through two questions in the survey instrument: (1) The physical settings of camps; and (2) The use of public lands (e.g., national forests or parks, state forests or parks, and local parks and recreational facilities) in camp programs. As summarized in Table 2, the physical settings of camps reflect diversity between the two denominations as well as within each denomination. A total of 76 PCUSA camps (65.0\%) also use public lands in their camp programs as compared to 21 UCC camps (45.7\%), yielding a total of 97 camps (59.5\%) in both denominations that use public lands in their camp programs.

As noted in Chapter 1, church camps represent an important aspect of the educational ministry programs in both the PCUSA and the UCC. As also noted in Chapters 1 and 2, the environment and environmental concerns have been an important focus in both the PCUSA and the UCC. To the extent that PCUSA and UCC church camps reflect and are representative of 
Table 1

States in Which Camps Are Located (Frequency)

\begin{tabular}{|c|c|c|}
\hline State & PCUSA & $\mathrm{UCC}$ \\
\hline Alabama & 3 & 0 \\
\hline Alaska & 2 & 0 \\
\hline Arizona & 1 & 1 \\
\hline Arkansas & 2 & 0 \\
\hline California & 2 & 3 \\
\hline Colorado & 2 & 1 \\
\hline Connecticut & 0 & 3 \\
\hline Florida & 5 & 1 \\
\hline Georgia & 2 & 0 \\
\hline Hawaii & 0 & 1 \\
\hline Idaho & 2 & 2 \\
\hline Illinois & 2 & 2 \\
\hline Indiana & 3 & 1 \\
\hline Iowa & 2 & 0 \\
\hline Kansas & 2 & 1 \\
\hline Kentucky & 2 & 0 \\
\hline Louisiana & 1 & 0 \\
\hline Maine & 1 & 1 \\
\hline Maryland & 1 & 0 \\
\hline Massachusetts & 0 & 1 \\
\hline Michigan & 6 & 3 \\
\hline Minnesota & 2 & 1 \\
\hline Mississippi & 1 & 1 \\
\hline Missouri & 3 & 2 \\
\hline Montana & 3 & 1 \\
\hline Nebraska & 2 & 1 \\
\hline New Hampshire & 1 & 1 \\
\hline New Jersey & 1 & 0 \\
\hline New Mexico & 3 & 0 \\
\hline New York & 5 & 2 \\
\hline North Carolina & 7 & 3 \\
\hline Ohio & 7 & 3 \\
\hline Oklahoma & 2 & 0 \\
\hline Oregon & 2 & 1 \\
\hline Pennsylvania & 10 & 3 \\
\hline Rhode Island & 0 & 1 \\
\hline South Carolina & 2 & 0 \\
\hline South Dakota & 1 & 1 \\
\hline Tennessee & 4 & 0 \\
\hline Texas & 6 & 1 \\
\hline Vermont & 0 & 1 \\
\hline Virginia & 8 & 0 \\
\hline Washington & 3 & 0 \\
\hline West Virginia & 1 & 0 \\
\hline Wisconsin & 1 & 1 \\
\hline Wyoming & 1 & 0 \\
\hline Total & 117 & 45 \\
\hline
\end{tabular}


Table 2

Physical Settings of Camps

(Frequency of Affirmative Response)

\begin{tabular}{lcccccc} 
Setting & \multicolumn{2}{c}{ PCUSA } & \multicolumn{2}{c}{ UCC } & \multicolumn{2}{c}{ ALL CAMPS } \\
\hline & $\%$ & Freq. & $\%$ & Freq. & $\%$ & Freq. \\
\cline { 2 - 7 } Urban Area & $0.0 \%$ & 0 & $4.3 \%$ & 2 & $1.2 \%$ & 2 \\
\hline Suburban Area & $11.1 \%$ & 13 & $8.5 \%$ & 4 & $10.4 \%$ & 17 \\
\hline Rural Area & $82.1 \%$ & 96 & $80.9 \%$ & 38 & $81.7 \%$ & 134 \\
\hline Primitive Area & $20.5 \%$ & 24 & $21.3 \%$ & 10 & $20.7 \%$ & 34 \\
\hline Coastal Area & $3.4 \%$ & 4 & $14.9 \%$ & 7 & $6.7 \%$ & 11 \\
\hline Lake(s) & $47.9 \%$ & 56 & $42.6 \%$ & 20 & $46.3 \%$ & 76 \\
\hline Stream (s) & $40.2 \%$ & 47 & $44.7 \%$ & 21 & $41.5 \%$ & 68 \\
\hline Mountain (s) & $28.2 \%$ & 33 & $31.9 \%$ & 15 & $29.3 \%$ & 48 \\
\hline Rolling Hills & $44.4 \%$ & 52 & $29.8 \%$ & 14 & $40.2 \%$ & 66 \\
\hline Plains or Flatlands & $7.7 \%$ & 9 & $12.8 \%$ & 6 & $9.1 \%$ & 15 \\
\hline Arid or Desert & $0.0 \%$ & 0 & $4.3 \%$ & 2 & $1.2 \%$ & 2 \\
\hline $\begin{array}{l}\text { Mostly/Completely } \\
\text { Wooded }\end{array}$ & $52.1 \%$ & 61 & $0.0 \%$ & 0 & $37.2 \%$ & 61 \\
\hline $\begin{array}{l}\text { Mixed } \\
\text { Woods/Fields }\end{array}$ & $44.4 \%$ & 52 & $53.2 \%$ & 25 & $47.0 \%$ & 77 \\
\hline Other Settings & $12.0 \%$ & 14 & $40.4 \%$ & 19 & $20.1 \%$ & 33 \\
\hline
\end{tabular}

their respective denominational positions, environmental concerns should be an emphasis in camp programs of each denomination.

Two questions in the survey instrument examined the strength of the relationship between camps and the denomination (PCUSA or UCC) with which they are affiliated:

(1) Sources of campers, especially from constituent churches in the respective denominations; and

(2) The strength of the ecclesiastical relationship between the camps and their respective denominations.

The sources of campers from (a) local churches affiliated with one or the other denomination, and (b) from local churches not affiliated with (i.e., independent of) either 
denomination were examined by cross-tabulation and the results are summarized in Table 3 . The chi-square test for independence $($ alpha $=.05)$ was performed, but yielded no statistically significant results as to any of the six sources of campers. This indicates that neither PCUSA nor UCC camps were likely to have a particular source for campers by reason of denominational affiliation. The strength of association between denominational affiliation and sources of campers was also examined. Lambda $=.000$ when all six sources of campers were examined, indicating that knowing a camp's denominational affiliation did not increase the likelihood of predicting a particular source of campers among any of the six sources.

Table 3

Source of Campers

(Frequency of Affirmative Response)

\begin{tabular}{|c|c|c|c|c|c|c|}
\hline Source of Campers & \multicolumn{2}{|c|}{ PCUSA } & \multicolumn{2}{|c|}{$\mathrm{UCC}$} & \multicolumn{2}{|c|}{ ALL CAMPS } \\
\hline & $\%$ & Freq. & $\%$ & Freq. & $\%$ & Freq. \\
\hline $\begin{array}{l}\text { Completely or Primarily } \\
\text { Affiliated Local Churches }\end{array}$ & $13.7 \%$ & 16 & $12.8 \%$ & 6 & $13.4 \%$ & 22 \\
\hline $\begin{array}{l}\text { Mostly Affiliated Local } \\
\text { Churches/Some Independent }\end{array}$ & $54.7 \%$ & 64 & $51.1 \%$ & 24 & $53.7 \%$ & 88 \\
\hline $\begin{array}{l}\text { Fairly Even Mix of } \\
\text { Affiliated Local Churches } \\
\text { and Independent }\end{array}$ & $20.5 \%$ & 24 & $23.4 \%$ & 11 & $21.3 \%$ & 35 \\
\hline $\begin{array}{l}\text { Mostly Independent/Some } \\
\text { Affiliated Local Churches }\end{array}$ & $6.0 \%$ & 7 & $6.4 \%$ & 3 & $6.1 \%$ & 10 \\
\hline $\begin{array}{l}\text { Completely or Primarily } \\
\text { Independent }\end{array}$ & $1.7 \%$ & 2 & $2.1 \%$ & 1 & $1.8 \%$ & 3 \\
\hline Other Sources of Campers & $3.4 \%$ & 4 & $6.4 \%$ & 3 & $4.3 \%$ & 7 \\
\hline
\end{tabular}

The strength of the ecclesiastical relationship between camps and the respective denomination with which they are affiliated was examined using a Likert-type scale $[1.000=$ very strong relationship to $5.000=$ very weak relationship]. The median for both PCUSA and UCC camps, as well as for all camps, was 2.000, indicating that the strength of ecclesiastical relationships between camps and their respective denominations was "strong," but not "very 
strong."13 The strength of ecclesiastical relationships by reference to denominational affiliation was also examined by cross-tabulation and the results are summarized in Table 4 . The chi-square test for independence (alpha $=.05$ ) was performed, but yielded no statistically significant result (chi-square $=3.575 ; \mathrm{p}=.467)$. This indicates that neither PCUSA nor UCC camps differed as to the strength of their ecclesiastical relationship on the basis of denominational affiliation. The strength of association was also examined between denominational affiliation and the strength of ecclesiastical relationships. Lambda $=.024$, indicating that knowledge of a camp's denominational affiliation increased the likelihood of predicting the strength of its ecclesiastical relationship by only $2 \%$.

Table 4

Strength of Ecclesiastical Relationship by Denomination (Cross-tabulation and Frequency of Affirmative Response)

\begin{tabular}{lcccccc} 
Strength of Relationship & \multicolumn{2}{c}{ PCUSA } & \multicolumn{2}{c}{ UCC } & \multicolumn{2}{c}{ ALL CAMPS } \\
\hline & $\%$ & Freq. & $\%$ & Freq. & $\%$ & Freq. \\
\cline { 2 - 7 } Very Strong Relationship & $39.8 \%$ & 43 & $43.9 \%$ & 18 & $40.9 \%$ & 61 \\
\hline Strong Relationship & $37.0 \%$ & 40 & $36.6 \%$ & 15 & $36.9 \%$ & 55 \\
\hline Neither Strong Nor Weak & $20.4 \%$ & 22 & $12.2 \%$ & 5 & $18.1 \%$ & 27 \\
\hline Weak Relationship & $1.9 \%$ & 2 & $2.4 \%$ & 1 & $2.0 \%$ & 3 \\
\hline Very Weak Relationship & $0.9 \%$ & 1 & $4.9 \%$ & 2 & $2.0 \%$ & 3 \\
\hline Total & $100.0 \%$ & 108 & $100.0 \%$ & 41 & $100.0 \%$ & 149 \\
\hline
\end{tabular}

\section{Religious Values}

Four questions in the survey instrument examined camp programs in terms of religious values: (1) The sources of program/curriculum materials; (2) The philosophy/ theology of outdoor religious education; (3) Philosophical/theological purposes served in camp programs;

\footnotetext{
${ }^{13}$ The median was used throughout this study rather than the mean because it is less sensitive to extreme scores and is a more conservative measure of central tendency. It was thus a more reliable measure for purposes of this study given the relatively small total population of camps surveyed and the disparity in population between PCUSA camps and UCC camps.
} 
and (4) The three most important philosophical/theological purposes (in terms of priority) served in camp programs.

\section{1(a). Sources of Program/Curriculum Materials}

The sources of program/curriculum materials used in PCUSA and UCC camp programs were examined by cross-tabulation and the results are summarized in Table 5. The mode for PCUSA and UCC camps, as well as for all camps, was 2.000, indicating that ecumenical program/curriculum materials were the most frequently selected source. While the results appear to show some differences both between denominations and within each denomination, the chisquare test for independence $($ alpha $=0.05)$ yielded no statistically significant differences between PCUSA and UCC camps as to any of the five categories of program/curriculum

Table 5

Sources of Camp Program/Curriculum Materials

(Cross-tabulation and Frequency of Affirmative Response)

Sources of Program/

$\begin{array}{llll}\text { Curriculum Material } & \text { PCUSA } & \text { UCC }\end{array}$

\begin{tabular}{lcccccc}
\hline & $\%$ & Freq. & $\%$ & Freq. & $\%$ & Freq. \\
\cline { 2 - 7 } Denominational & $25.7 \%$ & 26 & $11.6 \%$ & 5 & $21.5 \%$ & 31 \\
\hline Ecumenical & $35.6 \%$ & 36 & $48.8 \%$ & 21 & $39.6 \%$ & 57 \\
\hline Non-Denominational & $4.0 \%$ & 4 & $4.7 \%$ & 2 & $4.2 \%$ & 6 \\
\hline $\begin{array}{l}\text { Self Developed/Produced by } \\
\text { the Camp }\end{array}$ & $32.7 \%$ & 33 & $27.9 \%$ & 12 & $31.3 \%$ & 45 \\
\hline Other & $2.0 \%$ & 2 & $7.0 \%$ & 3 & $3.5 \%$ & 5 \\
\hline Total & $100.0 \%$ & 101 & $100 / 0 \%$ & 43 & $100.0 \%$ & 144 \\
\hline
\end{tabular}

Scale: $1.000=$ Denominational, $2.000=$ Ecumenical, $3.000=$ Non-Denominational, $4.000=$ Self Developed/Produced by Camp, $5.000=$ Other Source

materials (chi-square $=6.540 ; p=.162$ ). This indicates that neither PCUSA nor UCC camps were more likely to select a particular source of program/curriculum materials on the basis of 
denominational affiliation. The strength of association between denominational affiliation and the source of program/curriculum materials used in camp programs was also examined. Lambda $=.023$, indicating that knowing a camp's denomination increased the likelihood of predicting its particular source of program/curriculum materials by only $2 \%$.

\section{1(b). Philosophy/Theology of Outdoor Religious Education}

The philosophical/theological positions of PCUSA and UCC camps in relation to outdoor religious education were examined by cross-tabulation and the results are summarized in Table 6. The mode for both PCUSA and UCC camps, as well as for all camps, was 3.000, indicating that Reformed Mainline was the most frequently selected philosophical/theological position in

\section{Table 6}

\section{Philosophy/Theology of Outdoor Religious Education} (Cross-tabulation and Frequency of Affirmative Response)

\begin{tabular}{lcccccc} 
Philosophy/Theology & \multicolumn{2}{c}{ PCUSA } & \multicolumn{2}{c}{ UCC } & \multicolumn{2}{c}{ ALL CAMPS } \\
\hline & $\%$ & Freq. & $\%$ & Freq. & $\%$ & Freq. \\
\cline { 2 - 7 } Reformed (Liberal) & $13.6 \%$ & 14 & $28.6 \%$ & 12 & $17.9 \%$ & 26 \\
\hline Reformed (Conservative) & $9.7 \%$ & 10 & $2.4 \%$ & 1 & $7.6 \%$ & 11 \\
\hline Reformed (Mainline) & $63.1 \%$ & 65 & $45.2 \%$ & 19 & $57.9 \%$ & 84 \\
\hline Orthodox/Neo-Orthodox & $0.0 \%$ & 0 & $0.0 \%$ & 0 & $0.0 \%$ & 0 \\
\hline Environmental/Ecological & $6.8 \%$ & 7 & $9.5 \%$ & 4 & $7.6 \%$ & 11 \\
\hline Fundamentalist & $0.0 \%$ & 0 & $0.0 \%$ & 0 & $0.0 \%$ & 0 \\
\hline Creationist & $1.9 \%$ & 2 & $2.4 \%$ & 1 & $2.1 \%$ & 3 \\
\hline Non-Sectarian & $1.9 \%$ & 2 & $2.4 \%$ & 1 & $2.1 \%$ & 3 \\
\hline Other & $2.9 \%$ & 3 & $9.5 \%$ & 4 & $4.8 \%$ & 7 \\
\hline Total & $100 \%$ & 103 & $100 \%$ & 42 & $100 \%$ & 145 \\
\hline
\end{tabular}

Scale: $1.000=$ Reformed (Liberal), $2.000=$ Reformed (Conservative), $3.000=$ Reformed (Mainline), $4.000=$ Orthodox $/$ Neo-Orthodox, $5.000=$ Environmental/Ecological, $6.000=$ Fundamentalist, 7.000 $=$ Creationist, $8.000=$ Non-Sectarian, $9.000=$ Other Philosophy $/$ Theology

relation to outdoor religious education. While the results show some differences between denominations as well as within each denomination, the chi-square test for independence (alpha 
$=.05)$ yielded no statistically significant differences between PCUSA and UCC camps with reference to denominational affiliation (chi-square $=10.539 ; \mathrm{p}=.104)$. This indicates that neither PCUSA nor UCC camps were likely to select a category of philosophy/theology of outdoor religious education on the basis of denominational affiliation. The strength of association between denominational affiliation and the philosophy/theology of outdoor religious education was also examined. Lambda $=.024$, indicating that knowing a camp's denominational affiliation increased the likelihood of predicting its philosophy/ theology of outdoor religious education by only $2 \%$.

\section{1(c). Level of Importance of 13 Philosophical/Theological Purposes}

The level of importance of 13 philosophical/theological purposes served in PCUSA and UCC camp programs was measured on a Likert-type scale $[1.000=$ very important to $5.000=$ not important]. The medians of these philosophical/theological purposes are summarized in Table $7 .{ }^{14}$ These 13 philosophical/theological purposes were also examined by cross-tabulation. The results are summarized in Table 8 as to those purposes reported as "Important" or Very Important" ${ }^{\prime 15}$ and appear to show some differences between denominations as well as within each denomination. The chi-square test for independence $($ alpha $=.05)$ yielded statistically significant differences as to two of the 13 philosophical/theological purposes between PCUSA and UCC camps on the basis of denominational affiliation:

(1) "Providing opportunities to win campers for Jesus Christ through public witness and commitment to Jesus Christ as their personal Lord and Savior" [chi-square $=15.248$;

\footnotetext{
${ }^{14}$ As noted earlier, the median was used throughout this study rather than the mean because it is less sensitive to extreme scores and is a more conservative measure of central tendency. It was thus a more reliable measure for purposes of this study given the relatively small total population of camps surveyed and the disparity in population between PCUSA camps and UCC camps.

${ }^{15}$ The total percentages in Table 8 for each philosophical/theological purpose served in camp programs do not equal $100 \%$ because only two levels ("Important" and "Very Important") are included in the summary.
} 
$\mathrm{p}=.004]$. This indicates that there was a significant difference in the level of importance of this purpose between PCUSA and UCC camps; and

Table 7

Level of Importance of Philosophical/Theological

Purposes Served in Camp Program (Median)

Philosophical/Theological Purpose

PCUSA UCC

ALL

Win Campers for Jesus Christ as their
Personal Lord and Savior

CAMPS

$\begin{array}{lll}\text { Develop, Transmit, and Reinforce the Faith } \quad 2.000 & 2.000 \quad 2.000\end{array}$

Tradition of the Camper's Local Church

\begin{tabular}{llll}
\hline Help Build, Participate In, and Experience a & 1.000 & 1.000 & 1.000
\end{tabular}

Temporary Faith Community that is

Distinctively Christian

\begin{tabular}{|c|c|c|c|}
\hline $\begin{array}{l}\text { Grow Spiritually in Personal Faith Experience } \\
\text { and Religious Practices }\end{array}$ & 1.000 & 1.000 & 1.000 \\
\hline $\begin{array}{l}\text { Grow in Understanding of and Relationship to } \\
\text { God }\end{array}$ & 1.000 & 1.000 & 1.000 \\
\hline $\begin{array}{l}\text { Learn More about Relationship between God } \\
\text { and God's Creation }\end{array}$ & 1.000 & 1.000 & 1.000 \\
\hline $\begin{array}{l}\text { Provide Opportunities for Wholesome, Faith- } \\
\text { Building, and Spiritually-Enriching } \\
\text { Relationships in a Christian Community }\end{array}$ & 1.000 & 1.000 & 1.000 \\
\hline $\begin{array}{l}\text { Support and Extend the Religious Educational } \\
\text { Program of the Camper's Local Church }\end{array}$ & 2.000 & 2.000 & 2.000 \\
\hline $\begin{array}{l}\text { Gain More Knowledge about the Bible and } \\
\text { Christian Beliefs }\end{array}$ & 1.000 & 2.000 & 2.000 \\
\hline $\begin{array}{l}\text { Better Learn How to Apply Christian Beliefs } \\
\text { and Biblical Values }\end{array}$ & 1.000 & 1.000 & 1.000 \\
\hline $\begin{array}{l}\text { Gain More Knowledge of God's Creation } \\
\text { (including the Natural World) and Christian } \\
\text { Responsibility toward God's Creation }\end{array}$ & 2.000 & 1.500 & 2.000 \\
\hline $\begin{array}{l}\text { Develop Positive Inter-Personal } \\
\text { Relationships, Build Self-Esteem, and Grow } \\
\text { Physically, Emotionally and Spiritually }\end{array}$ & 1.000 & 1.000 & 1.000 \\
\hline Other Philosophical/Theological Purposes & 1.000 & 1.000 & 1.000 \\
\hline
\end{tabular}

Scale: $1.000=$ Very Important to $5.000=$ Not Important 
(2) "Providing opportunities for campers to gain more knowledge about the Bible and Christian beliefs" [chi-square $=12.019 ; \mathrm{p}=0.017$ ]. This indicates that there was a significant difference in the level of importance of this purpose between PCUSA and UCC camps.

The strength of association between denominational affiliation and the 13 philosophical/ theological purposes was also examined and knowledge of the denominational affiliation of a camp increased the likelihood of predicting its position as to four purposes:

(1) "Providing opportunities to win campers for Jesus Christ through public witness and commitment to Jesus Christ as their personal Lord and Savior." Lambda $=.093$, indicating that knowledge of the denominational affiliation of a camp increased the likelihood of predicting its position as to this purpose by just over $9 \%$

(2) "Providing opportunities to develop, transmit, and reinforce the particular faith tradition of the camper's local church or religious group." Lambda $=.019$, indicating that knowledge of the denominational affiliation of a camp increased the likelihood of predicting its position as to this purpose by just under $2 \%$;

(3) "Providing opportunities for campers to support and extend the religious educational program of the camper's local church or religious group. Lamba $=.009$, indicating that knowledge of the denominational affiliation of a camp increased the likelihood of predicting its position as to this purpose by just under $1 \%$; and

(4) "Providing opportunities for campers to gain more knowledge about the Bible and Christian beliefs." Lambda equaled .048, indicating that knowing the 
Table 8

Philosophical/Theological Purposes Served in Camp Programs Reported as Very Important or Important (Cross-tabulation; Bold = statistically significant difference between denominations)

\begin{tabular}{|c|c|c|c|c|c|c|c|}
\hline \multicolumn{2}{|l|}{ Philosophical/Theological Purposes } & \multicolumn{2}{|c|}{ PCUSA } & \multicolumn{2}{|c|}{$\mathrm{UCC}$} & \multicolumn{2}{|c|}{ ALL CAMPS } \\
\hline \multirow{4}{*}{$\begin{array}{l}\text { Win Campers for Jesus Christ as their } \\
\text { Personal Lord and Savior } \\
\text { Chi-square }=15.248 ; \underline{p}=.004\end{array}$} & & $\%$ & Freq. & $\%$ & Freq. & $\%$ & Freq. \\
\hline & Very & $33.9 \%$ & 38 & $10.8 \%$ & 4 & $28.2 \%$ & 42 \\
\hline & Imp. & & & & & & \\
\hline & Imp. & $18.8 \%$ & 21 & $10.8 \%$ & 4 & $16.8 \%$ & 25 \\
\hline \multirow{3}{*}{$\begin{array}{l}\text { Develop, Transmit, and Reinforce the } \\
\text { Faith Tradition of the Camper's Local } \\
\text { Church }\end{array}$} & Very & $20.5 \%$ & 23 & $31.0 \%$ & 13 & $23.4 \%$ & 36 \\
\hline & Imp. & & & & & & \\
\hline & Imp. & $35.7 \%$ & 40 & $26.2 \%$ & 11 & $33.1 \%$ & 51 \\
\hline \multirow{2}{*}{$\begin{array}{l}\text { Help Build, Participate In, and } \\
\text { Experience a Temporary Faith } \\
\text { Community that is Distinctively } \\
\text { Christian }\end{array}$} & $\begin{array}{l}\text { Very } \\
\text { Imp. }\end{array}$ & $77.9 \%$ & 88 & $71.1 \%$ & 30 & $76.1 \%$ & 118 \\
\hline & Imp. & $14.2 \%$ & 16 & $21.1 \%$ & 9 & $16.1 \%$ & 25 \\
\hline \multirow[t]{2}{*}{$\begin{array}{l}\text { Grow Spiritually in Personal Faith } \\
\text { Experience and Religious Practices }\end{array}$} & $\begin{array}{l}\text { Very } \\
\text { Imp. }\end{array}$ & $83.6 \%$ & 97 & $77.3 \%$ & 34 & $81.9 \%$ & 131 \\
\hline & Imp. & $10.3 \%$ & 12 & $20.5 \%$ & 9 & $13.1 \%$ & 21 \\
\hline \multirow[t]{2}{*}{$\begin{array}{l}\text { Grow in Understanding of and } \\
\text { Relationship to God }\end{array}$} & $\begin{array}{l}\text { Very } \\
\text { Imp. }\end{array}$ & $86.2 \%$ & 100 & $84.1 \%$ & 37 & $85.6 \%$ & 137 \\
\hline & Imp. & $10.3 \%$ & 12 & $13.6 \%$ & 6 & $11.3 \%$ & 18 \\
\hline \multirow[t]{2}{*}{$\begin{array}{l}\text { Learn More about Relationship between } \\
\text { God and God's Creation }\end{array}$} & $\begin{array}{l}\text { Very } \\
\text { Imp. }\end{array}$ & $57.4 \%$ & 66 & $60.5 \%$ & 26 & $58.2 \%$ & 92 \\
\hline & Imp. & $31.3 \%$ & 36 & $20.9 \%$ & 9 & $28.5 \%$ & 45 \\
\hline \multirow{2}{*}{$\begin{array}{l}\text { Provide Opportunities for Wholesome, } \\
\text { Faith-Building, and Spiritually-Enriching } \\
\text { Relationships in a Christian Community }\end{array}$} & $\begin{array}{l}\text { Very } \\
\text { Imp. }\end{array}$ & $73.9 \%$ & 85 & $79.5 \%$ & 35 & $75.5 \%$ & 120 \\
\hline & Imp. & $19.1 \%$ & 22 & $13.6 \%$ & 6 & $17.6 \%$ & 28 \\
\hline \multirow{2}{*}{$\begin{array}{l}\text { Support and Extend the Religious } \\
\text { Educational Program of the Camper's } \\
\text { Local Church }\end{array}$} & $\begin{array}{l}\text { Very } \\
\text { Imp. }\end{array}$ & $25.7 \%$ & 28 & $30.2 \%$ & 13 & $27.0 \%$ & 41 \\
\hline & Imp. & $29.4 \%$ & 32 & $27.9 \%$ & 12 & $28.9 \%$ & 44 \\
\hline \multirow{2}{*}{$\begin{array}{l}\text { Gain More Knowledge about the Bible } \\
\text { and Christian Beliefs } \\
\text { Chi-square = 12.019; } \mathbf{p}=\mathbf{0 . 0 1 7}\end{array}$} & $\begin{array}{l}\text { Very } \\
\text { Imp. }\end{array}$ & $52.2 \%$ & 60 & $27.5 \%$ & 11 & $45.8 \%$ & 71 \\
\hline & Imp. & $32.2 \%$ & 37 & $37.5 \%$ & 15 & $33.5 \%$ & 52 \\
\hline \multirow[t]{2}{*}{$\begin{array}{l}\text { Better Learn How to Apply Christian } \\
\text { Beliefs and Biblical Values }\end{array}$} & $\begin{array}{l}\text { Very } \\
\text { Imp. }\end{array}$ & $69.6 \%$ & 80 & $67.4 \%$ & 29 & $69.0 \%$ & 109 \\
\hline & Imp. & $21.7 \%$ & 25 & $20.9 \%$ & 9 & $21.5 \%$ & 34 \\
\hline \multirow{2}{*}{$\begin{array}{l}\text { Gain More Knowledge of God's } \\
\text { Creation (including the Natural World) } \\
\text { and Christian Responsibility toward } \\
\text { God's Creation }\end{array}$} & $\begin{array}{l}\text { Very } \\
\text { Imp. }\end{array}$ & $49.1 \%$ & 56 & $50.0 \%$ & 22 & $49.4 \%$ & 78 \\
\hline & Imp. & $36.8 \%$ & 42 & $29.5 \%$ & 13 & $34.8 \%$ & 55 \\
\hline \multirow{2}{*}{$\begin{array}{l}\text { Develop Positive Inter-Personal } \\
\text { Relationships, Build Self-Esteem, and } \\
\text { Grow Physically, Emotionally and } \\
\text { Spiritually }\end{array}$} & $\begin{array}{l}\text { Very } \\
\text { Imp. }\end{array}$ & $73.9 \%$ & 85 & $75.6 \%$ & 34 & $74.4 \%$ & 119 \\
\hline & Imp. & $20.9 \%$ & 24 & $20.0 \%$ & 9 & $20.6 \%$ & 33 \\
\hline \multirow[t]{2}{*}{$\begin{array}{l}\text { Other Philosophical/Theological } \\
\text { Purposes }\end{array}$} & $\begin{array}{l}\text { Very } \\
\text { Imp. }\end{array}$ & $75.0 \%$ & 6 & $100.0 \%$ & 8 & $87.5 \%$ & 14 \\
\hline & Imp. & $25.0 \%$ & 2 & $0.0 \%$ & 0 & $12.5 \%$ & 2 \\
\hline
\end{tabular}


denominational affiliation of a camp increased the likelihood of predicting its position as to this purpose by just under $5 \%$.

\section{1(d). Three Most Important Philosophical/Theological Purposes}

Finally, in terms of prioritizing the three most important philosophical/theological purposes served in camp programs, those purposes that tended to emphasize relationships seemed to predominate in selection among PCUSA and UCC camps:

(1) "Providing opportunities for campers to grow in their understanding of and relationship to God" was indicated as the most important purpose among PCUSA camps (18.9\%) and the second most important purpose among PCUSA camps $(28.3 \%)^{16}$ and UCC camps $(25.0 \%)$;

(2) "Providing opportunities for campers to help build, participate in, and experience a temporary faith community that is distinctively Christian" was indicated as the most important purpose among UCC camps (25.0\%);

(3) "Providing opportunities for campers to develop positive inter-personal relationships, to build their self-esteem, and to grow physically, emotionally and spiritually" was indicated as the third most important purpose among PCUSA camps (25.0\%); and

(4) "Providing opportunities for wholesome, faith-building and spiritually-enriching relationships with other campers and camp leaders in a Christian community" was indicated as the third most important purpose among UCC camps (23.1\%).

\section{Environmental Values}

Three questions in the survey instrument examined camp programs in terms of environmental values: (1) The level of importance of environmental/ecological activities; (2) The

\footnotetext{
${ }^{16}$ Respondents could indicate three of the items on each form of this question in the questionnaire in level or priority of importance. In summarizing the results, an item on this form of question could thus be reported as comprising one or more levels of importance for either PCUSA or UCC camps.
} 
level of importance of seven environmental/ecological indicators (developed by Negra and Manning); and (3) The three most important environmental/ecological indicators (in terms of priority) in camp programs.

\section{2(a). Level of Importance of Environmental/Ecological Activities}

The level of importance of environmental/ecological activities in PCUSA and UCC camp programs was examined using a Likert-type scale $[1.000=$ very important to $5.000=$ not important]. The median for both PCUSA and UCC camps, as well as for all camps, was 2.00, indicating that the level of importance of environmental/ecological activities in camp programs was important, but not very important. ${ }^{17}$ The level of importance of environmental/ecological activities in camp programs by reference to denominational affiliation was also examined by cross-tabulation and the results are summarized in Table 9.

A chi-square test for independence (alpha $=0.05)$ was performed as to the level of importance of environmental/ecological activities in camp programs by reference to denominational affiliation. The results showed a statistically significant difference between PCUSA and UCC camps (chi-square $=17.860 ; p=.001)$. This indicates that there was a significant difference in the level of importance of environmental/ecological activities in camp programs between PCUSA camps and UCC camps.

The strength of association between the level of importance of environmental/ecological activities and denominational affiliation was also examined. Lambda $=.091$, indicating that knowledge of a camp's denominational affiliation increased the likelihood of predicting the level of importance of environmental/ ecological activities in its camp programs by just over $9 \%$.

\footnotetext{
${ }^{17}$ As noted earlier, the median was used throughout this study rather than the mean because it is less sensitive to extreme scores and is a more conservative measure of central tendency. It was thus a more reliable measure for purposes of this study given the relatively small total population of camps surveyed and the disparity in population between PCUSA camps and UCC camps.
} 
Table 9

Level of Importance of Environmental/Ecological Activities in Camp Programs (Cross-tabulation)

\begin{tabular}{lcccccc} 
Level of Importance & \multicolumn{2}{c}{ PCUSA } & \multicolumn{2}{c}{ UCC } & \multicolumn{2}{c}{ Total } \\
\hline & $\%$ & Freq. & $\%$ & Freq. & $\%$ & Freq. \\
\cline { 2 - 8 } Very Important & $12.6 \%$ & 14 & $18.2 \%$ & 8 & $14.2 \%$ & 22 \\
\hline Important & $39.6 \%$ & 44 & $38.6 \%$ & 17 & $39.4 \%$ & 61 \\
\hline $\begin{array}{l}\text { More Important } \\
\text { than Unimportant }\end{array}$ & $40.5 \%$ & 45 & $18.2 \%$ & 8 & $34.2 \%$ & 53 \\
\hline $\begin{array}{l}\text { More Unimportant than } \\
\text { Important }\end{array}$ & $7.2 \%$ & 8 & $15.9 \%$ & 7 & $9.7 \%$ & 15 \\
\hline Unimportant & $0.0 \%$ & 0 & $9.1 \%$ & 4 & $2.6 \%$ & 4 \\
\hline Total & $100 \%$ & 111 & $100 \%$ & 44 & $100 \%$ & 155 \\
\hline Scale & & & & & & \\
\hline
\end{tabular}

Scale: $1.00=$ Very Important to $5.00=$ Unimportant

\section{2(b). Level of Importance of Seven Environmental/Ecological Indicators}

The level of importance of seven environmental/ecological indicators in PCUSA and

UCC camp programs, using the model developed by Negra and Manning (1997), was examined using a Likert-type scale $[1.000=$ very important to $5.000=$ not important $]$. The medians for the seven indicators are summarized in Table $10 .^{18}$

The level of importance of these seven indicators was also examined by cross-tabulation by reference to denominational affiliation and the results reported as "important" or "very important" ${ }^{\prime 19}$ are summarized in Table 11. A chi-square test for independence (alpha $\left.=.05\right)$ as to the level of importance of the seven indicators by reference to denomination yielded statistically significant differences between PCUSA and UCC camps as to three indicators:

\footnotetext{
${ }^{18}$ As noted earlier, the median was used throughout this study rather than the mean because it is less sensitive to extreme scores and is a more conservative measure of central tendency. It was thus a more reliable measure for purposes of this study given the relatively small total population of camps surveyed and the disparity in population between PCUSA camps and UCC camps.

${ }^{19}$ The total percentages in Table 11 for each of the seven environmental/ecological indicators do not equal $100 \%$ because only two levels ("Important" and "Very Important") are included in the summary.
} 
Table 10

Level of Importance of Seven Environmental/

Ecological Indicators in Camp Programs (Median)

\begin{tabular}{|c|c|c|c|}
\hline Environmental/Ecological Indicators & PCUSA & UCC & ALL CAMPS \\
\hline \multirow[b]{2}{*}{$\begin{array}{l}\text { Campers participate in outdoor activities and develop } \\
\text { sensitivity, concern and empathy for the } \\
\text { environment. }\end{array}$} & Median & Median & Median \\
\hline & 2.000 & 2.000 & 2.000 \\
\hline $\begin{array}{l}\text { Campers develop knowledge of environmental issues } \\
\text { and perceive the potential harm to the environment } \\
\text { from various forms of human impact. }{ }^{21}\end{array}$ & 3.000 & 2.000 & 3.000 \\
\hline $\begin{array}{l}\text { Campers develop a sense of personal investment in } \\
\text { environmental issues and perceive the importance of } \\
\text { engaging in environmental protection. }{ }^{22}\end{array}$ & 3.000 & 3.000 & 3.000 \\
\hline $\begin{array}{l}\text { Campers develop knowledge of strategies for } \\
\text { environmental action and familiarity with activities } \\
\text { that promote or preserve environmental quality. }{ }^{23}\end{array}$ & 3.000 & 3.000 & 3.000 \\
\hline $\begin{array}{l}\text { Campers develop skills in using environmental action } \\
\text { strategies and actually engage in activities that } \\
\text { promote or preserve environmental quality. }\end{array}$ & 3.000 & 3.000 & 3.000 \\
\hline $\begin{array}{l}\text { Campers develop and/or change their own } \\
\text { environmental values through increased perception } \\
\text { that their own activities promote or preserve } \\
\text { environmental quality. }\end{array}$ & 3.000 & 3.000 & 3.000 \\
\hline $\begin{array}{l}\text { Campers develop and/or change their own } \\
\text { environmental behavior through actual and expressed } \\
\text { intention to engage in environmentally responsible } \\
\text { actions. }\end{array}$ & 3.000 & 3.000 & 3.000 \\
\hline
\end{tabular}

Scale: $1.000=$ Very Important to $5.000=$ Not Important

(1) "Campers develop knowledge of environmental issues and perceive the potential harm to the environment from various forms of human impact" ${ }^{27}$ (chi-square $=30.392 ; \mathrm{p}=.000$ ).

\footnotetext{
${ }^{20}$ This is defined as an "Entry Level" environmental indicator in the Negra and Manning (1997) model (pp. 12, 14).

${ }^{21}$ This is defined as an "Ownership" environmental indicator in the Negra and Manning (1997) model (pp. 12, 14).

${ }^{22}$ This is defined as an "Ownership" environmental indicator in the Negra and Manning (1997) model (pp. 12, 14).

${ }^{23}$ This is defined as an "Empowerment" environmental indicator in the Negra and Manning (1997) model (pp. 12, 14).

${ }^{24}$ This is defined as an "Empowerment" environmental indicator in the Negra and Manning (1997) model (pp. 12, 14).

${ }^{25}$ This is defined as an "Empowerment" environmental indicator in the Negra and Manning (1997) model (pp. 12, 14).

${ }^{26}$ This is defined as an "Empowerment" environmental indicator in the Negra and Manning (1997) model (pp. 12, 14).
} 
This indicates that there was a significant difference in the level of importance of this indicator between PCUSA and UCC camps;

(2) "Campers develop a sense of personal investment in environmental issues and perceive the importance of engaging in environmental protection" ${ }^{, 28}$ (chi-square $=16.638 ; \underline{p}=$ .002). This indicates that there was a significant difference in the level of importance of this indicator between PCUSA and UCC camps; and

(3) "Campers develop knowledge of strategies for environmental action and familiarity with activities that promote or preserve environmental quality" ${ }^{, 29}$ (chi-square $=21.121 ; \mathrm{p}=$ .000). This indicates that there was a significant difference in the level of importance of this indicator between PCUSA and UCC camps.

The strength of association between denominational affiliation and the level of importance of these seven environmental/ecological indicators was also examined. The results indicated that knowledge of the denominational affiliation of a camp increased the likelihood of predicting its position by more than $3 \%$ only as to three indicators:

(1) "Campers develop knowledge of environmental issues and perceive the potential harm to the environment from various forms of human impact."30 Lambda $=.205$, indicating that knowledge of the denominational affiliation of a camp increased the likelihood of predicting its position as to this purpose by just over $20 \%$;

\footnotetext{
27 This is defined as an "Ownership" environmental indicator in the Negra and Manning (1997) model (pp. 12, 14).

28 This is defined as an "Ownership" environmental indicator in the Negra and Manning (1997) model (pp. 12, 14).

${ }^{29}$ This is defined as an "Empowerment" environmental indicator in the Negra and Manning (1997) model (pp. 12, 14).

${ }^{30}$ This is defined as an "Ownership" environmental indicator in the Negra and Manning (1997) model (pp. 12, 14).
} 
Table 11

Seven Environmental/Ecological Indicators in Camp Programs Reported as Very Important or Important (Cross-tabulation; Bold = statistically significant difference between denominatio

\begin{tabular}{|c|c|c|c|c|c|c|c|}
\hline \multicolumn{2}{|l|}{ Environmental/Ecological Indicator } & \multicolumn{2}{|c|}{ PCUSA } & \multicolumn{2}{|c|}{ UCC } & \multicolumn{2}{|c|}{ ALL CAMPS } \\
\hline \multirow{3}{*}{$\begin{array}{l}\text { Campers participate in outdoor } \\
\text { activities and develop sensitivity, } \\
\text { concern and empathy for the } \\
\text { environment. }\end{array}$} & & $\%$ & Freq. & $\%$ & Freq. & $\%$ & Freq. \\
\hline & $\begin{array}{l}\text { Very } \\
\text { Imp. }\end{array}$ & $35.4 \%$ & 40 & $43.2 \%$ & 19 & $37.6 \%$ & 59 \\
\hline & Imp. & $43.4 \%$ & 49 & $27.3 \%$ & 12 & $38.9 \%$ & 61 \\
\hline \multirow{2}{*}{$\begin{array}{l}\text { Campers develop knowledge of } \\
\text { environmental issues and perceive } \\
\text { the potential harm to the } \\
\text { environment from various forms of } \\
\text { human impact. } \\
\text { Chi-square }=30.392 ; p=.000\end{array}$} & $\begin{array}{l}\text { Very } \\
\text { Imp. }\end{array}$ & $10.7 \%$ & 12 & $34.1 \%$ & 15 & $17.3 \%$ & 27 \\
\hline & Imp. & $32.1 \%$ & 36 & $20.5 \%$ & 9 & $28.8 \%$ & 45 \\
\hline \multirow{2}{*}{$\begin{array}{l}\text { Campers develop a sense of } \\
\text { personal investment in } \\
\text { environmental issues and perceive } \\
\text { the importance of engaging in } \\
\text { environmental protection. } \\
\text { Chi-square }=16.638 ; p=.002\end{array}$} & $\begin{array}{l}\text { Very } \\
\text { Imp. }\end{array}$ & $10.0 \%$ & 11 & $22.7 \%$ & 10 & $13.6 \%$ & 21 \\
\hline & Imp. & $28.2 \%$ & 31 & $25.0 \%$ & 11 & $27.3 \%$ & 42 \\
\hline \multirow{2}{*}{$\begin{array}{l}\text { Campers develop knowledge of } \\
\text { strategies for environmental action } \\
\text { and familiarity with activities that } \\
\text { promote or preserve } \\
\text { environmental quality. } \\
\text { Chi-square }=21.121 \text {; }=.000\end{array}$} & $\begin{array}{l}\text { Very } \\
\text { Imp. }\end{array}$ & $6.4 \%$ & 7 & $20.9 \%$ & 9 & $10.5 \%$ & 16 \\
\hline & Imp. & $24.5 \%$ & 27 & $18.6 \%$ & 8 & $22.9 \%$ & 35 \\
\hline \multirow{2}{*}{$\begin{array}{l}\text { Campers develop skills in using } \\
\text { environmental action strategies and } \\
\text { actually engage in activities that } \\
\text { promote or preserve environmental } \\
\text { quality. }\end{array}$} & $\begin{array}{l}\text { Very } \\
\text { Imp. }\end{array}$ & $6.4 \%$ & 7 & $18.6 \%$ & 8 & $9.8 \%$ & 15 \\
\hline & Imp. & $22.7 \%$ & 25 & $20.9 \%$ & 9 & $22.2 \%$ & 34 \\
\hline \multirow{2}{*}{$\begin{array}{l}\text { Campers develop and/or change their } \\
\text { own environmental values through } \\
\text { increased perception that their own } \\
\text { activities promote or preserve } \\
\text { environmental quality. }\end{array}$} & $\begin{array}{l}\text { Very } \\
\text { Imp. }\end{array}$ & $8.4 \%$ & 9 & $14.3 \%$ & 5 & $9.9 \%$ & 14 \\
\hline & Imp. & $27.1 \%$ & 29 & $28.6 \%$ & 10 & $27.5 \%$ & 39 \\
\hline \multirow{2}{*}{$\begin{array}{l}\text { Campers develop and/or change their } \\
\text { own environmental behavior through } \\
\text { actual and expressed intention to } \\
\text { engage in environmentally } \\
\text { responsible actions. }\end{array}$} & $\begin{array}{l}\text { Very } \\
\text { Imp. }\end{array}$ & $5.6 \%$ & 6 & $16.2 \%$ & 6 & $8.3 \%$ & 12 \\
\hline & Imp. & $20.6 \%$ & 22 & $21.6 \%$ & 8 & $20.8 \%$ & 30 \\
\hline
\end{tabular}


(2) "Campers develop a sense of personal investment in environmental issues and perceive the importance of engaging in environmental protection., ${ }^{31}$ Lambda $=.091$, indicating that knowledge of the denominational affiliation of a camp increased the likelihood of predicting its position as to this purpose by just over $9 \%$; and

(3) "Campers develop knowledge of strategies for environmental action and familiarity with activities that promote or preserve environmental quality. ${ }^{, 32}$ Lambda $=.116$, indicating that knowledge of the denominational affiliation of a camp increased the likelihood of predicting its position as to this purpose by just under $12 \%$.

\section{2(c). Three Most Important Environmental/Ecological Indicators}

Similar uniformity appears in prioritizing the three most important environmental/ ecological indicators in PCUSA and UCC camp programs:

(1) "Campers participate in outdoor activities and develop sensitivity, concern and empathy for the environment, ${ }^{, 33}$ was indicated as the most important environmental indicator by both PCUSA camps (80.7\%) and UCC camps (80.6\%);

(2) "Campers develop knowledge of environmental issues and perceive the potential harm to the environment from human impact, ${ }^{34}$ was indicated as the second most important environmental indicator by both PCUSA camps (48.1\%) and UCC camps $(51.4 \%) ;$ and

\footnotetext{
${ }^{31}$ This is defined as an "Ownership" environmental indicator in the Negra and Manning (1997) model (pp. 12, 14).

${ }^{32}$ This is defined as an "Empowerment" environmental indicator in the Negra and Manning (1997) model (pp. 12, 14).

${ }^{33}$ This is defined as an "Entry Level" environmental indicator in the Negra and Manning (1997) model (pp. 12, 14).

${ }^{34}$ This is defined as an "Ownership" environmental indicator in the Negra and Manning (1997) model (pp. 12, 14).
} 
(3) "Campers develop a sense of personal investment in environmental issues and perceive the importance of engaging in environmental protection," 35 was indicated as the third most important environmental indicator by both PCUSA camps $(38.0 \%)$ and UCC camps (30.3\%).

\section{Integration of Religious and Environmental Values}

Three questions in the survey instrument examined camp programs in terms of the integration of religious and environmental values: (1) The strength of the relationship between environmental/ecological activities and philosophical/theological purposes in camp programs; (2) The relationship between environmental/ecological aspects and philosophical/theological aspects of camp programs in terms of the likelihood of 16 environmental ethics statements, representing a typology developed by Negra and Manning (1997), being taught in camp programs; and (3) The three statements most likely to be taught in camp programs (in terms of priority) among these 16 environmental ethics statements.

\section{3(a). Relating Environmental/Ecological Activities and Philosophical/Theological Purposes}

The strength of the relationship between environmental/ecological activities and philosophical/theological purposes in PCUSA and UCC camp programs was examined using a Likert-type scale $[1.000=$ very strong relationship to $5.000=$ very weak relationship $]$. The median for PCUSA camps and for all camps was 2.000, indicating a "strong," but not "very strong," relationship, while the median for UCC camps was 3.000, indicating a relationship that is "neither strong nor weak.",36 The strength of this relationship by reference to denominational

\footnotetext{
35 This is defined as an "Ownership" environmental indicator in the Negra and Manning (1997) model (pp. 12, 14).

${ }^{36}$ As noted earlier, the median was used throughout this study rather than the mean because it is less sensitive to extreme scores and is a more conservative measure of central tendency. It was thus a more reliable measure for purposes of this study given the relatively small total population of camps surveyed and the disparity in population between PCUSA camps and UCC camps.
} 
affiliation was also examined by cross-tabulation. The results, summarized in Table 12, indicate a significant difference between PCUSA and UCC camp programs at several levels of strength in this relationship.

Table 12

Strength of the Relationship between Environmental/Ecological Activities and Philosophical/Theological Purposes (Cross-tabulation)

\begin{tabular}{lcccccc} 
Level of Strength & \multicolumn{2}{c}{ PCUSA } & \multicolumn{2}{c}{ UCC } & \multicolumn{2}{c}{ Total } \\
\hline \multirow{2}{*}{ Very Strong } & $\%$ & Freq. & $\%$ & Freq. & $\%$ & Freq. \\
\cline { 2 - 7 } Strong & $13.4 \%$ & 15 & $25.6 \%$ & 11 & $16.8 \%$ & 26 \\
\hline Neither Strong nor Weak & $42.9 \%$ & 48 & $23.3 \%$ & 10 & $37.4 \%$ & 58 \\
\hline Weak & $36.6 \%$ & 41 & $25.6 \%$ & 11 & $33.5 \%$ & 52 \\
\hline Very Weak & $6.3 \%$ & 7 & $9.3 \%$ & 4 & $7.1 \%$ & 11 \\
\hline Total & $0.9 \%$ & 1 & $16.3 \%$ & 7 & $5.2 \%$ & 8 \\
\hline Scalyyyyyy
\end{tabular}

Scale: $1.00=$ Very Strong to $5.00=$ Very Weak

A chi-square test for independence $($ alpha $=.05)$ as to the strength of this relationship by reference to denominational affiliation was also performed and yielded results that showed a statistically significant difference between PCUSA and UCC camps [chi-square $=21.727 ; \mathrm{p}=$ .000]. This indicates that there was a significant difference in the strength of this relationship between PCUSA and UCC camps.

The strength of association between denominational affiliation and the strength of this relationship was also examined. Lambda $=.140$, indicating that knowledge of a camp's denominational affiliation increased the likelihood of predicting the strength of this relationship by $14 \%$.

\section{3(b). Likelihood of 16 Environmental Ethics Statements Being Taught in Camp Programs}

The relationship between environmental/ecological aspects and philosophical/ theological aspects of PCUSA and UCC camp programs in terms of the likelihood of 16 environmental 
ethics statements (developed as a typology by Negra and Manning) being taught in camp programs was examined using a Likert-type scale $(1.000=$ more likely to be taught to $5.000=$ less likely to be taught). The medians as to the likelihood of the 16 environmental ethics statements being taught in camp programs are summarized in Table $13 .{ }^{37}$ The likelihood, by reference to denominational affiliation, of these 16 environmental ethics statements being "likely" or "more likely" 38 to be taught in camp programs was also examined by cross-tabulation and the results are summarized in Table 14. The chi-square test for independence (alpha $=.05)$ was also performed as to the likelihood of the 16 environmental ethics statements being taught in camp programs by reference to denominational affiliation. The results indicated statistically significant differences as to three of the 16 statements:

(1) "Humans were created as fundamentally different from other living things" ${ }^{39}$ [chi-square $=9.775 ; \mathrm{p}=.044]$. This indicates that there was a significant difference in the likelihood of this statement being taught in camp programs between PCUSA and UCC camps;

(2) "Nature is God's creation" ${ }^{40}[$ chi-square $=9.568 ; \mathrm{p}=.023]$. This indicates that there was a significant difference in the likelihood of this statement being taught in camp programs between PCUSA and UCC camps; and

(3) "All living things are sacred" ${ }^{\prime 1}$ [chi-square $\left.=9.993 ; \mathrm{p}=.041\right]$. This indicates that there was a significant difference in the likelihood of this statement being taught in camp programs between PCUSA and UCC camps.

\footnotetext{
${ }^{37}$ As noted earlier, the median was used throughout this study rather than the mean because it is less sensitive to extreme scores and is a more conservative measure of central tendency. It was thus a more reliable measure for purposes of this study given the relatively small total population of camps surveyed and the disparity in population between PCUSA camps and UCC camps.

${ }^{38}$ The total percentages in Table 14 for each of the 16 environmental ethics statements do not equal $100 \%$ because only two levels ("Likely" and "Very Likely") are included in the summary.

${ }^{39}$ This is defined as "Benign Indifference" in the Negra and Manning (1997) typology (pp. 13, 15-16).

${ }^{40}$ This is defined as "Stewardship" in the Negra and Manning (1997) typology (pp. 13, 15-16).

${ }^{41}$ This is defined as "Stewardship" in the Negra and Manning (1997) typology (pp. 13, 15-16).
} 
Table 13

Relationship between the Environmental/Ecological Aspects and the Philosophical/Theological Aspects of Camp Programs in terms of the Likelihood of 16 Environmental Ethics Statements Being Taught in Camp Programs

\begin{tabular}{|c|c|c|c|}
\hline Environmental Ethics Statement & PCUSA & $\mathrm{UCC}$ & ALL CAMPS \\
\hline & Median & Median & Median \\
\hline Nature can be dangerous to human survival. ${ }^{42}$ & 5.000 & 5.000 & 5.000 \\
\hline Nature is sometimes evil. ${ }^{43}$ & 5.000 & 5.000 & 5.000 \\
\hline Nature is a valuable storehouse of raw materials. ${ }^{44}$ & 3.000 & 3.000 & 3.000 \\
\hline $\begin{array}{l}\text { Humans were created as fundamentally different from other } \\
\text { living things. } 45\end{array}$ & 3.000 & 4.000 & 3.000 \\
\hline $\begin{array}{l}\text { The ability to think makes humans fundamentally different } \\
\text { from other living things. }{ }^{46}\end{array}$ & 3.000 & 3.000 & 3.000 \\
\hline Cruelty toward animals makes people less human. ${ }^{47}$ & 2.000 & 2.000 & 2.000 \\
\hline $\begin{array}{l}\text { The supply of goods and services provided by nature is } \\
\text { limited. }\end{array}$ & 2.000 & 2.000 & 2.000 \\
\hline Nature adds to the quality of our lives. ${ }^{49}$ & 1.000 & 1.000 & 1.000 \\
\hline Human survival depends on nature and natural processes. ${ }^{50}$ & 2.000 & 1.000 & 2.000 \\
\hline It is our religious/spiritual duty to take care of nature. ${ }^{51}$ & 1.000 & 1.000 & 1.000 \\
\hline Nature will be important to future generations. ${ }^{52}$ & 1.000 & 1.000 & 1.000 \\
\hline Nature is God's creation. ${ }^{53}$ & 1.000 & 1.000 & 1.000 \\
\hline All living things have a spirit. ${ }^{54}$ & 3.000 & 3.000 & 3.000 \\
\hline Animals should be free from needless pain and suffering. ${ }^{55}$ & 2.000 & 2.000 & 2.000 \\
\hline All living things are sacred. ${ }^{56}$ & 2.000 & 1.000 & 2.000 \\
\hline $\begin{array}{l}\text { Humans are related to other living things through } \\
\text { evolution. }{ }^{57}\end{array}$ & 4.000 & 3.000 & 4.000 \\
\hline
\end{tabular}

Scale: 1.000 = Very Likely to Be Taught to $5.000=$ More Unlikely to Be Taught

\footnotetext{
${ }^{42}$ This is defined as "Anti-Environment" in the Negra and Manning (1997) typology (pp. 13, 15-16).

${ }^{43}$ This is defined as "Anti-Environment" in the Negra and Manning (1997) typology (pp. 13, 15-16).

${ }^{44}$ This is defined as "Benign Indifference" in the Negra and Manning (1997) typology (pp. 13, 15-16).

45 This is defined as "Benign Indifference" in the Negra and Manning (1997) typology (pp. 13, 15-16).

46 This is defined as "Benign Indifference" in the Negra and Manning (1997) typology (pp. 13, 15-16).

47 This is defined as "Utilitarian Conservation" in the Negra and Manning (1997) typology (pp. 13, 15-16).

48 This is defined as "Utilitarian Conservation" in the Negra and Manning (1997) typology (pp. 13, 15-16).

49 This is defined as "Utilitarian Conservation" in the Negra and Manning (1997) typology (pp. 13, 15-16).

${ }^{50}$ This is defined as "Utilitarian Conservation" in the Negra and Manning (1997) typology (pp. 13, 15-16).

51 This is defined as "Stewardship" in the Negra and Manning (1997) typology (pp. 13, 15-16).

52 This is defined as "Stewardship" in the Negra and Manning (1997) typology (pp. 13, 15-16).

${ }^{53}$ This is defined as "Stewardship" in the Negra and Manning (1997) typology (pp. 13, 15-16).

54 This is defined as "Stewarship" in the Negra and Manning (1997) typology (pp. 13, 15-16).

55 This is defined as "Radical Environmentalism" in the Negra and Manning (1997) typology (pp. 13, 15-16).

56 This is defined as "Radical Environmentalism" in the Negra and Manning (1997) typology (pp. 13, 15-16).

57 This is defined as "Radical Environmentalism" in the Negra and Manning (1997) typology (pp. 13, 15-16).
} 
Table 14

Relationship between the Environmental/Ecological Aspects and the Philosophical/Theological Aspects of Camp Programs in terms of the Likelihood of 16 Environmental Ethics Statements Being Taught in Camp Programs (Cross-tabulation; Bold = statistically significant difference between denominations)

\begin{tabular}{|c|c|c|c|c|c|c|c|}
\hline \multicolumn{2}{|l|}{ Environmental Ethics Statement } & \multicolumn{2}{|c|}{ PCUSA } & \multicolumn{2}{|c|}{ UCC } & \multicolumn{2}{|c|}{ ALL CAMPS } \\
\hline \multirow{3}{*}{$\begin{array}{l}\text { Nature can be dangerous to human } \\
\text { survival. }\end{array}$} & & $\%$ & Freq. & $\%$ & Freq. & $\%$ & Freq. \\
\hline & $\begin{array}{l}\text { More } \\
\text { Likely }\end{array}$ & $4.1 \%$ & 4 & $5.6 \%$ & 2 & $4.5 \%$ & 6 \\
\hline & Likely & $6.1 \%$ & 6 & $2.8 \%$ & 1 & $5.2 \%$ & 7 \\
\hline \multirow[t]{2}{*}{ Nature is sometimes evil. } & $\begin{array}{l}\text { More } \\
\text { Likely }\end{array}$ & $0.0 \%$ & 0 & $0.0 \%$ & 0 & $0.0 \%$ & 0 \\
\hline & Likely & $0.0 \%$ & 0 & $0.0 \%$ & 0 & $0.0 \%$ & 0 \\
\hline \multirow[t]{2}{*}{$\begin{array}{l}\text { Nature is a valuable storehouse of } \\
\text { raw materials. }\end{array}$} & $\begin{array}{l}\text { More } \\
\text { Likely }\end{array}$ & $19.8 \%$ & 21 & $21.6 \%$ & 8 & $20.3 \%$ & 29 \\
\hline & Likely & $23.6 \%$ & 25 & $24.3 \%$ & 9 & $23.8 \%$ & 34 \\
\hline \multirow{2}{*}{$\begin{array}{l}\text { Humans were created } \\
\text { fundamentally different from } \\
\text { other living things. } \\
\text { Chi-square = } 9.775 ; p=.044\end{array}$} & $\begin{array}{c}\text { More } \\
\text { Likely }\end{array}$ & $22.7 \%$ & 22 & $5.6 \%$ & 2 & $18.0 \%$ & 24 \\
\hline & Likely & $21.6 \%$ & 21 & $13.9 \%$ & 5 & $19.5 \%$ & 26 \\
\hline \multirow{2}{*}{$\begin{array}{l}\text { The ability to think makes humans } \\
\text { fundamentally different from other } \\
\text { living things. }\end{array}$} & $\begin{array}{c}\text { More } \\
\text { Likely }\end{array}$ & $18.6 \%$ & 18 & $12.5 \%$ & 5 & $16.8 \%$ & 23 \\
\hline & Likely & $25.8 \%$ & 25 & $15.0 \%$ & 6 & $22.6 \%$ & 31 \\
\hline \multirow[t]{2}{*}{$\begin{array}{l}\text { Cruelty toward animals makes } \\
\text { people less human. }\end{array}$} & $\begin{array}{l}\text { More } \\
\text { Likely }\end{array}$ & $27.4 \%$ & 26 & $27.0 \%$ & 10 & $27.3 \%$ & 36 \\
\hline & Likely & $23.2 \%$ & 22 & $24.3 \%$ & 9 & $23.5 \%$ & 31 \\
\hline \multirow[t]{2}{*}{$\begin{array}{l}\text { The supply of goods and services } \\
\text { provided by nature is limited. }\end{array}$} & $\begin{array}{l}\text { More } \\
\text { Likely }\end{array}$ & $37.1 \%$ & 39 & $39.0 \%$ & 16 & $37.7 \%$ & 55 \\
\hline & Likely & $34.3 \%$ & 36 & $31.7 \%$ & 13 & $33.6 \%$ & 49 \\
\hline \multirow[t]{2}{*}{$\begin{array}{l}\text { Nature adds to the quality of our } \\
\text { lives. }\end{array}$} & $\begin{array}{c}\text { More } \\
\text { Likely }\end{array}$ & $71.8 \%$ & 79 & $76.7 \%$ & 33 & $73.2 \%$ & 112 \\
\hline & Likely & $19.1 \%$ & 21 & $14.0 \%$ & 6 & $17.6 \%$ & 27 \\
\hline \multirow[t]{2}{*}{$\begin{array}{l}\text { Human survival depends on nature } \\
\text { and natural processes. }\end{array}$} & $\begin{array}{c}\text { More } \\
\text { Likely }\end{array}$ & $39.3 \%$ & 42 & $61.9 \%$ & 26 & $45.6 \%$ & 68 \\
\hline & Likely & $25.2 \%$ & 27 & $11.9 \%$ & 5 & $21.5 \%$ & 32 \\
\hline \multirow[t]{2}{*}{$\begin{array}{l}\text { It is our religious/spiritual duty to } \\
\text { take care of nature. }\end{array}$} & $\begin{array}{c}\text { More } \\
\text { Likely }\end{array}$ & $67.9 \%$ & 76 & $79.1 \%$ & 34 & $71.0 \%$ & 110 \\
\hline & Likely & $24.1 \%$ & 27 & $9.3 \%$ & 4 & $20.0 \%$ & 31 \\
\hline \multirow[t]{2}{*}{$\begin{array}{l}\text { Nature will be important to future } \\
\text { generations. }\end{array}$} & $\begin{array}{c}\text { More } \\
\text { Likely }\end{array}$ & $67.3 \%$ & 74 & $76.7 \%$ & 33 & $69.9 \%$ & 107 \\
\hline & Likely & $22.7 \%$ & 25 & $14.0 \%$ & 6 & $20.3 \%$ & 31 \\
\hline
\end{tabular}


Table 14 continued

Relationship between the Environmental/Ecological Aspects and the Philosophical/Theological Aspects of Camp Programs in terms of the Likelihood of 16 Environmental Ethics Statements Being Taught in Camp Programs (Cross-tabulation; Bold = statistically significant difference between denominations)

\begin{tabular}{|c|c|c|c|c|c|c|c|}
\hline \multicolumn{2}{|l|}{ Environmental Ethics Statement } & \multicolumn{2}{|c|}{ PCUSA } & \multicolumn{2}{|c|}{ UCC } & \multicolumn{2}{|c|}{ ALL CAMPS } \\
\hline \multirow{3}{*}{$\begin{array}{l}\text { Nature is God's creation. } \\
\text { Chi-square }=9.568 ; p=.023\end{array}$} & & $\%$ & Freq. & $\%$ & Freq. & $\%$ & Freq. \\
\hline & $\begin{array}{l}\text { More } \\
\text { Likely }\end{array}$ & $94.7 \%$ & 107 & $83.7 \%$ & 36 & $91.7 \%$ & 143 \\
\hline & Likely & $2.7 \%$ & 3 & $7.0 \%$ & 3 & $3.8 \%$ & 6 \\
\hline \multirow[t]{2}{*}{ All living things have a spirit. } & $\begin{array}{l}\text { More } \\
\text { Likely }\end{array}$ & $15.4 \%$ & 14 & $25.7 \%$ & 9 & $18.3 \%$ & 23 \\
\hline & Likely & $11.0 \%$ & 10 & $14.3 \%$ & 5 & $11.9 \%$ & 15 \\
\hline \multirow[t]{2}{*}{$\begin{array}{l}\text { Animals should be free from } \\
\text { needless pain and suffering. }\end{array}$} & $\begin{array}{l}\text { More } \\
\text { Likely }\end{array}$ & $32.0 \%$ & 32 & $24.3 \%$ & 9 & $29.9 \%$ & 41 \\
\hline & Likely & $26.0 \%$ & 26 & $27.0 \%$ & 10 & $26.3 \%$ & 36 \\
\hline \multirow[t]{2}{*}{$\begin{array}{l}\text { All living things are sacred. } \\
\text { Chi-square }=9.993 ; p=.041\end{array}$} & $\begin{array}{l}\text { More } \\
\text { Likely }\end{array}$ & $38.8 \%$ & 40 & $52.5 \%$ & 21 & $42.7 \%$ & 61 \\
\hline & Likely & $16.5 \%$ & 17 & $27.5 \%$ & 11 & $19.6 \%$ & 28 \\
\hline \multirow[t]{2}{*}{$\begin{array}{l}\text { Humans are related to other } \\
\text { living things through evolution. }\end{array}$} & $\begin{array}{l}\text { More } \\
\text { Likely }\end{array}$ & $9.1 \%$ & 8 & $18.2 \%$ & 6 & $11.6 \%$ & 14 \\
\hline & Likely & $9.1 \%$ & 8 & $21.2 \%$ & 7 & $12.4 \%$ & 15 \\
\hline
\end{tabular}

The strength of association between denominational affiliation and the likelihood of these 16 environmental ethics statements being taught in camp programs was also examined. The results indicated that knowledge of the denominational affiliation of a camp increased the likelihood of predicting the likelihood of two statements being taught:

(1) "Nature adds to the quality of our lives." ${ }^{, 58}$ Lambda $=.023$, indicating that knowledge of the denominational affiliation of a camp increased the likelihood of predicting the likelihood of this statement being taught by just over $2 \%$; and

\footnotetext{
${ }^{58}$ This is defined as "Utilitarian Conservation" in the Negra and Manning (1997) typology (pp. 13, 15-16).
} 
(2) "Nature is God's creation." ${ }^{59}$ Lambda $=.070$, indicating that knowledge of the denominational affiliation of a camp increased the likelihood of predicting the likelihood of this statement being taught by just $7 \%$.

\section{3(c). Three Most Likely Environmental Ethics to be Taught in Camp Programs}

There was also uniformity between PCUSA and UCC camps as to selection, but not as to frequency, in terms of prioritizing the three environmental ethics statements most likely to be taught in camp programs:

(1) "Nature is God's creation," ${ }^{, 60}$ was indicated as the most likely statement to be taught in PCUSA camps (57.1\%) and UCC camps (37.8\%);

(2) "It is our religious/spiritual duty to take care of nature," ${ }^{\prime 61}$ was indicated as the second most likely statement to be taught in PCUSA camps (40.7\%) and UCC camps (32.4\%). This statement was also indicated as the third most likely statement to be taught in UCC camps $(22.2 \%) ;^{62}$ and

(3) "Nature adds to the quality of our lives," ${ }^{63}$ was indicated as the third most likely statement to be taught in PCUSA camps (25.0\%).

\footnotetext{
${ }^{59}$ This is defined as "Stewardship" in the Negra and Manning (1997) typology (pp. 13, 15-16).

${ }^{60}$ This is defined as "Stewardship" in the Negra and Manning (1997) typology (pp. 13, 15-16).

${ }^{61}$ This is defined as "Stewardship" in the Negra and Manning (1997) typology (pp. 13, 15-16).

${ }^{62}{ }^{62}$ Respondents could indicate three of the items on each form of this question in the questionnaire in level or priority of importance. In summarizing the results, an item on this form of question could thus be reported as comprising one or more levels of importance for either PCUSA or UCC camps.

${ }^{63}$ This is defined as "Utilitarian Conservation" in the Negra and Manning (1997) typology (pp. 13, 15-16).
} 


\section{Chapter 5 - Interpretation and Conclusions}

\section{Descriptive Profiles of PCUSA and UCC Camps}

Three general observations germane to the focus of this study can be made initially from the results as to outdoor settings of PCUSA and UCC camps in combination with some of the organizational and descriptive-type results:

(1) Most of the camps in both denominations have physical settings that provide effective opportunities for outdoor programming, including nature study and environmental education. For example:

(a) Over $80 \%$ of PCUSA camps $(82.1 \%)$, including $20.5 \%$ in primitive areas, and UCC camps (80.9\%), including $21.3 \%$ in primitive areas, are located in rural areas;

(b) Over $95 \%$ of PCUSA camps $(96.5 \%)$ are mostly or completely wooded or are mixed woods and fields while just over $50 \%$ of UCC camps (53.2\%) are mixed woods and fields;

(c) Almost $90 \%$ of PCUSA camps $(88.1 \%)$ and of UCC camps $(87.3 \%)$ have lakes or streams;

(d) Over $70 \%$ of PCUSA camps (72.6\%) and over $60 \%$ of UCC camps (61.7\%) are located in rolling hills or mountains; and

(e) Over $60 \%$ of PCUSA camps (65.0\%) and over $45 \%$ of UCC camps $(45.7 \%)$ use public lands in their camp programs;

(2) Almost $70 \%$ of the campers in PCUSA camps (68.4\%) and over $60 \%$ of the campers in UCC camps (63.9\%) come "completely/primarily" or "mostly" from local churches affiliated with their respective denomination This indicates that a strong 
ecclesiastical affinity exists in both denominations between the camps and the local churches affiliated with their respective denomination from which the camps draw their campers; and

(3) The strength of the ecclesiastical relationship between camps and the respective denomination with which they are affiliated was reported as "strong," although not "very strong," for both denominations. The strength of this relationship also showed no statistically significant difference between PCUSA and UCC camps and had only a weak measure of association (lambda $=.024$ ) by reference to denominational affiliation.

For purposes of this study, the significance of these three initial observations is two-fold:

(1) As noted in Chapter 1, church camps represent an important aspect of educational ministry programs in both the PCUSA and the UCC. As also noted in Chapter 1, and as both the policy papers and statements and the denominational surveys in Chapter 2 make clear, the environment and environmental concerns are an important focus in both the PCUSA and the UCC. The strong ecclesiastical relationship noted above that PCUSA and UCC camps have with their respective denominations thus logically suggests that: (1) PCUSA and UCC camps should reflect and be representative of their respective denominational positions in this regard; and (2) Environmental values should be an emphasis in camp programs of each denomination, especially in terms of environmental education.

(2) As also noted in Chapter 1, the physical settings of church camps are usually at a sufficient distance from more developed areas as to be (or seem to be) "set apart" in order to foster a sense of "living in the out-of-doors" or being in the midst of "God's 
creation." As noted above, the physical settings reported by the camps in this study clearly fit this concept. The opportunities thus effectively afforded camps by their physical settings in combination with the strength of their ecclesiastical relationship to the respective denomination with which they are affiliated - to the extent that the camps reflect and represent the important focus of both denominations on the environment and environmental concerns - logically suggests that environmental values should be an emphasis in camp programs of each denomination, especially in terms of environmental education.

\title{
Three Aspects of PCUSA and UCC Camp Programs
}

As noted in Chapters 3 and 4, ten questions form the core focus of the study in relation to PCUSA and UCC camp programs. Four of the questions focus on religious values, three of the questions focus on environmental values, and three of the questions focus on the integration of religious values and environmental values. The three hypotheses for the study thus focus on these three aspects of PCUSA and UCC camp programs - religious values, environmental values, and the integration of religious values and environmental values - and are discussed below in that order.

\section{Religious Values}

The hypothesis under this aspect of the study focused on the association between denominational affiliation and religious values in PCUSA and UCC church camp programs:

\author{
$\mathrm{H}_{1}$ : Religious values in PCUSA and UCC church camp programs are \\ independent of denominational affiliation and the association between them \\ is not statistically significant.
}


In arriving at a conclusion for this hypothesis, the results are discussed and interpreted in the order of the four questions in the questionnaire that focused on this aspect of the study.

\section{1(a). Sources of Program/Curriculum Materials}

The mode for both PCUSA and UCC camps was "ecumenical" program/curriculum materials. This is generally consistent with the nature and content of the program/curriculum material reviewed in Chapter 2 which, given its somewhat generic nature, can be viewed as "ecumenical" in nature. There was also no statistically significant difference between PCUSA and UCC camps as to sources of program/curriculum materials and the measure of association was weak (lambda $=.023$ ). The conclusion therefore follows that there is no association between denominational affiliation and religious values in PCUSA and UCC camps that is statistically significant insofar as sources of program/curriculum materials in camp programs.

\section{1(b). Philosophy/Theology of Outdoor Religious Education}

The mode of philosophy/theology of outdoor religious education for both PCUSA and UCC camps was "Reformed Mainline." This is consistent with the ecclesiastical and historical affinity that the PCUSA and UCC share in terms of the Reformed tradition discussed in Chapter 1. There was also no statistically significant difference between PCUSA and UCC camps as to philosophy/theology on the basis of denominational affiliation and the measure of association was weak (lambda $=.024)$. The conclusion therefore follows that there is no association between denominational affiliation and religious values in PCUSA and UCC camps that is statistically significant insofar as philosophy/theology of outdoor religious education. 


\section{1(c). Level of Importance of 13 Philosophical/Theological Purposes}

Two of 13 philosophical/theological purposes served in PCUSA and UCC camps ${ }^{64}$ examined showed a statistically significant difference between PCUSA and UCC camps on the basis of denominational affiliation:

(1) "Providing opportunities to win campers for Jesus Christ through public witness and commitment to Jesus Christ as their personal Lord and Savior" [chi-square $=15.248$; $\mathrm{p}=.004]$. This indicates that there was a significant difference in the level of importance of this purpose between PCUSA and UCC camps. The median for this purpose was "important" for PCUSA camps, but "not very important" for UCC camps. While this purpose had a weak measure of association (lambda $=.093$ ), it had the strongest measure among the 13 purposes examined; and

(2) "Providing opportunities for campers to gain more knowledge about the Bible and Christian beliefs" [chi-square $=12.019 ; \mathrm{p}=0.017$ ]. This indicates again that there was a significant difference in the level of importance of this purpose between PCUSA and UCC camps. The median for this purpose was also "very important" for PCUSA camps, but only "important" for UCC camps. Moreover, while the measure of association for this purpose was weak (lambda $=.043)$, it had the second strongest measure among the 13 purposes examined.

The conclusion therefore follows that the association between denominational affiliation and religious values in PCUSA and UCC camps is statistically significant insofar as the level of importance reported for these two philosophical/theological purposes, such that the hypothesis under this aspect of the study is not supported. This conclusion is also generally consistent with

\footnotetext{
${ }^{64}$ This question represented the primary question under religious values.
} 
the sort of differences in adherence to doctrinal and "confessional" standards reflected in the respective beliefs and practices of the PCUSA and the UCC discussed in Chapter 1.

\section{1(d). Three Most Important Philosophical/Theological Purposes}

The relative uniformity indicated between PCUSA and UCC camps insofar as the three most important philosophical/theological purposes served in camp programs is, again, generally consistent with both the emphasis in the PCUSA and UCC on educational ministry, especially outdoor educational ministry, and the ecclesiastical and historical affinity that they share in the Reformed tradition discussed in Chapter 1 . However, it should also be noted that neither of the philosophical/theological purposes for which a statistically significant difference was indicated between PCUSA and UCC camps were among the three purposes deemed most important by either PCUSA or UCC camps.

While the bounds of the study's results preclude any definitive conclusion regarding this latter point, it does represent something of a "mixed bag;" that is, while the conclusion clearly follows that the hypothesis regarding the religious values aspect of the study is not supported on the basis of significant statistical differences indicated for two philosophical/theological purposes served in camp programs, there is also other, not insubstantial, data indicative of a considerable degree of uniformity between PCUSA and UCC camps. Two inferences, if not conclusions, that relate significantly to the other two aspects of the study, can be drawn from this "mixed bag:"

(1) As discussed in Chapter 1, the affinity that exists between the PCUSA and the UCC is also reflected to a substantial degree by the data for PCUSA and UCC camps. However, there are also significant differences reflected between both the denominations and the denominational camps that appear to be grounded in theology (e.g., doctrines, beliefs and practices). These differences thus give rise to the question as to whether differences, if 
any, in environmental values and the integration of religious and environmental values between PCUSA and UCC camp programs are themselves grounded in these sort of religious differences; and

(2) PCUSA and UCC camps not only report a strong ecclesiastical relationship with their respective denominations, but they also appear to reflect the theological doctrines, beliefs and practices of their respective denominations, including those in which the PCUSA and UCC seem to differ. As introduced in Chapter 1 and discussed at length in Chapter 2 in terms of reviewing the strong environment-related policy papers and positions of both denominations, the question arises as to whether differences, if any, in environmental values and the integration of religious and environmental values between PCUSA and UCC camp programs are, again, theologically grounded?

\section{Environmental Values}

The hypothesis under this aspect of the study focused on the association between denominational affiliation and environmental values in PCUSA and UCC church camp programs:

\section{$\mathrm{H}_{2}$ : Environmental values in PCUSA and UCC church camp programs are independent of denominational affiliation and the association between them is not statistically significant.}

In arriving at a conclusion for this hypothesis, the results are discussed and interpreted in the order of the three questions in the questionnaire that focused on this aspect of the study.

\section{2(a). Level of Importance of Environmental/Ecological Activities}

The median indicated for the level of importance of environmental/ecological activities in camp programs for both PCUSA and UCC camps was "important," but not "very important." 
However, although the measure of association was also weak (lambda $=.091$ ), a statistically significant difference was indicated between PCUSA and UCC camps in the level of importance (chi-square $=17.860 ; \mathrm{p}=.001)$. This indicates that there was a significant difference in the level of importance between PCUSA camps and UCC camps. The conclusion therefore follows that the association between denominational affiliation and environmental values in PCUSA and UCC camps is statistically significant insofar as the level of importance of environmental/ ecological activities in camp programs, such that the hypothesis under this aspect of the study is not supported.

\section{2(b). Level of Importance of Seven Environmental/Ecological Indicators}

Three of the seven environmental/ecological indicators examined as to level of importance ${ }^{65}$ in camp programs showed a statistically significant difference between PCUSA and UCC camps on the basis of denominational affiliation:

(1) "Campers develop knowledge of environmental issues and perceive the potential harm to the environment from various forms of human impact" ${ }^{\prime 66}$ (chi-square $=$ $30.392 ; \mathrm{p}=.000)$. This indicates that there was a significant difference in the level of importance of this indicator between PCUSA and UCC camps. This indicator also had the strongest measure of association (lambda $=.205$ ) among the seven indicators examined. The median was also reported as "important" in UCC camps, but "neither important nor unimportant" in PCUSA camps. Over 50\% of UCC camps (54.6\%) also reported it as "important" or "very important" as compared to just over $40 \%$ of PCUSA camps $(42.8 \%)$;

\footnotetext{
${ }^{65}$ This question represented the primary question under environmental values and follows the first model or framework developed by Negra and Manning (1997).

${ }^{66}$ This is defined as an "Ownership" environmental indicator in the Negra and Manning (1997) model (pp. 12, 14).
} 
(2) "Campers develop a sense of personal investment in environmental issues and perceive the importance of engaging in environmental protection" ${ }^{\prime 67}$ (chi-square $=$ $16.638 ; \mathrm{p}=.002)$. This indicates that there was a significant difference in the level of importance of this indicator between PCUSA and UCC camps. However, the measure of association for this indicator was not very strong (lambda $=.091)$. The median was also "neither important nor unimportant" in both PCUSA and UCC camps, although almost $50 \%$ of UCC camps $(47.7 \%)$ reported it as "important" or "very important" as compared to just under $40 \%$ of PCUSA camps (38.2\%); and

(3) "Campers develop knowledge of strategies for environmental action and familiarity with activities that promote or preserve environmental quality" ${ }^{\prime 68}$ (chi-square $=$ $21.121 ; \mathrm{p}=.000)$. This indicates that there was a significant difference in the level of importance of this indicator between PCUSA and UCC camps. This indicator also had the second strongest measure of association (lambda $=.116)$ among the seven indicators examined. Although the median was "neither important nor unimportant" in both PCUSA and UCC camps, almost $40 \%$ of UCC camps (39.5\%) reported it to be "important" or "very important" as compared to just over $30 \%$ of PCUSA camps $(30.9 \%)$.

It should also be noted that the two indicators reported by UCC camps as "important," "Campers participate in outdoor activities and develop sensitivity, concern, and empathy for the environment" 69 and "Campers develop knowledge of environmental issues and perceive the

\footnotetext{
${ }^{67}$ This is defined as an "Ownership" environmental indicator in the Negra and Manning (1997) model (pp. 12, 14).

${ }^{68}$ This is defined as an "Empowerment" environmental indicator in the Negra and Manning (1997) model (pp.12, 14).

${ }^{69}$ This is defined as an "Entry Level" environmental indicator in the Negra and Manning (1997) model (pp. 12, 14).
} 
potential harm to the environment from various forms of human impact, ${ }^{, 70}$ reflect an emphasis on environmental values at the "Ownership" level as well as "Entry-level" in the Negra and Manning model (1997). According to Negra and Manning (1997), “Ownership” indicators are "variables [that] personalize environmental issues through expanded understanding and investment" (pp. 12, 14). In contrast, PCUSA camps reported only the first of these indicators as "important," indicating that the emphasis in PCUSA camps on environmental values is "Entrylevel" only, defined by Negra and Manning (1997) as "variables [that] function as prerequisites for environmentally responsible behavior by providing the foundation for proenvironmental (sic) attitudes and decision making" (pp. 12, 14) (emphasis supplied).

The conclusion therefore follows that the association between denominational affiliation and environmental values in PCUSA and UCC camps is statistically significant on level of importance as to several of these indicators, so the hypothesis under this aspect of the study is, again, not supported.

\section{2(c). Three Most Important Environmental/Ecological Indicators}

In contrast to significant statistical differences in terms of the indicators summarized above, there was general uniformity as to the three most important environmental/ecological indicators in PCUSA and UCC camp programs. Therefore, no further conclusion is drawn on this basis regarding the hypothesis under this aspect of the study.

\section{Integration of Religious and Environmental Values}

The hypothesis under this aspect of the study focused on the association between denominational affiliation and the integration of religious and environmental values in PCUSA and UCC church camp programs:

\footnotetext{
${ }^{70}$ This is defined as an "Ownership" environmental indicator in the Negra and Manning (1997) model (pp. 12, 14).
} 


\section{$\mathrm{H}_{3}$ : Integration of religious and environmental values in PCUSA and UCC church camp programs is independent of denominational affiliation and the association between them is not statistically significant.}

In arriving at a conclusion for this hypothesis, the results are discussed and interpreted in the order of the three questions in the questionnaire that focused on this aspect of the study.

\section{3(a). Relating Environmental/Ecological Activities and Philosophical/Theological Purposes}

The median indicated for PCUSA camps in terms of the strength of the relationship between environmental/ecological activities and philosophical/theological purposes in camp programs was "strong," but not "very strong," while the median for UCC camps was "neither strong nor weak." There was also a statistically significant difference between PCUSA and UCC camps as to the strength of this relationship [chi-square $=21.727 ; \mathrm{p}=.000]$. This indicates that there was a significant difference in the strength of this relationship between PCUSA and UCC camps. Moreover, the measure of association between denominational affiliation and the strength of this relationship was moderately strong (lambda $=.140$ ).

The conclusion therefore follows that the association between denominational affiliation and the integration of religious values and environmental values in PCUSA and UCC camps is statistically significant insofar as the strength of the relationship between environmental/ ecological activities and philosophical/theological purposes in camp programs, such that the hypothesis under this aspect of the study is not supported. 


\section{3(b). Likelihood of 16 Environmental Ethics Statements Being Taught in Camp Programs}

Three of 16 environmental ethics statements examined as to their likelihood of being taught in camp programs ${ }^{71}$ showed a statistically significant difference between PCUSA and UCC camps on the basis of denominational affiliation:

(1) "Humans were created as fundamentally different from other living things"72 [chi-square $=9.775 ; \mathrm{p}=.044]$. This indicates that there was a significant difference in the likelihood of this statement being taught in camp programs between PCUSA and UCC camps. The median for statement was also reported as "more likely than less likely" to be taught in PCUSA camps, but "less likely than more likely" to be taught in UCC camps. Over $40 \%$ of PCUSA camps (44.3\%) reported this statement as "likely" or "more likely" to be taught in camp programs as compared to less than $20 \%$ of UCC camps (19.5\%);

(2) "Nature is God's creation",73 [chi-square $=9.568 ; \mathrm{p}=.023$ ]. This indicates that there was a significant difference in the likelihood of this statement being taught in camp programs between PCUSA and UCC camps. However, the median reported for this statement indicated that it was "very likely" to be taught in both PCUSA and UCC camp programs and it also had a weak measure of association (lambda $=.023$ ). Almost $98 \%$ of PCUSA camps (97.4\%) reported this statement as "likely" or "more likely" to be taught in camp programs as compared to just over $90 \%$ of UCC camps (90.7\%); and

(3) "All living things are sacred" $" 74$ chi-square $=9.993 ; \mathrm{p}=.041]$. This indicates that there was a significant difference in the likelihood of this statement being taught in camp programs between PCUSA and UCC camps. The median for this statement was also

\footnotetext{
${ }^{71}$ This question represented the primary question in terms of the integration of religious values and environmental values and follows the second model or typology developed by Negra and Manning (1997).

${ }^{72}$ This is defined as "Benign Indifference" in the Negra and Manning (1997) typology (pp. 13, 15-16).

${ }^{73}$ This is defined as "Stewardship" in the Negra and Manning (1997) typology (pp. 13, 15-16).

${ }^{74}$ This is characterized as a "Stewardship" category in the Negra and Manning (1997) typology (13, 15-16).
} 
reported as "likely" to be taught in PCUSA camps, but "very likely" to be taught in UCC camps. Just over 55\% of PCUSA camps (55.3\%) reported this statement as "likely" or "more likely" to be taught in camp programs as compared to $80.0 \%$ of UCC camps.

Both PCUSA and UCC camps reported one statement defined by Negra and Manning (1997) as "Utilitarian Conservation",75 and three statements defined as "Stewardship"76 as "very likely" to be taught in camp programs. However, while PCUSA camps did not report any other statements in any of the ethical categories as "very likely" to be taught, UCC camps reported one additional statement defined as "Utilitarian Conservation"" and one additional statement defined as "Radical Environmentalism",78 as "very likely" to be taught in camp programs. Moreover, in terms of the integration of religious and environmental values in camp programs, it also seems to be significant, but not surprising, that two of the "Stewardship" statements on which PCUSA and UCC camps concurred are expressly religious ${ }^{79}$ while the additional statement under "Radical Environmentalism" that UCC camps reported as "very likely" to be taught is also expressly religious. ${ }^{80}$

This suggests that while the two "Stewardship" statements on which PCUSA and UCC camps concur show some shared affinity for integrating religious and environmental values, UCC camps reported an emphasis that is not only broader in its integration of religious and environmental values, but one that is more "radical" than that reported by PCUSA camps in terms of both religion and environmentalism. In terms of the "three key concepts" (p. 12) of the

\footnotetext{
75 "Nature adds to the quality of our lives."

76 "It is our religious/spiritual duty to take care of nature."

"Nature will be important to future generations."

"Nature is God's creation."

77 "Human survival depends on nature and natural processes."

78 "All living things are sacred."

79 "It is our religious/spiritual duty to take care of nature." "Nature is God's creation."

80 "All living things are sacred."
} 
typology developed by Negra and Manning describe (1997), it follows from this broader and more "radical" emphasis that:

(1) UCC camps tend to fall closer to the "biocentric" end of the "anthropocentric-biocentric continuum" (p. 12) than do PCUSA camps;

(2) UCC camps tend to show a stronger measure of openness to "ethical extensionism" and "egalitarian ethics" [that] "morally equates humans and nonhumans" (p. 13) than do PCUSA camps; and

(3) UCC camps tend to show a greater measure of "convergence" between "secular, religious and spiritual beliefs" and "secular environmental ethics based in rational thought" and between "spiritually based ethics" and "beliefs regarding spiritual qualities of nature" (p. 13) than do PCUSA camps.

The conclusion therefore follows that the association between denominational affiliation and the integration of religious and environmental values in PCUSA and UCC camps is statistically significant as to the likelihood of several of the statements being taught in camp programs, so that the hypothesis under this aspect of the study is, again, not supported.

\section{3(c). Three Most Likely Environmental Ethics Statement to be Taught in Camp Programs}

In contrast to significant statistical differences in terms of the statements summarized above, there was general uniformity as to the three environmental ethics statements most likely to be taught in PCUSA and UCC camp programs. Therefore, no further conclusion is drawn on this basis regarding the hypothesis under this aspect of the study.

\section{Implications of the Study}

The results regarding the three foci of the study - religious values, environmental values, and the integration of religious values and environmental values - indicate that none of the three 
hypotheses are supported. However, interpretation of statistically significant differences that do exist between PCUSA camps and UCC camps suggest three areas of significant implications in terms of church camping as it relates to PCUSA and UCC camps:

(1) The literature reviewed relating to studies and prior research in the organized camping and environmental education fields that, by analogy or implication, can be used to consider the potential for emphasis of religious and environmental values, and their integration, in PCUSA and UCC church camp programs, the environmental policies and positions of the PCUSA and UCC, denominational surveys in the PCUSA, and the spectrum of church camping literature;

(2) The practice of church camping, especially in relation to environmental values and concerns as an aspect of educational ministry in the PCUSA and the UCC; and

(3) The limitations of the study and the potential for further research related to church camping.

\section{Implications Related to the Literature}

As noted in Chapter 1, church camping, or outdoor education ministry, is characterized by three dimensions - theological, pedagogical, and environmental - with all three dimensions being essential to its practice. As also noted, it is the synthesis or integration of all three of these dimensions by which church camp programs can contribute to a more informed and responsible understanding of the natural environment by grounding the relationship between God and God's creation, including humanity, more ecologically and holistically. Organizational and descriptive profiles of both PCUSA and UCC camps, together with the strong environmental positions and strong educational traditions characteristic of their respective denominations, strongly suggests that both PCUSA and UCC camps are uniquely suited to practice all three dimensions of outdoor educational ministry. However, the results of the study also clearly indicate that the theological 
dimension, characterized by an emphasis on religious values, tends be the overriding focus in PCUSA and UCC camp programs.

This emphasis on religious values is not surprising, but rather is characteristic of the field historically. What is surprising is the virtual lack of a comparably significant, or even emerging, emphasis on environmental values in PCUSA and UCC camps given the strong environmental positions of the PCUSA and UCC, together with the strong ecclesiastical relationship that the camps report with their respective denominations. This lack of an emphasis on environmental values is also surprising in view of the literature that is, and is not, to be found in the field:

(1) Prior studies and research related to organized camping and environmental education, but virtually no studies or research related to church camping, especially in relation to either environmental values in church camping or the integration of religious and environmental values in church camp programs;

(2) The sheer breadth and depth, theologically as well as environmentally, of policy papers and statements on the environment and environment-related concerns adopted by the PCUSA and UCC;

(3) The extensive survey research by the PCUSA on environment-related topics, but also the limited scope of the one PCUSA survey purportedly focused on church camping; and

(4) The extensive church camping literature that effectively integrates religious values and environmental values, especially as compared to other church camping literature in which the primary or even exclusive emphasis is on religious values.

These areas of review of the literature will be discussed in order: 


\section{Outdoor Recreation Program Studies}

It should be noted at the outset that the view advanced here is not that every camp, or even every church camp, can be expected to have environmental values incorporated as part of their camp programs, although that expectation seems to have some particular relevance and applicability to PCUSA and UCC camps for the reasons stated earlier. Unquestionably, camps exist for a variety of purposes and interests as the studies and research in organized camping and environmental education reviewed earlier indicate.

For example, in addition to the extensive discussion of both Hungerford and Volk (1990) and Negra and Manning (1997), the studies and research reviewed in relation to organized camping clearly indicate that camps are effectively achieving outcomes and providing benefits for campers related to youth development such as building self-esteem and developing positive self-identity, developing social and leadership skills, making friends and healthy peer relationships, developing mental and physical skills, increasing self-confidence through adventure and challenge activities, and developing positive values (Henderson, Powell, \& Scanlin, 2005; Henderson, Scanlin, Whitaker, Thurber, Marsh, Burkhardt, \& Bialeschki, 2005; Ross \& Driver, 1988; Sekine, 1994). These outcomes and benefits also include environmental awareness and spiritual growth either as a specific and distinct benefit or in combination with other benefits in relation to both non-religious and religious camp programs (Henderson \& Bialeschki, 2008; Henderson, Powell, \& Scanlin, 2005; Henderson, Scanlin, Whitaker, Thurber, Marsh, Burkhardt, \& Bialeschki, 2005; Schnell, 1996).

Similarly, the studies and research reviewed show achievement of outcomes and benefits related to environmental education in outdoor programs such as the positive effects of outdoor activities (e.g., camps and adventure activities) on environmental attitudes and behaviors and as a 
basis for developing environmental responsibility (Palmberg \& Kuru, 2000; Thapa, 2010), fostering positive attitudes toward wildlife on the part of students in residential programs (Dettman-Easler \& Pease, 1999), building self-esteem and increasing environmental awareness and naturalist skills in campers at nature camps (Dresner \& Gill, 1994), developing more positive attitudes toward the outdoors and increasing understanding of ecological principles and the interconnectedness of humans and the environment on the part of staff in residential camps (Strickland, 1991), and, from a religious perspective, developing a view of nature as a sacred symbol on the part of campers in religiously-oriented camps (Clampit, 1970).

Similarly, the studies and research reviewed show achievement of outcomes and benefits related to environmental education in school and other education-related programs in terms of developing environmental attitudes and knowledge and increasing environmental perception through children's activities (Eagles \& Demare, 1999), using natural settings for educational purposes (Simmons, 1998), using science to help students become better environmental decisionmakers (Arvai, Campbell, Baird, \& Rivers, 2004), using a "multiple perspectives approach" to environmental issues (Christenson, 2004), using pre-trip and post-trip activities in a residential environmental education program (Smith-Sebasto \& Cavern, 2006), and the use of particular environmental education programs such as NatureScope (Armstrong \& Impara, 1991).

If, as these studies indicate, these types of outcomes and benefits are being effectively achieved in organized camping and environmental education, then the question that arises by analogy or implication is why an emphasis on environmental values and the integration of religious and environmental values, comparable to that on religious values, is not observable in PCUSA and UCC camp programs? Although the bounds of the study's result do not permit a definitive answer to this question, the reason may be theologically grounded as suggested earlier. 


\section{Denominational Policy Papers or Statements}

As discussed at length in the literature review, the PCUSA and UCC have adopted a number of denominational policy papers and statements indicating not only a growing awareness of an environmental crisis, but also articulating steps intended to address its myriad aspects and implications for people as well as other life forms on earth. However, even with the emergence of this emphasis on environmental concerns at a denominational level in both the PCUSA and UCC, together with the strong ecclesiastical relationship reported by PCUSA and UCC camps with their respective denominations, the results of this study clearly indicate that no comparable emphasis on environmental values or the integration of religious values and environmental values has emerged in PCUSA and UCC camps to counterbalance the historical and overriding emphasis on religious values.

However, as with the literature reviewed regarding outdoor recreation program studies, and although the bounds of the study's result do not permit a definitive answer to the question it raises, the reasons for this may, again, be theologically grounded as suggested earlier. Moreover, it is significant that, despite the breath and depth of theological and environmental discussion in these policy papers and statements, there is virtually no consideration given toward addressing environmental concerns, raising environmental awareness, or proposing environmental actions through an emphasis on environmental values and the integration of religious and environmental values in the outdoor educational ministry programs represented by PCUSA and UCC camps.

\section{Denominational Surveys in the PCUSA}

As discussed at length in the literature review, the PCUSA has done three denominationwide surveys that are related, either directly or by implication, to the environment and environmental concerns and another survey that purports to focus on church camps and retreats. While 
the results of the first three surveys, as might be expected, indicate a range of environmental attitudes and beliefs among PCUSA members, elders and clergy, the very fact that these surveys were done simply reinforces the conclusion that the environment and environmental concerns are viewed as having significant relevance to PCUSA beliefs and practices. The question is therefore raised again as to why, if they are significant to the denomination, that significance is not also reflected in PCUSA camps insofar as an emphasis on environmental values and the integration of religious and environmental values in PCUSA camp programs?

Moreover, the only relevant findings in the subsequent survey purportedly focusing on church camps and retreats involved spiritual growth and formation and the sorts of physical amenities that persons attending retreats expected to have in the retreat facilities. This suggests, again, that an effective emphasis on environmental values and the integration of religious and environmental values, comparable to the primary emphasis on religious values, is lacking even in how the PCUSA itself views outdoor educational ministry and church camp programs.

However, as with both the literature reviewed regarding outdoor recreation program studies and environmental policy papers and statements, the bounds of the study's result do not permit a definitive answer as to why this is the case, although the reasons for it may have to do with the historical tradition of PCUSA church camping or, again, may be theologically grounded.

\section{Church Camping Literature}

As noted and already discussed at length in the literature review by reference to the broad spectrum of church camping literature, there is little if any reference to nature or the natural world in terms of philosophy and programs at one end of the spectrum. The overriding focus and emphasis at this end of the spectrum is on religious values, such that any environmental focus and emphasis is either lacking or is confined to nature-type activities - in effect, an "entry level" 
approach - even where the literature expressly purports to have reference to things like nature, ecology, creation, and God's world.

In contrast, the other end of the spectrum comprises extensive church camping literature reflecting either a stronger emphasis on nature and the natural environment or a more intentional attempt to integrate religious values and environmental values in both philosophy and activities in church camp programs. Given the volume of church camping literature that is available and that does effectively make more effective use of nature and the natural environment in terms of integrating religious values and environmental values in camp programs, it is surprising that there is not a stronger emphasis on environmental values in PCUSA and UCC camps. For example, although the bounds of the study's results do not permit any conclusions to be drawn as to what literature is actually used by PCUSA and UCC camps, the selection of curriculum for use in camp programs from the more environmentally-grounded end of the spectrum could have a very significant effect on providing an emphasis on environmental values and the integration of religious and environmental values comparable to the emphasis on religious values.

As noted earlier, the strong emphasis given to the environment and to environmental concerns in the numerous policy papers and statements adopted by the PCUSA and UCC might be expected to result in selecting curriculum and other material from this end of the spectrum for use in PCUSA and UCC camp programs, especially in terms of the emphasis on environmental values and the effective integration of theology and environmental concern and practice reflected in these policy papers and statements. The results of this study, however, indicate that this is not the case in regard to PCUSA and UCC camps at present. 


\section{Implications or Conclusions Related to the Practice of Church Camping}

The results of this study also suggest four significant implications or conclusions about the practice of church camping as it relates to PCUSA and UCC camps:

(a) Neither PCUSA nor UCC camp programs reflect the strong environmental policy positions articulated by their respective denominations, especially as an aspect of educational ministry. However, UCC camps appear to provide slightly more of environmental emphasis and focus in camp programs than do PCUSA camps, although the difference seems to be one of degree.

(b) Neither denomination has effectively utilized the unique outdoor educational settings of their respective church camps to implement the strong environmental policies they have articulated. However, while the environmental position of the UCC appears to have been implemented to a greater degree, in view of the slightly stronger environmental emphasis and focus in UCC camps than in PCUSA camps, the difference seems to be, again, one of degree.

(c) The overriding emphasis and focus of educational ministry in PCUSA and UCC camps is religious values characteristic of their respective denominations. Despite the emergence of the natural environment as a theological and social concern in both denominations (in effect, rendering protection and restoration of the natural environment a religious value), the dominant paradigm that remains characteristic of PCUSA and UCC camps is grounded on the historical and theological traditions under which the camps were organized and developed. However, while this paradigm now appears to be somewhat less dominant in UCC camps, at least in terms of a slightly stronger environmental emphasis and focus in UCC camps than in PCUSA camps, the difference seems to be, again, one of degree. 
(d) As discussed in Chapter 1, this historical and theological paradigm that continues to be characteristic of PCUSA and UCC camps is in marked contrast to the more recent emergence of environmentally-oriented programs (e.g., environmental education and experiential education) in the organized camping field. While there may be slightly less of a contrast insofar as UCC camps, at least in terms of the slightly stronger environmental emphasis and focus in UCC camps than in PCUSA camps, the difference seems to be, again, one of degree.

As also noted in Chapter 1, no attempt was made in the study to determine (except indirectly) any reasons for the lack of an emphasis and focus on environmental values, and the continued dominance of an emphasis and focus on religious values, in PCUSA and UCC camps. However, the results suggest some possible reasons for these four implications that also conform to the material discussed in Chapter 1 having reference to the denominational backgrounds of the PCUSA and the UCC as well as the historical development of the organized camping field (including church camping):

(a) White and several other writers discussed in Chapter 1 are representative of the view that Christianity has contributed to, if not actually caused, much of the environmental crisis by, for example, historically exploitative practices of some developed nations, having Christianity as their dominant religious tradition, directed against both natural resources and indigenous peoples in undeveloped and less developed nations. It is argued that, at least historically, Christianity has been characterized more by anthropocentricism than environmentalism (Berry, 1973; BoumaPrediger, 2001; Gustafson, 1994; Johnson, 2000; McFague, 1993, 1997; Nash, 1997; Oelschlaeger, 1994; Rasmussen, 1996; Rolston, 1992; Santmire, 1985; Whilte, 1967; White, 1973). It can be further argued, however, that this anthropocentric tradition is not simply historical, but still persists. For example, it was not until 1982, two decades after the 
environmental crisis was recognized ${ }^{81}$ that the PCUSA adopted any position or statement regarding the environment.

There are also a number of other social, cultural and theological issues, many of them conflicted and divisive, that have increasingly commanded attention in "mainline" denominations such as the PCUSA and the UCC. It can be argued that the environmental issue has thus been marginalized and is of relatively less significance compared to other issues now facing the PCUSA and the UCC, especially given that both denominations have done little to implement their strong environmental policies beyond the adoption of the policy paper and statements. Santmire (1985) aptly describes the situation in The Travail of Nature as the "ambiguous ecological promise of Christian theology" when he observes that:

In traditional Christian thought...the rudiments for a rich theology of nature are not lacking. Indeed, at points, the tradition is dramatically suggestive for those who have eyes to see. But such rudiments must be carefully and cautiously identified, and then separated from numerous less promising or even antithetical elements which also permeate the same tradition. That is why it is appropriate to speak of the ambiguous ecological promise of Christian theology. As a whole, Christian thought is both promising and not promising for those seeking to find solid traditional foundations for a new theology of nature (p. 8-9).

(b) The results regarding philosophies/theologies of outdoor religious education indicate that the predominant philosophy/theology of both PCUSA and UCC camps is "Reformed Mainline" although PCUSA camps report a higher percentage in this regard (63.1\%) than do

\footnotetext{
${ }^{81}$ While there are several points in the historical timeline at which a sense of environmental "crisis" may be said to have been first recognized and articulated, a useful demarcation point was the publication in 1962 of Silent Spring by Rachel Carson. Carson's book, reflecting not only her academic and vocational credentials in science, but also her thorough scientific research, alerted the United States as well as other nations to the adverse environmental effects of chemical pesticides such as DDT.
} 
UCC camps (45.2\%). When all three of the categories of "Reformed" are included ("Reformed Mainline," "Reformed Liberal," and "Reformed Conservative"), "Reformed" is clearly the dominant philosophy/theology of PCUSA camps (86.4\%) and, to a lesser extent, of UCC camps (76.2\%). The strong environmental positions of both the PCUSA and UCC are grounded in the context of the Reformed tradition, indicating that religious values and environmental values can be effectively integrated.

However, the higher percentage of PCUSA camps than UCC camps in the "Reformed" category could be attributable to the fact that this tradition is very strongly grounded in the PCUSA, to the point of being normative, by reference to the mid- $20^{\text {th }}$ century theology of Karl Barth. Barth held that the only source of God's revelation is the person of Jesus Christ and scripture as it bears witness to Jesus Christ. Barthian theology also tends to be unsympathetic, if not altogether hostile, to any theological orientation grounded in the natural order (e.g., natural theology or a theology of nature). It also tends to discount or reject altogether even the potential of any sort of revelatory attribute or aspect of God within the natural order. Barthian theology is also characterized by an emphasis on historical and juridical paradigms and tends to ignore, discount or reject any alternative grounded in the natural world, even in terms of creation, as a valid or legitimate source for formulating a doctrine of God. Historical and juridical paradigms also tend to be, both in form and essence, anthropocentric. (Barth \& Brunner, 1946). Given the Christocentric (i.e., grounded exclusively or primarily in Jesus Christ) orientation of Barthian theology, it is consequently less theocentric (i.e., grounded in the diverse attributes or aspects of God, including, for example, God's "nature" as it relates to creation of the natural order). By defining itself so strongly in Christocentric terms and being grounded in historical and juridical paradigms, a Barthian orientation may give greater credence to the position of White and other 
writers discussed above that the environmental crisis can be attributed to the anthropocentric nature of Christian tradition.

In contrast, Barthian theology is much less significant as a theological orientation in the UCC. For example, in terms of the level of importance of philosophical/theological purposes served in camp programs, a statistically significant difference is reported between PCUSA camps and UCC camps as to two purposes grounded in Barthian theology:

(1) "Provide opportunities to win campers for Jesus Christ through public witness and commitment to Jesus Christ as their personal Lord and Savior:" This purpose was deemed “important” by PCUSA, but "not very important" by UCC camps; and

(2) "'Provide opportunities for campers to gain more knowledge about the Bible and Christian beliefs:" This purpose was deemed "very important" by PCUSA camps, but only "important" by UCC camps.

While the difference is not statistically significant, UCC camps also deemed the purpose, "Provide opportunities for campers to gain more knowledge of God's creation (including the natural world) and their Christian responsibility toward God's creation," as "very important." In contrast, PCUSA camps deemed this purpose as only "important." This stronger emphasis on environmental values in UCC camps may thus be attributable to a theological orientation in the UCC that, while still "Reformed," not only tends to be more open to the natural order (e.g., natural theology or a theology of nature), but that is also significantly less proscriptive than the Barthian theology characteristic of the PCUSA.

(c) As discussed in Chapter 1, the organized camping movement, and the church camping movement to a lesser extent, originated in the United States in an era strongly characterized by an increased and even romantic appreciation of nature and the natural world, particularly in 
terms of wilderness areas threatened both by population growth and resource-intensive industrial development. However, it was not an era in which the state of the environment was considered to be in "crisis." This was also a time of significant church growth, including the development of denominational church camps. The present paradigm in PCUSA and UCC camps thus developed in a time in which church growth and evangelism was the predominant emphasis and focus in the PCUSA and UCC. By reason of the importance of educational ministry in both denominations, there was also a strong emphasis and focus on religious education, including the development of church camps as an extension of the educational ministry of local churches. In the context of this strong emphasis on educational ministry, church growth, and evangelism, these "foundationaltype" values (i.e., religious values) not only constituted, but appear to continue as the normative paradigm for PCUSA and UCC camps.

(d) Lastly, as briefly noted in Chapter 1 in terms of developments in the organized camping field in the modern era, the nature of campers and of campers' expectations regarding camp experiences have changed significantly in relation to exposure to nature and the natural world (e.g., "outdoor living"). To what extent do expectations of campers in terms of camp experiences, including church camp experiences, reflect everyday life experiences distinct from campers' experiences in earlier eras? For example, the PCUSA survey purportedly focusing on church camps and retreats involved findings that, in significant part, focused only on what sort of amenities were expected in retreat facilities. To what extent are the myriad types of camps now available (e.g., computer camps, music and drama camps, and various kinds of sports camps) simply reflective of programs that do not require a natural setting and that, in fact, are often better served by and require more developed settings? To what extent are they also reflective of camp programs that make an extensive and instrumental use of natural settings (e.g., adventure 
camps) without necessarily fostering any care for or appreciation of the intrinsic value of the natural setting? Again, while the bounds of this study's result do not permit any conclusion to be drawn as to these kinds of questions, they certainly represent implications for PCUSA and UCC camps in terms of the study's results.

\section{Implications Related to Limitations of the Study and Further Research}

Six limitations or ways are discussed by which the study could have been improved, followed by discussion of four areas of the study having potential value for further research.

\section{(a) Limitations of the Study}

(1) It would have improved the study considerably if the several questions in the survey instrument related to religious values had been organized into models or typologies comparable to those developed by Negra and Manning (1997) and used for the several questions related to environmental values and the integration of religious values and environmental values. While the questions related to religious values were developed from a number of applicable sources (e.g., beliefs and doctrines characteristic of the PCUSA and UCC, purposes of church camping in the literature, purposes of organized camping in the literature, and personal experience of the author in the church camping and organized camping fields), the model and typology developed by Negra and Manning (1997) was used to develop questions that permitted categorization and ranking of values. In development of the survey instrument, no comparable categorization or ranking of the questions related to religious values was made, such that the religious values could not be categorized or ranked in a manner comparable to environmental values.

(2) Many questions (and all of the primary questions) in the survey instrument assessing religious values, environmental values, and the integration of religious values and environmental 
values utilized a Likert-type scale. It would have improved the study if, in addition to responses on a Likert-type scale, responses were also reported on other bases to permit:

(a) Ranking of the relative importance of each response, value, etc. compared to others;

(b) Performance of more or other types of statistical analysis than could be performed using interval data from a Likert-type scale; and

(c) In combination with developing models and/or typologies for religious values comparable to those of Negra and Manning (1997) and used for environmental values discussed in (1) above, more effective statistical analysis of the relationships (e.g., correlation) between each category of religious values, each category of environmental values, and each category of the integration of religious values and environmental values.

This type of analysis was attempted (e.g., using lambda to determine the strength of association) between: (i) Each individual religious value and each individual environmental value; and (ii) Each individual religious value and each individual value having reference to the integration of religious values and environmental values. However, this ended up producing so much data as to be entirely unwieldy for useful analysis.

(3) As noted in Chapter 3, no measures were taken to control non-response error in the collection of data. The possible measures that could have been taken to control non-response error are "doubledipping," comparing early to late respondents, comparing respondents to nonrespondents on known characteristics, and comparing non-respondents to the population on known characteristics. However, given that collection of data comprised the entire population of PCUSA and UCC camps, and that there were no known characteristics of non-respondents, only the first two measures would have been useable in this study. 
(4) The study would have been improved considerably by shortening the length of both the survey instrument itself and of particular questions in the instrument. As noted in Chapter 3, content validity of the instrument was based on its review by four persons with expertise and/or experience in pertinent fields (e.g., organized camping, church camping, and outdoor recreation). While all of these persons concurred in the questions initially included in the instrument, their suggestions (particularly from the two church camp directors) for additional questions increased the length of the instrument by approximately a third. The additional questions, however, were virtually all demographic or financial in nature (e.g., sources, number, and range of ages of campers, size and range of ages of staff, and sources of financial support for facilities and programs), such that the data obtained did not contribute significantly (if at all) to the primary focus of the study.

(5) As noted in Chapter 3, no measures were taken to establish the reliability of the survey instrument. The possible measures that could have been taken to establish the reliability of the instrument include those yielding a coefficient of internal consistency (split-half, oddeven, Kuder-Richardson, and Cronbach's Alpha), test-retest, and a pilot test. Simply on practical terms, a pilot test would have improved the study by providing opportunity to refine both the instrument and particular questions, while also establishing the reliability of the instrument.

(6) Related to (4) and (5) above (content and reliability of the survey instrument), the survey instrument would have been improved by inclusion of questions (or modification of some questions) to examine more directly:

(a) To what extent PCUSA and UCC camps are aware of and apply any aspects of the environmental policies and statements of their respective denominations reviewed in Chapter 2 in their camp programs; and 
(b) To what extent PCUSA and UCC camps are even aware of and/or use any of the curriculum material reviewed in Chapter 2 (or comparable curriculum material), that more effectively integrates religious values and environmental values in their camp programs.

Despite the relevance of both kinds of curriculum material to PCUSA and UCC camps, none of the questions in the survey instrument make a direct connection between these kinds of material and the specific focus of the study. It would have improved the study if this connection was made directly in order to more accurately evaluate and assess the emphasis (or its lack) on environmental values and the integration of religious values and environmental values in PCUSA and UCC camp programs. For this reason, this limitation is also included under possible further research.

\section{(b) Potential for Further Research}

(1) A necessary area for further research involves two kinds of material reviewed in Chapter 2: (a) Environmental policies and statements of the PCUSA and the UCC; and (b) Church camping curriculum materials. As discussed above, making a more direct connection between both kinds of material and the actual extent to which these kinds of material are utilized in PCUSA and UCC camp programs would permit a more accurate evaluation and assessment of the programs in terms of an emphasis (or its lack) on environmental values and the integration of religious values and environmental values.

(2) A related area of potential value for further research involves both identifying and evaluating the curriculum material actually used in PCUSA and UCC camp programs. It might be useful to do this through qualitative research (e.g., document analysis) in order to evaluate and assess the extent to which the material emphasizes environmental values and the integration of 
religious values and environmental values through a more effective use of nature and the natural world in camp programs.

(3) Related to (1) above insofar as the limitations of the study, another area of potential value for further research involves more specifically assessing the particular religious values, attitudes, etc. that influence PCUSA and UCC camp programs. Barthian theology, for example, influences PCUSA camp programming, but the actual form and degree of that influence or other theological orientations (e.g., natural theology or a theology of nature) has yet to be assessed for either PCUSA or UCC camps.

(4) A final area of potential value for further research involves identifying and assessing what particular program activities (or types of activities) are used in PCUSA and UCC camps to implement religious values, environmental values, and the integration of religious values and environmental values. It might be useful to also develop a model or typology of activities to categorize and rank the level of emphasis in each set of values (religious, environmental, etc.) or, as noted above in relation to curriculum materials, to utilize qualitative research in this regard. 


\section{ENVIRONMENTAL VALUES IN OUTDOOR RELIGIOUS EDUCATION}

1. Please indicate the state in which your camp is located:

3. Please mark ALL of the following that describe your camp's physical setting:

$\begin{array}{lll}\text { Urban area } & \text { Lake(s) } & \text { Plains or flatlands } \\ \text { Suburban area } & \text { Stream(s) } & \text { Arid or desert } \\ \text { Rural area } & \text { Mountain(s) } & \text { Mostly/completely wooded } \\ \text { Primitive area } & \text { Rolling hills } & \text { Mixed woods/field } \\ \text { Coastal } & \text { Other (please specify: } & \\ \end{array}$

3. Please indicate whether you use public lands (e.g., national forests or parks, state forests or parks, local parks or recreational facilities) for any of your camp programs: Yes No

4. Please mark ALL of the following that describe the "home" areas from where your campers come (excluding retreat groups or other user groups that utilize the site but not the camp's programs):
Urban
Rural
Suburban
Other (please specify:

5. Please mark the $\mathbf{O N E}$ response which best indicates the approximate number of campers who participate in your camp's programs each year (excluding retreat groups or other user groups that utilize the site but not the camp's programs):

$$
\begin{array}{llll}
100-250 & 250-500 & 500-750 & 750-1000
\end{array}
$$

6. Please mark ALL of the following age/grade groups that your camp serves:

Infant (Birth to Preschool)

Primary (Preschool to Grade 1)

Elementary (Grades 1 to 6)

Junior High (Grades 7 - 9)

Senior High (Grades $10-12$ )

Young Adults Attending College or Other Post-High Schooling

Young Adults (Ages 18 to 35)

Mid-Life Adults (Ages 35 to 65)

Retired or Senior Citizens (Age 65 and above)

(QUESTION \#7 ON REVERSE SIDE) 
7. Please mark the ONE response which best describes your source of campers:

Completely or primarily from the membership of local churches affiliated with the camp Mostly from the membership of local churches affiliated with the camp but some independent or otherwise outside the membership of local churches affiliated with the camp

Fairly even mix from the membership of local churches affiliated with the camp and independent or otherwise outside the membership of local churches affiliated with the camp Mostly independent or otherwise outside the membership of local churches affiliated with the camp but some from the membership of local churches affiliated with the camp Completely or primarily independent or otherwise outside the membership of local churches affiliated with the camp

Other (please specify:

8. Please mark ALL of the following that apply to your camp staff (with the exception of yourself):

Seasonal paid staff

Seasonal volunteer staff

Full time paid staff

Full time volunteer staff

Exclusively high school age

Exclusively college age

Exclusively adults
Primarily college age with some adults (no high school age)

Primarily adults with some high school age and/or college age

Primarily college age with some high school age and/or adults

Primarily high school age with some college age and/or adults

9. If "management relationship" is defined as the measure or extent of support, cooperation, etc., that your camp has with the denominational entity or religious group with which your camp is affiliated, please circle the ONE response which best describes the strength of your camp's management relationship with that denominational entity or religious group ( $1=$ very strong relationship to $5=$ very weak relationship):

$$
\begin{array}{llllll}
1 & 2 & 3 & 4 & 5 & \text { Not Sure } \quad \text { Not Applicable }
\end{array}
$$

10. If "ecclesiastical relationship" is defined as the measure or extent of identification, adherence, etc. between your camp's program and the faith tradition of the denominational entity or religious group with which your camp is affiliated, please circle the ONE response which best describes the strength of your camp's ecclesiastical relationship with that denominational entity or religious group ( $1=$ very strong relationship to $5=$ very weak relationship):

$\begin{array}{llllll}1 & 2 & 3 & 4 & 5 & \text { Not Sure } \quad \text { Not Applicable }\end{array}$ 
11. Please mark ALL of the following that describe the source of financial and other means of support for your camp's programs (but not the camp's physical facility):

Direct financial support from the denominational entity or religious group with which the camp is affiliated

Indirect support (e.g., services or goods rather than financial support) from the denominational entity or religious group with which the camp is affiliated

Direct financial support from governmental agencies

Indirect support (e.g., services or goods rather than financial support) from governmental agencies

Direct financial support from local churches affiliated with the camp

Indirect support (e.g., services or goods rather than financial support) from local churches affiliated with the camp

Direct financial support from other churches or non-profit entities not affiliated with the camp

Indirect support (e.g., services or goods rather than financial support) from other churches or non-profit entities not affiliated with the camp

Fundraisers, organized seasonal solicitations, capital campaigns, etc.

Camper fees

Gifts from parents, alumni, "friends of the camp," etc.

Other (please specify:

12. Of the financial and other support sources for your camp's programs that you marked in Question \#11, please indicate the three most important to your camp in terms of amount or level of support ( 1 =most important, $2=$ second most important, $3=$ third most important):

(1)

(2)

(3)

13. Please mark ALL of the following that describe the sources of financial and other means of support for your camp's physical facility (but not the camp's programs):

Direct financial support from the denominational entity or religious group with which the camp is affiliated

(QUESTION \#13 CONTINUED ON REVERSE SIDE) 
Indirect support (e.g., services or goods rather than financial support) from the denominational entity or religious group with which the camp is affiliated.

Direct financial support from governmental agencies

Indirect support (e.g., services or goods rather than financial support) from governmental agencies

Direct financial support from local churches affiliated with the camp

Indirect support (e.g., services or goods rather than financial support) from local churches affiliated with the camp

Direct financial support from other churches or non-profit entities not affiliated with the camp

Indirect support (e.g., services or goods rather than financial support) from the other churches or non-profit entities not affiliated with the camp

Fundraisers, organized seasonal solicitations, capital campaigns, etc.

Camper fees

Gifts from parents, alumni, "friends of the camp," etc.

Other (please specify:

14. Of the financial and other support sources for your camp's physical facility that you marked in Question \#13, please indicate the three most important to your camp in terms of amount or level of support ( $1=$ most important, $2=$ second most important, $3=$ third most important):

(1)

15. Please mark the ONE response which best describes the source(s) of your camp's program/ curriculum materials:

Denominational

Ecumenical (e.g., cooperative among several denominations)

Non-denominational (e.g., independent religious publisher or national camping organization such as the American Camping Association or Christian Camping International)

Self-developed and produced by your camp

Other (please specify:

(QUESTION \#15 CONTINUED ON NEXT PAGE) 


\section{IF POSSIBLE, PLEASE PROVIDE A COPY OF YOUR CAMP'S CURRICULUM (ESPECIALLY AS IT RELATES TO ENVIRONMENTAL/ECOLOGICAL ASPECTS OF YOUR CAMP'S PROGRAM) WHEN YOU RETURN THIS QUESTIONNAIRE. YOU WILL BE REIMBURSED FOR ANY COPYING, POSTAGE, ETC. COSTS.}

16. Please mark the $\mathbf{O N E}$ response which best describes your philosophy/theology of outdoor religious education:

$\begin{array}{lll}\text { Reformed (liberal) } & \text { Orthodox/neo-orthodox } & \text { Creationist } \\ \text { Reformed (conservative) } & \text { Environmental/ecological } & \text { Non-sectarian } \\ \text { Reformed (mainline) } & \text { Fundamentalist } & \text { Other (please specify: }\end{array}$

17. Please circle the $\mathbf{O N E}$ response which best describes the level of importance of $\mathbf{E A C H}$ of the

following philosophical/theological purposes in terms of your camp's program $(1=$ very important to $5=$ not important).

a. Provide opportunities to win campers for Jesus Christ through public witness and commitment to Jesus Christ as their personal Lord and Savior:

$$
\begin{array}{lllllll}
1 & 2 & 3 & 4 & 5 & \text { Not Sure } & \text { Not Applicable }
\end{array}
$$

b. Provide opportunities to develop, transmit and reinforce the particular faith tradition of camper's local church or religious group

$$
\begin{array}{lllllll}
1 & 2 & 3 & 4 & 5 & \text { Not Sure } & \text { Not Applicable }
\end{array}
$$

c. Provide opportunities for campers to help build, participate in, and experience a temporary faith community that is distinctively Christian:

$$
\begin{array}{lllllll}
1 & 2 & 3 & 4 & 5 & \text { Not Sure } & \text { Not Applicable }
\end{array}
$$

d. Provide opportunities for campers to grow spiritually in their personal faith experience and religious practices:

$$
\begin{array}{lllllll}
1 & 2 & 3 & 4 & 5 & \text { Not Sure } & \text { Not Applicable }
\end{array}
$$

e. Provide opportunities for campers to grow in their understanding of and relationship to God;

$\begin{array}{lllllll}1 & 2 & 3 & 4 & 5 & \text { Not Sure } & \text { Not Applicable }\end{array}$


f. Provide opportunities for campers to learn more about the relationship between God and God's creation:
2
3
$4 \quad 5$
Not Sure
Not Applicable

g. Provide opportunities for wholesome, faith-building and spiritually-enriching relationships with other campers and camp leaders in a Christian community:
12
$3 \quad 4$
5
Not Sure
Not Applicable

h. Provide opportunities for campers to support and extend the religious educational program of the camper's local church or religious group:
1
2
34
$5 \quad$ Not Sure
Not Applicable

i. Provide opportunities for campers to gain more knowledge about the Bible and Christian beliefs:
1
2
3
45
Not Sure
Not Applicable

j. Provide opportunities for campers to better learn how to apply Christian beliefs and Biblical values in their own lives:

$$
\begin{array}{lllllll}
1 & 2 & 3 & 4 & 5 & \text { Not Sure } & \text { Not Applicable }
\end{array}
$$

k. Provide opportunities for campers to gain more knowledge of God's creation (including the natural world) and their Christian responsibility toward God's creation:

$$
\begin{array}{llllll}
1 & 2 & 3 & 4 & 5 & \text { Not Sure }
\end{array}
$$

1. Provide opportunities for campers to develop positive inter-personal relationships, to build their self-esteem and to grow physically, emotionally and spiritually:

$$
\begin{array}{lllllll}
1 & 2 & 3 & 4 & 5 & \text { Not Sure } & \text { Not Applicable }
\end{array}
$$

m. Other (please specify:

$\begin{array}{lllllll}1 & 2 & 3 & 4 & 5 & \text { Not Sure } & \text { Not Applicable }\end{array}$

18. Please indicate (using the letters from Question \#17) the three most philosophical/ theological purposes of your camp's program from Question \#17 (1=most important, $2=$ second most important, $3=$ third most important):

(1)

(2)

(3)

\section{(QUESTION \#19 ON NEXT PAGE)}


19. Please circle the ONE response which best describes the level of importance of environmental/ecological activities in your camp's program (1=very important to $5=$ not important):

$$
\begin{array}{llllll}
1 & 2 & 3 & 4 & 5 & \text { Not Sure }
\end{array}
$$

20. Please circle the ONE response which best describes the strength of the relationship between environmental/ecological activities in your camp's program and the philosophical/ theological purposes of your camp's program (1=very strong relationship to $5=$ very weak relationship):

$\begin{array}{lllllll}1 & 2 & 3 & 4 & 5 & \text { Not Sure } & \text { Not Applicable }\end{array}$

21. Please circle the ONE response which best describes the level of importance of EACH of the following environmental/ecological indicators in terms of your camp's program (1=very important to $5=$ not important):

a. Campers participate in outdoor activities and develop sensitivity, concern and empathy for the environment:

$$
\begin{array}{lllllll}
1 & 2 & 3 & 4 & 5 & \text { Not Sure } & \text { Not Applicable }
\end{array}
$$

b. Campers develop knowledge of environmental issues and perceive the potential harm to the environment from various forms of human impact:

$\begin{array}{lllllll}1 & 2 & 3 & 4 & 5 & \text { Not Sure } & \text { Not Applicable }\end{array}$

c. Campers develop a sense of personal investment in environmental issues and perceive the importance of engaging in environmental protection:

$\begin{array}{lllllll}1 & 2 & 3 & 4 & 5 & \text { Not Sure } & \text { Not Applicable }\end{array}$

d. Campers develop knowledge of strategies for environmental action and familiarity with activities that promote or preserve environmental quality:
12
34
5
Not Sure
Not Applicable

e. Campers develop skills in using environmental action strategies and actually engage in activities that promote or preserve environmental quality:
1
2
3
4
5
Not Sure
Not Applicable

(QUESTION 321 CONTINUED ON REVERSE SIDE) 
f. Campers develop and/or change their own environmental values through increased perception that their own activities promote or preserve environmental quality:

$$
\begin{array}{llllll}
1 & 2 & 3 & 4 & 5 & \text { Not Sure }
\end{array}
$$

g. Campers develop and/or change their own environmental behavior through actual and expressed intention to engage in environmentally responsible actions:

$$
\begin{array}{llllll}
1 & 2 & 3 & 4 & 5 & \text { Not Sure }
\end{array}
$$

22. Please indicate (using the letters from Question \#21), the three most important environmental/ecological indicators in your camp's program from Question \#21 (1=most important, $2=$ second most important, $3=$ third most important);

(1)

(2)

(3)

23. Please circle the $\mathbf{O N E}$ response which best describes what the relationship between the environmental/ecological aspects and the philosophical/ theological aspects of your camp's program teaches (or is intended to teach) your campers in terms of EACH of the following statements ( $1=$ more likely to be taught this to $5=$ less likely to be taught this):

a. Nature can be dangerous to human survival:

b. Nature is sometimes evil:
$\begin{array}{lll}2 & 2 & 3 \\ \text { is sometimes evil: }\end{array}$
$4 \quad 5$
Not Sure
Not Applicable

$\begin{array}{lllllll}1 & 2 & 3 & 4 & 5 & \text { Not Sure } & \text { Not Applicable }\end{array}$

c. Nature is a valuable storehouse of raw materials:
12
34
5
Not Sure
Not Applicable

d. Humans were created as fundamentally different from other living things:
12
3
$4 \quad 5$
Not Sure
Not Applicable

e. The ability to think makes humans fundamentally different from other living things:

$\begin{array}{llllll}1 & 2 & 3 & 4 & 5 & \text { Not Sure }\end{array}$

f. Cruelty toward animals makes people less human:
1
2
3
$4 \quad 5$
Not Sure
Not Applicable
(QUESTION \#23 CONTINUED ON NEXT PAGE) 
g. The supply of goods and services provided by nature is limited:

$\begin{array}{lllllll}1 & 2 & 3 & 4 & 5 & \text { Not Sure } & \text { Not Applicable }\end{array}$

h. Nature adds to the quality of our lives:

$$
\begin{array}{lllllll}
1 & 2 & 3 & 4 & 5 & \text { Not Sure } & \text { Not Applicable }
\end{array}
$$

i. Human survival depends on nature and natural processes:

$$
\begin{array}{lllllll}
1 & 2 & 3 & 4 & 5 & \text { Not Sure } & \text { Not Applicable }
\end{array}
$$

j. It is our religious/spiritual duty to take care of nature:

$$
\begin{array}{llllll}
1 & 2 & 3 & 4 & 5 & \text { Not Sure } \quad \text { Not Applicable }
\end{array}
$$

k. Nature will be important to future generations:

$\begin{array}{lllllll}1 & 2 & 3 & 4 & 5 & \text { Not Sure } & \text { Not Applicable }\end{array}$

1. Nature is God's creation:

$\begin{array}{lllllll}1 & 2 & 3 & 4 & 5 & \text { Not Sure } & \text { Not Applicable }\end{array}$

m. All living things have a spirit:

$\begin{array}{lllllll}1 & 2 & 3 & 4 & 5 & \text { Not Sure } & \text { Not Applicable }\end{array}$

n. Animals should be free from needless pain and suffering:

$$
\begin{array}{lllllll}
1 & 2 & 3 & 4 & 5 & \text { Not Sure } & \text { Not Applicable }
\end{array}
$$

o. All living things are sacred:

$$
\begin{array}{lllllll}
1 & 2 & 3 & 4 & 5 & \text { Not Sure } & \text { Not Applicable }
\end{array}
$$

p. Humans are related to other living things through evolution:

$$
\begin{array}{lllllll}
1 & 2 & 3 & 4 & 5 & \text { Not Sure } & \text { Not Applicable }
\end{array}
$$

24. Please indicate (using the letters from Question \#23), the three most important things that your campers are taught (or that are intended to be taught) in terms of the relationship 
between the environmental/ecological aspects and the philosophical/theological aspects of your camp's program from Question \#23 (1=most important, 2=second most important, 3=third most important):

(1) (2) (3)

25. Please use the space below to add any other comments about the issues, statements, etc. raised in this questionnaire: 


\section{References}

Allen, R. (1983). Using environmental education, adventure and survival experiences. In J.S. Kerr (Ed.), Sow seeds: trust the promise (Environmental Education, pp. 1-36). New York, NY: National Council of the Churches of Christ in the U.S.A.

Allen, R.R. (2000). Environmental education. In N. Ferguson (Ed.), Outdoor ministries program leadership manual (pp. 193-205). New York, NY: National Council of the Churches of Christ in the U.S.A.

Alston, W.M., Jr. (1984). Guides to the Reformed tradition: The church. Atlanta, GA: John Knox Press.

American Camping Association. (1998). Accreditation standards for camp programs and services (1998 ed.). Martinsville, IN: American Camping Association.

Anderson, R. (1985). Community: Resources for outdoor ministry: Basic resource guide. Valley Forge, PA: Judson Press.

Andre, E.H. (1961). It can happen away from home. International Journal of Religious Education, 37(7), 8-9.

Angell, J.W. (1984). How to spell Presbyterian (Rev. ed.). Philadelphia, PA: Geneva Press.

Armstrong, J.B., \& Impara, J.C. (1991). The impact of an environmental education program on knowledge and attitude. The Journal of Environmental Education, 22(4), 36-40.

Arvai, J.L., Campbell, V.E., Baird, A., \& Rivers, L. (2004). Teaching students to make better decisions about the environment: Lessons from decision sciences. The Journal of Environmental Education, 36(1), 33-44.

Astle, J.H., \& Boss, J. (2000). Your wetlands are not a wasteland: Developing natural areas for program use. Camping Magazine, 73(5), 34-37. 
Badke, J. (1998). The Christian camp counselor: Becoming a camp counselor after God's own heart. British Columbia, Canada: Qwanoes Publishing.

Ball, A., \& Ball, B. (1995). Basic camp management: An introduction to camp administration ( $4^{\text {th }}$ ed.). Martinsville, IN: American Camping Association.

Ballinger, J.L. (1972). What's happening to church camps and conferences? Spectrum: International Journal of Religious Education, 48(2), 10-15.

Balmer, R. (1989). Adirondack fundamentalism. The Reformed Journal of Religious Education, $39(6), 4-21$.

Barr, J. (1993). Biblical faith and natural theology. New York, NY: Oxford University Press, Inc.

Barth, K., \& Brunner, E. (1946). Natural theology comprising "nature and grace" by Professor Dr. Emil Brunner and the reply "no!" by Dr. Karl Barth (P. Frankel, Trans.). London, England: The Centenary Press.

Bass, D.J. (1987). The Reformation heritage of the UCC and its meaning for twentieth-century Christians. In D.C. Bass \& K.B. Smith (Eds.), The United Church of Christ: Studies in identity and polity. Chicago, IL: Exploration Press.

Berry, W. (1973). A secular pilgrimage. In I.G. Barbour (Ed.), Western man and environmental ethics: Attitudes toward nature and technology. Reading, MA: Addison-Wesley Publishing Co.

Bogardus, L. (1955). Planning the church camp for juniors. Chicago, IL: National Council of the Churches of Christ in the United States of America.

Bogardus, L. (1961). Living and learning in God's world: A guide for leaders in junior camps and other outdoor activities of the church with juniors. Nashville, TN: Abingdon Press. 
Bogardus, L. (1971). Outdoor living: A guide for camping and other outdoor activities of the church with older elementary children. Nashville, TN: Abingdon Press.

Bonnell, J.S. (1975). What is a Presbyterian? In L. Rosten (Ed.), Religions in America: Ferment and faith in an age of crisis. New York, NY: Simon \& Schuster, Inc.

Borko, D. (2000). Stewardship. In N. Ferguson (Ed.), Outdoor ministries program leadership manual (pp. 81-90). New York, NY: National Council of the Churches of Christ in the U.S.A.

Bouma-Prediger, S. (2001). For the beauty of the earth: a Christian vision for creation care. Grand Rapids, MI: Baker Book House Co.

Bowman, C.M. (1954). Spiritual values in camping: What they are and how to put them into camper's lives. New York, NY: Association Press.

Bowman, W.D. (1979). The church and camping - some biblical considerations. Brethren Life and Thought, 24 (Winter), 7-11.

Brown, E. (1963). Outdoor experiences are not "extras." International Journal of Religious Education, 39(5), 10-11.

Burgess, H.W. (1975). An invitation to religious education. Birmingham, AL: Religious Education Press.

Calvin, J. (1559, 1960). Institutes of the Christian religion. J.T. McNeill (Ed.). F.L. Battles (Trans.). Philadelphia, PA: The Westminster Press.

Carson, R. (1962). Silent spring. Boston, MA: Houghton MifflinCompany.

Celebrate: Resources for camping facilities. (1970). Harrisburg, PA: Pennsylvania Council of Churches. 
Chamberlain, R.K. (2000). Trip and travel camping. In N. Ferguson (Ed.), Outdoor ministries program leadership manual (pp. 206-218). New York, NY: National Council of the Churches of Christ in the U.S.A.

Chandler, R.E. (1971). Ministry to campers: The gospel on the go. Christianity Today, 25(19), $31-32$.

Christensom, M.A. (2004). Teaching multiple perspectives on environmental issues in elementary classrooms: A story of teacher inquiry. The Journal of Environmental Education, 35.4, 3-16.

Church camping for junior highs: a manual of planning and administration for junior high camps. (1960). Philadelphia, PA: The Westminster Press.

Clampit, M.K. (1970). Nature as a sacred symbol in religiously oriented summer camps. Scientific Study of Religion, 9(2), 151-152.

Clark, C. (1990). The youth specialties handbook for great camps \& retreats. Grand Rapids, MI: Zondervan Publishing House.

Clyde, N.L. (1934). Discovering God in the beautiful. Philadelphia, PA: The Judson Press. Coalter, M.M., Multer, J.M., \& Weeks, L.B. (1990). Introduction. In M.J. Coalter, J.M. Multer, \& L.B. Weeks (Eds.), The Presbyterian predicament: Six perspectives (pp. 17-20). Louisville, KY: Westminster/John Knox Press.

Cobb, J.B., Jr. (1992). Sustainability: Economics, ecology \& justice. Philadelphia, PA: The Westminster Press.

Cobric, K. (1983). Lifestyles of faithfulness: Resources for outdoor ministry: Guide for older children. St. Louis, MO: Bethany Press. 
Cockrell, D. (Ed.). (1991). The wilderness educator: The wilderness education association curriculum guide. Merrillville, IN: ICS Books, Inc.

Cramer, C. (1983). Theology of stewardship. In J.S. Kerr (Ed.), Sow seeds: Trust the promise (Stewardship, pp. 1-10). New York, NY: National Council of the Churches of Christ in the U.S.A.

Crouser, W.C. (1984). Stewardship of creation: Resources for outdoor ministry: Basic resource guide. Philadelphia, PA: Westminster Press.

Cruger, D.W. (1973). The church school goes to camp: Discovery weekends. Spectrum: International Journal of Religious Education, 49(4), 8-11.

Cues for church camping for counselors of juniors and junior highs. (1962). Philadelphia, PA: The Geneva Press.

Daly, L.C. (2000). A moment to decide: The crisis in mainstream Presbyterianism. New York, NY: Institute for Democracy Studies.

Davis, L. (1954). Juniors in God's world: A guide for camp leaders on conservation and stewardship. Philadelphia, PA: The Christian Education Press.

Dettman-Easler, D., \& Pease, J.L. (1999). Evaluating the effectiveness of residential environmental education programs in fostering positive attitudes toward wildlife. The Journal of Environmental Education, 31(1), 33-39.

Devall, W., \& Sessions, G. (1985). Deep ecology: Living as if nature mattered. Salt Lake City, UT: G.M. Smith.

Dillenberger, J., \& Welch, C. (1954). Protestant Christianity interpreted through its development. New York, NY: Charles Scribner's Sons. 
Dimock, H.S. (Ed.). (1948). Administration of the modern camp. New York, NY: Association Press.

Dresner, M., \& Gill, M. (1994). Environmental education at summer nature camp. The Journal of Environmental Education, 25(3), 35-41.

Dunn, D., Crusius, P.N., Friedli, J., Menzel, T.W., Schneider, C.E., \& Toth, W. (1990). A history of the Evangelical and Reformed Church. New York, NY: The Pilgrim Press.

Eagles, P.F., \& Demare, R. (1999). Factors influencing children's environmental attitudes. The Journal of Environmental Education, 30(4), 33-37.

Eells, E. (1986). History of organized camping: The first 100 years. Martinsville, IN: American Camping Association.

Ensign, J., \& Ensign, R. (1958). Camping together as Christians: A guide for junior high camp leaders. Richmond, VA: John Knox Press.

Fackre, C. (1990). Christian doctrine in the United Church of Christ. In D.L. Johnson, \& C. Hambrick-Stowe (Eds.), Theology and identity: Traditions, movements, and polity in the United Church of Christ (pp. 90-99). Cleveland, OH: United Church Press.

Farly, E.W. (1990). The Presbyterian heritage as modernism: Reaffirming a forgotten past in hard times. In M.J. Coalter, J.M. Multer, \& L.B. Weeks (Eds.), The Presbyterian predicament: Six perspectives (pp. 52-66). Louisville, KY: Westminster/John Knox Press.

Fawver, G.K. (1995). Rediscovering the outdoors. Unpublished doctoral dissertation. Western Conservative Baptist Seminary, Portland, Oregon.

Ferguson, N. (Ed.). (2000). Outdoor Ministries Program Leadership Manual. New York, NY: National Council of the Churches of Christ in the U.S.A. 
Fraenkel, P. (Trans.). (1946). Natural theology: Comprising "nature and grace" by Professor Dr. Emil Brunner and the reply "no!" by Dr. Karl Barth. London, England: the Centenary Press.

Gehris, K. (1983). Lifestyles of faithfulness: Resources for outdoor ministry: Guide for older children. St. Louis, MO: Bethany Press.

Gehris, K. (1984). Stewardship of creation: Resources for outdoor ministry: Guide for older children. Philadelphia, PA: Westminster Press.

Gehris, K. (1985). Community: Resources for outdoor ministry: Guide for older children. Valley Forge, PA: Judson Press.

Genné, E., \& Genné, W.H. (1962). Church family camps and conferences: An administrative and program manual. Philadelphia, PA: The Christian Education Press.

Genné, W.H. (1961). Summer ways are changing. International Journal of Religious Education, 37(7), 5-7, 48.

Gieschen, D.W. (Ed.). (1971). Creative church camping: group leader's manual and program guide. Philadelphia, PA: Lutheran Church Press.

Gingrich, K.A. (1979). A theology of leisure. Brethren Life and Thought, 24 (Winter), 50-54.

Glasscock, E.H. (1961). Summertime is "outdoors" time. International Journal of Religious Education, 37(7), 10-14, 46.

Goodrich, L. (1959). Decentralized camping: A completely updated book on how to administer and program for outdoor living in small groups. Martinsville, IN: American Camping Association.

Graber, L. (1976). Wilderness as sacred space. Washington, DC: The Association of American Geographers. 
Grabher, J. (1990, 1998). God is in our midst: Resources for outdoor ministry: Camper's resource for older children (Rev. ed.). Louisville, KY: Geneva Press.

Grabher, J. (1990, 1998). God is in our midst: Resources for outdoor ministry: Camper's resource for primary children (Rev. ed.). Louisville, KY: Geneva Press.

Grabher, J., \& Rose-Heim, D.R. (1990, 1998). God is in our midst: Resources for outdoor ministry: Leader's guide for children (Rev. ed.). Louisville, KY: Geneva Press.

Graendorf, W.C., \& Mattson, L.D. (1979). Introduction to Christian camping. Chicago, IL: Moody Press.

Graham, J. (1997). Outdoor leadership: Common sense \& self-confidence. Seattle, WA: The Mountaineers.

Gray, J.S., \& Tucker, J.C. (1986). Presbyterian polity for church officers. Atlanta, GA: John Knox Press.

Grenz, S.J., Guretzki, D., \& Nordling, C.F. (1999). Natural theology. In S.J. Grenz, D. Guretzki, \& C.F. Nordling (Eds.), Pocket dictionary of theological terms. Downers Grove, IL: InterVarsity Press.

Guideposts to junior high camping in Westminster fellowship. (1958). Philadelphia, PA: Presbyterian Church in the U.S.A.

Gunneman, L.H. (1987). United and uniting: The meaning of an ecclesial journey: United Church of Christ 1957-1987. New York, NY: United Church Press.

Gustafson, J.M. (1994). A sense of the divine: The natural environment from a theocentric perspective. Cleveland, $\mathrm{OH}$ : The Pilgrim Press. 
Haldane, J. (2000). Natural theology. In A. Hastings, A. Mason, \& H. Pyper (Eds.), The Oxford companion to Christian thought: Intellectual, spiritual, and moral horizons of Christianity. New York, NY: Oxford University Press, Inc.

Hammerman, D.R., Hammerman W.M., and Hammerman, E.L. (1994). Teaching in the outdoors ( $4^{\text {th }}$ ed.). Danville, IL: Interstate Publishers, Inc.

Harder, G. (1978). A theology for Christian camping. In P. Paetkau, G. Harder, \& D. Sawatzky (Eds.), God man land: Interrelationship programs for camps. Newton, KS: Faith and Life Press.

Hargrove, E. (1989). Foundations of environmental ethics. Englewood Cliffs, NJ: Prentice Hall. Harris, M. (1989). Fashion me a people: Curriculum in the church. Louisville, KY: Westminster/John Knox Press.

Harrison, P., \& Pearce, F. (Eds.). (2000). AAAS atlas of population and environment. Berkeley, CA: University of California Press in association with the American Association for the Advancement of Science.

Harvey, V.A. (1964). Theology. In V.A. Harvey (Ed.), A handbook of theological terms. New York, NY: Macmillan Publishing Co., Inc.

Hauerwas, S. (2001). With the grain of the universe: The church's witness and natural theology. Grand Rapids, MI: Baker Book House Co.

Henderson, K.A., \& Bialeschki, M.D. (2008). Spiritual development and camp experiences. New Directions for Youth Development, 118, 107-110.

Henderson, K.A., Powell, G.M., \& Scanlin, M.M. (2005). Observing outcomes in youth development: An analysis of mixed methods. Journal of Park and Recreation Administration, 23(4), 58-77. 
Henderson, K.A., Scanlin, M.M., Whitaker, L.S., Thurber, C., Marsh, P., Burkhardt, M., \& Bialeschki, M.D. (2005). Intentionality and youth development through camp experiences. Eleventh Canadian Congress on Leisure Research, 1-4. Abstract retrieved from http://lin.ca/Uploads/cclr11/CCLR11-58.pdf

Hendry, G.S. (1980). Theology of nature. Philadelphia, PA: The Westminster Press.

Hungerford, H., \& Volk, T. (1990). Changing learner behavior through environmental education. The Journal of Environmental Education, 21(3), 8-21.

Hunt, J.S., Jr. (1994). Ethical issues in experiential education. Dubuque, IA: Kendall/Hunt Publishing Company.

Johnson, E.A. (2000). Losing and finding creation in the Christian tradition. In D.T. Hessel, \& R.R. Ruether (Eds.), Christianity and ecology: Seeking the well-being of earth and humans. Cambridge, MA: Harvard University Press.

Junior camping cues for churches. (1957). Philadelphia, PA: Presbyterian Church in the U.S.A.

Kamm, R.T. (1983). Lifestyles offaithfulness: Resources for outdoor ministry: Guide for younger youth. St. Louis, MO: Bethany Press.

Kamm, R.T. (1984). Stewardship of creation: Resources for outdoor ministry: Guide for younger youth. Philadelphia, PA: Westminster Press.

Kamm, R.T. (1985). Community: Resources for outdoor ministry: Guide for younger youth. Valley Forge, PA: Judson Press.

Keener, C.S. (1985). Toward a holistic view of nature: A process perspective. In L. Mattson (Ed.), God's good earth: Christian values in outdoor education (pp.131-138). Duluth, MN: Camping Guideposts. 
Kellert, S.R. (1980). Knowledge, affection and basic attitudes toward animals in American society: Phase III. Washington, DC: United States Government Printing Office.

Kellert, S.R., \& Berry, J.K. (1979). Public attitudes toward critical wildlife and natural habitat issues: Phase I. Washington, DC: U.S. Government Printing Office.

Kemper, K. (Ed.). (1991). Caring for God's world. Prescott, AZ: Educational Ministries, Inc.

Kemper, K. (Ed.). (1991). Co-workers in creation. Prescott, AZ: Educational Ministries, Inc.

Kemper, K. (Ed.). (1991). Co-workers in creation: First steps in ecology. Brea, CA: Educational Ministries, Inc.

Kerr, J.S. (Ed.). (1983). Leadership development notebook for outdoor ministries. New York, NY: National Council of the Churches of Christ in the U.S.A.

Klopfenstein, D.E., Klopfenstein, D.S., \& Williams, G. (1993). Come yourselves apart: Christian leadership in the temporary community. Azusa, CA: SP Publications, Inc.

Kraus, R.G., \& Scanlin, M.M. (1983). Introduction to camp counseling. Englewood Cliffs, NJ: Prentice-Hall, Inc.

Laroe, E.T., Farris, G.S., Puckett, C.E., Doran, P.D., \& Mac, M.J. (Eds.). (1995). Our living resources: A report on the distribution, abundance, and health of U.S. plants, animals, and ecosystems. Washington, DC: U.S. Government Printing Office.

Larre, D. (1979). Environment and world tourism. EPA Journal, 5(16), 27-29.

Leith, J.H. (1977, 1981). Introduction to the Reformed tradition: a way of being the Christian community (Rev. ed.). Atlanta, GA: John Knox Press.

Leopold, A. (1949). A Sand County almanac. New York, NY: Oxford University Press. Leyburn, J.G. (1962). The Scotch-Irish: A social history. Chapel Hill, NC: The University of North Carolina Press. 
Little, S. (1995). Reformed theology and religious education. In R.C. Miller (Ed.), Theologies of religious education (pp. 25-30). Birmingham, AL: Religious Education Press.

Lomborg, B. (2001). The skeptical environmentalist: Measuring the real state of the world. Cambridge, England: Cambridge University Press.

Long, A.H. (1961). International day camping. International Journal of Religious Education, $37(7), 11-12,48$.

Louth, A. (1991). The wilderness of God. Nashville, TN: Abingdon Press.

MacInnes, G.A. (1962). A guide to worship in camp and conference. Philadelphia, PA: The Westminster Press.

Mackay, J. (1984). Creative camping. Wheaton, IL: SP Publications, Inc.

Malone, T. (1979). Rejoicing with creation: A camp counselor's manual for leaders of older elementary children. Atlanta, GA: John Knox Press.

Manley, J. (1983). Theology of music. In J.S. Kerr (Ed.), Sow seeds: Trust the promise (Music, pp. 1-15). New York, NY: National Council of the Churches of Christ in the U.S.A.

Marheine, A.H. (1995). You belong: A handbook for church members (Rev. ed.). Cleveland, OH: United Church Press.

Martin-Adkins, A. (1983). Lifestyles of faithfulness: Resources for outdoor ministry: Guide for older youth. St. Louis, MO: Bethany Press.

Martin-Adkins, A. (1984). Stewardship of creation: Resources for outdoor ministry: Guide for older youth. Philadelphia, PA: Westminster Press.

Martin-Adkins, A. (1985). Community: Resources for outdoor ministry: Guide for older youth. Valley Forge, PA: Judson Press. 
Mason, M.E. (1962). Let the bible speak outdoors. New York, NY: National Council of the Churches of Christ in the U.S.A.

Mattson, L. (1984). Build your church through camping: Camping: The church's best friend. Duluth, MN: Camping Guideposts.

Mattson, L. (1985). Beyond the nature trail. In L. Mattson (Ed.), God's good earth: Christian values in outdoor education (pp. 51-57). Duluth, MN: Camping Guideposts.

Mattson, L. (Ed.). (1985). God's good earth: Christian values in outdoor education. Duluth, MN: Camping Guideposts.

Mattson, L. (1985). Introduction. In L. Mattson (Ed.), God's good earth: Christian values in outdoor education (pp. 13-16). Duluth, MN: Camping Guideposts.

Mattson, L. (1998). Christian camping today: A complete handbook for the short-term staff. Wheaton, IL: Harold Shaw Publishers.

McCollough, C., \& McCollough, C. (1983). Lifestyles of faithfulness: Resources for outdoor ministry: Basic resource guide. St. Louis, MO: Bethany Press.

McFague, S. (1993). The body of God: An ecological theology. Minneapolis, MN: Fortress Press. McFague, S. (1997). Super, natural Christians: How we should love nature. Minneapolis, MN: Fortress Press.

Mead, F.S., \& Hill, S.S. (1985). Handbook of denominations in the United States ( $8^{\text {th }}$ ed.). Nashville, TN: Abindgon Press.

Meier, J.F., \& Mitchell, A.V. (1993). Camp counseling: Leadership and programming for the organized camp ( $7^{\text {th }}$ ed.). DuBuque, IA: Brown \& Benchmark Publishers.

Messinger, C.F., Simpson, J.E., \& Ulrich, G.F. (1966). Seeking meaning with junior highs in camp. Philadelphia, PA: The Geneva Press. 
Messinger, F. (1975). Let's go outdoors. Spectrum: International Journal of Religious Education, 51(1), 24-26.

Miles, J.C., \& Priest, P. (Eds.) (1990). Adventure education. State College, PA: Venture Publishing Inc.

Miller, D.E. (1979). The biblical basis for ecology. Brethren Life and Thought, 24 (Winter), $12-$ 17.

Miller, R.F. (1990, 1998). God is in our midst: Resources for outdoor ministry: Camper's resource for younger youth (Rev. ed.). Louisville, KY: Geneva Press.

Miller, R. F., \& Rose-Heim, D.R. (1990, 1998). God is in our midst: Resources for outdoor ministry: Leader's guide for younger youth (Rev. ed.). Louisville, KY: Geneva Press.

Milton, J.L. (1935). Let’s go out-of-doors. Nashville, TN: Cokesbury Press.

Mitchell, A.V., Robberson, J.D., \& Obley, J.W. (1977). Camp counseling (5 ${ }^{\text {th }}$ ed.). Philadelphia, PA: W.B. Saunders Company.

Mitchell, F.H. (1979). Observations on campground ministry. Brethren Life and Thought, 24 (Winter), 40-44.

Monkres, P.R., \& Ostermiller, R.K. (1995). The rite of confirmation: Moments when faith is strengthened. Cleveland, OH: United Church Press.

Moore, M.E. (1990, 1998). God is in our midst. In J. Grabher, \& D.R. Rose-Heim (Ed.), God is in our midst: Resources for outdoor ministry: Leader's guide for children (Rev. ed., pp. 6-10). Louisville, KY: Geneva Press.

Morgan, G. (1994). The mythologies of outdoor and adventure recreation and the environmental ethos. The Ontario Journal of Outdoor Education, 6(6), 11-16. 
Nash, J.A. (1991). Loving nature: Ecological integrity and Christian responsibility. Nashville, TN: Abingdon Press.

Nash, R.F. (1989). The rights of nature. Madison, WI: The University of Wisconsin Press.

Negra, C. \& Manning, R.E. (1997). Incorporating environmental behavior, ethics and values into non-formal environmental education programs. The Journal of Environmental Education, 28(2), 10-21.

Nordbeck, E.C. (1990). Theological tradition of Congregationalism: In D.L. Johnson \& C. Johnson, D.L., \& Hambrick-Stowe, C. (Eds.). (1990). Theology and identity: Traditions, movements, and polity in the United Church of Christ (pp. 3-16). Cleveland, OH: United Church Press.

Novacek, M.J. (Ed.). (2001). The biodiversity crisis: Losing what counts. New York, NY: The New Press in association with the American Museum of Natural History.

Oelschlaeger, M. (1994). Caring for creation: An ecumenical approach to the environment. New Haven, CT: Yale University Press.

Paetkau, P., Harder, G., \& Sawatzky, D. (Eds.) (1978). God man land: Interrelationship programs for camps. Newton, KS: Faith and Life Press.

Palmberg, I.E., \& Kuru, J. (2000). Outdoor activities as a basis for environmental responsibility. The Journal of Environmental Education, 31(4), 32-36.

Peters, R.R. (1979). The impact of camping on Brethren leadership. Brethren Life and Thought, 23 (Winter), 30-33.

Peterson, M. (1985). Gaining a mountain-top perspective. In L. Mattson (Ed.), God's good earth: Christian values in outdoor education (pp. 109-111). Duluth, MN: Camping Guideposts. 
Presbyterian Church (U.S.A.). (n.d.). Association of Presbyterian Church Educators. Retrieved from http://www.apcenet.org/

Presbyterian Church (U.S.A.). (2001). Book of order: 2001-2002 (IIII G-1.0305, G-3.0100G-3.0401, G-4.0300-G-4.0302, G-4.0301b, G-5.0201, G-6.0100-G-6.0503, G-6.0104, G-9.0100-G-9.0902, G-10.0100-G-10.0401, G-10-0102f, G-11.0100-G-11.0504, G-12.0100-G-12.0306, G-13.0100-G-13.0202, G-14.0100-G-14.0103, G-14.0300G-14.0517, W-1.4007-W-1.409, W-2.3013, W-6.2005). Louisville, KY: the Office of the General Assembly of the Presbyterian Church (U.S.A.).

Presbyterian Church (U.S.A.). (1999). Book of confessions (IIII4.103, 5.146-5.147, 9.36). Louisville, KY: The Office of the General Assembly of the Presbyterian Church (U.S.A.).

Presbyterian Church (U.S.A.). (n.d.) Christian education in the Presbyterian Church (U.S.A.). Retrieved from http://www.horeb.pcusa.org/cc/

Presbyterian Church (U.S.A.). (n.d.). Presbyterian Church Camp and Conference Associates. Retrieved from http://www.pcca.net/

Presbyterian Church (U.S.A.). (1999-2000). PCUSA Camp, conference and retreat centers directory. Louisville, KY: Congregational Ministries Division of the Presbyterian Church U.S.A.

Presbyterian Church (U.S.A.) (2009). Presbyterian Church Camp and Conference Associates vision statement. Retrieved from http://www.pccca.net/resources/PCCCAVisionStatement.pdf

Presbyterian Church (U.S.A.). Church camps and retreats. Louisville, KY: Office of the General Assembly of the Presbyterian Church (U.S.A.). 
Presbyterian Church (U.S.A.). (n.d.). Environmental justice office. Retrieved from http://www.pcusa.org/environment/

Presbyterian Church (U.S.A.) (1996). Hope for a global future: Toward just and sustainable human development. Louisville, KY: Office of the General Assembly of the Presbyterian Church (U.S.A.).

Presbyterian Church (U.S.A.). (1997). Nature and the environment. Louisville, KY: Office of the General Assembly of the Presbyterian Church (U.S.A.).

Presbyterian Church (U.S.A.). (n.d.). Presbyterians for Restoring Creation. Retrieved from http://www.pcusa.org/prc/html/main.html

Presbyterian Church (U.S.A. (1990). Restoring creation for ecology and justice. Louisville, KY: Office of the General Assembly of the Presbyterian Church (U.S.A.).

Presbyterian Church (U.S.A.). (1998). Science, technology, and faith. Louisville, KY: Office of the General Assembly of the Presbyterian Church (U.S.A.).

Presbyterian Church (U.S.A.). (n.d.). Social justice ministries. Retrieved from http://www.pcusa.org/social/

Presbyterian Church (U.S.A.). (1991). The environment. Louisville, KY: Office of the General Assembly of the Presbyterian Church (U.S.A.).

Priest, S. \& Gass, M.A. (1997). Effective leadership in adventure programming. Champaign, IL: Human Kinetics.

Quellhorst, R.C. (1990). Evangelical Synod theology. In D.L. Johnson, \& C. Hambrick-Stowe (Eds.), Theology and identity: Traditions, movements, and polity in the United Church of Christ (pp. 17-23). Cleveland, OH: United Church Press.

Rasmussen, L.L. (1996). Earth community earth ethics. Maryknoll, NY: Orbis Books. 
Rian, E.H. (1940). The Presbyterian conflict. Grand Rapids, MI: Wm. B. Eerdmans Publishing Co.

Rice, R. (1935). Exploring God's out-of-doors. Boston, MA: The Pilgrim Press.

Rodney, L.S., \& Ford, P.M. (1971). Camp administration: School, communities,organizations. New York, NY: John Wiley and Sons, Inc.

Rogers, J. (1995). Claiming the center: Churches and conflicting worldviews. Louisville, KY: Westminster/John Knox Press.

Rolston, H. (1989). Philosophy gone wild: Essays in environmental ethics. Buffalo, NY. Prometheus Books.

Rolston, H., III. (1992). Wildlife and wildlands: A Christian perspective. In D.T. Hessel (Ed.), After nature's revolt: Eco-justice and theology. Minneapolis, MN: Fortress Press.

Ross, D.M., \& Driver, B.L. (1988). Benefits of residential and nonresidential youth summer camps. Journal of Outdoor Education, 22, 14-20.

Sadek, H. (1994). A future for the past. National Parks, 68.2, 38-42.

Santmire, H.P. (1985). The travail of nature: The ambiguous promise of Christian theology. Philadelphia, PA: Fortress Press.

Scharper, S.B. (1997). Redeeming time: A political theology of the environment. New York, NY: The Continuum Publishing Co.

Schnell, J. (1996). Understanding a spiritual youth camp as a consciousness raising group: The effects of a subculture's communication. Report retrieved from http://www.eric.ed.gov/ERICDocs/data/ericdocs2sq1/content_storage_01/0000019b/80/1 7/80/d7.pdf 
Schreckhise, R.F. (1979). A Christian ministry in the national parks. Brethren Life and Thought, 24 (Winter), 45-49.

Schroeder, W.W. (1987). The United Church of Christ: The quest for denominational identity and the limits of pluralism. In D.C. Bass \& K.B. Smith (Eds.), The United Church of Christ: Studies in identity and polity (pp. 1-14). Chicago, IL: Exploration Press.

Sekine, A. (1994). The effect of camp experience upon the locus of control and general self-efficacy of school children. Bulletin of Institute of Health and Sports Sciences, 17, 177-183.

Sheares, R.A., II. (1990). A covenant polity. In D.L. Johnson \& C. Hambrick-Stowe (Eds.), Theology and identity: Traditions, movements, and polity in the United Church of Christ (pp. 67-78). Cleveland, OH: United Church Press.

Shetler, J.C. (1990). Reformed Church theological tradition. In D.L. Johnson \& C. HambrickStowe (Eds.), Theology and identity: Traditions, movements, and polity in the United Church of Christ (pp. 17-23). Cleveland, OH: United Church Press.

Shivers, J.S. (1989). Camping: Organization and operation. Englewood Cliffs, NJ: PrenticeHall, Inc.

Simmons, D. (1998). Using natural setting for environmental education: Perceived benefits and barriers. The Journal of Environmental Education, 29(3), 23-31.

Simpson, J.E. (1983). Do you worship nature? In J.S. Kerr (Ed.), Sow seeds: Trust the promise (Worship, pp. 7-8). New York, NY: National Council of the Churches of Christ in the U.S.A. 
Simpson, J.E. (1983). Guidelines for worship in outdoor settings. In J.S. Kerr (Ed.), Sow seeds: Trust the promise (Worship, pp. 1-13). New York, NY: National Council of the Churches of Christ in the U.S.A.

Simpson, S. (1996). A Leopold for the nineties: The ecological age in outdoor recreation. Outdoor Recreation, 19(1), 14-21.

Sittler, J. (1972). Essays on nature and grace. Philadelphia, PA: Fortess Press.

Smart, J.D. (1954). The teaching ministry of the church: An examination of the basic principles of Christian education. Philadelphia, PA: The Westminster Press.

Smith-Sebasto, N.J. (1995). The effects of an environmental studies course on selected variables related to environmentally responsible behavior. The Journal of Environmental Education, 26(4), 30-34.

Snyder, G.F. (1979). The impact of camping on the life-style of the faith community. Brethren Life and Thought, 24 (Winter), 18-23.

Spotts, C.D. (1963). God's voice in the out-of-doors. International Journal of Religious Education, 39.5, 6-7.

Stone, C. (1972). Should trees have standing? Los Altos, CA: William Kaufmann.

Strickland, M.A. (1991). The use of the residential summer camp for promoting responsible environmental behavior through environmental education (Master's thesis). Dalhousie University, Halifax, Nova Scotia, Canada. Retrieved from http://www.acacamps.org/research/bib/strickland.htm

Suess, S., \& Ferguson, N.W. (1990, 1998). God is in our midst: Resources for outdoor ministry: Camper's resource for older youth (Rev. ed.). Louisville, KY: Geneva Press. 
Suess, S., \& Ferguson, N.W. (1990, 1998). God is in our midst: Resources for outdoor ministry: Leaders's guide for older youth (Rev. ed.). Louisville, KY: Geneva Press.

Taylor, R.H. (1990). Christian church perspectives. In D.L. Johnson \& C. Hambrick-Stowe (Eds.), Theology and identity: Traditions, movements, and polity in the United Church of Christ (pp. 17-23). Cleveland, OH: United Church Press.

Thapa, B. (2010). The mediation effect of outdoor recreation participation on environmental attitude-behavior correspondence. The Journal of Environmental Education, 41(3), 133150.

Trost, F.R. The gift of authority. In D.L. Johnson \& C. Hambrick-Stowe (Eds.), Theology and identity: Traditions, movements, and polity in the United Church of Christ (pp. 90-99). Cleveland, OH: United Church Press.

Tucker, M.E., \& Grim, J. (2000). Rethinking worldviews and ethics. In D.T. Hessel, \& R.R. Ruether (Eds.), Christianity and ecology: Seeking the well-being of earth and humans (pp. xv-xviii). Cambridge, MA: Harvard University Press.

Tully, B. (1979). Historical perspectives of camping among the Brethren. Brethren Life and Thought, 24 (Winter), 24-28.

United Church of Christ (n.d.). About us: Frequently asked questions (faqs) about the United Church of Christ. Retrieved from http://www.ucc.org/aboutus/faq.htm

United Church of Christ (n.d.). About us: The constitution of the United Church of Christ (IIII5-6, 9-10, 15-16, 20-30, 37-55). Retrieved from http://www.ucc.org/aboutus/constitution.htm United Church of Christ. (n.d.). About us: What is the United Church of Christ? Retrieved from http://www.ucc.org/aboutus/whatis. 
United Church of Christ. (1959). Call to Christian action in society. Cleveland, OH: United Church of Christ.

United Church of Christ (n.d.). Directory of UCC outdoor ministry sites and programs.

Retrieved from http://www.oma-ucc.org/camp-dir.htm

United Church of Christ. (1989). Integrity of creation, justice and peace. Cleveland, OH: United Church of Christ.

United Church of Christ. (1969). Hunger, population and world development. Cleveland, OH: United Church of Christ.

United Church of Christ. (1967). Justice and international development. Cleveland, OH: United Church of Christ.

United Church of Christ. (n.d.). Justice and peace. Retrieved from http://www.ucc.org/justice/index.html

United Church of Christ. (n.d.). Justice and peace: Biblical foundations. Retrieved from http://www.ucc.org/justice/bf.htm

United Church of Christ. (n.d.). Justice and peace: Take action! Retrieved from http://www.ucctakeaction.org/action/index.asp

United Church of Christ. (1994) My confirmation: A guide for confirmation and instruction (Rev. ed., pp. 113-126, 160-162). Cleveland, OH: United Church Press.

United Church of Christ. (n.d.). Neighbors in need: It's about justice! Retrieved from http://www.ucc.org/steward/nin/index.html

United Church of Christ. (n.d.). Network for Environmental and Economic Responsibility. Retrieved from http://www.Centerl.com/NEER/NEERl.html 
United Church of Christ (n.d.). Outdoor Ministry Association. Retrieved from http://oma-ucc.org/

United Church of Christ (n.d.). Ooutdoor Ministry Association mission statement. Retrieved from http://oma-ucc.org/mission.htm

United Church of Christ. (1975). Overture on the bicentennial with an affirmation of human interdependence. Cleveland, $\mathrm{OH}$ : United Church of Christ.

United Church of Christ. (1977). Overture on the domestic impact of energy resource development. Cleveland, $\mathrm{OH}$ : United Church of Christ.

United Church of Christ. (1979). Pronouncement on energy: Policy and program. Cleveland, OH: United Church of Christ.

United Church of Christ. (1985). Pronouncement on national toxic injustice. Cleveland, OH: United Church of Christ.

United Church of Christ. (1975). Pronouncement on the world food crisis. Cleveland, OH: United Church of Christ.

United Church of Christ. (1983). Pronouncement on toxic and hazardous waste. Cleveland, OH: United Church of Christ.

United Church of Christ. (1980). Religion and energy in the 80s. Cleveland, OH: United Church of Christ.

United Church of Christ. (1975). Report on Christian life style and ecology. Cleveland, $\mathrm{OH}$ : United Church of Christ.

United Church of Christ. (1977). Report on Christian life style and ecology. Cleveland, OH: United Church of Christ. 
United Church of Christ. (1977). Resolution and report on racial and economic justice.

Cleveland, OH: United Church of Christ.

United Church of Christ. (1991). Resolution for support of the United Nations conference on environment and development. Cleveland, $\mathrm{OH}$ : United Church of Christ.

United Church of Christ. (1993). Resolution in support of international fair trade. Cleveland, OH: United Church of Christ.

United Church of Christ. (1993). Resolution in support of the United Nations conference on population and development. Cleveland, $\mathrm{OH}$ : United Church of Christ.

United Church of Christ. (1991). Resolution in support of UCC delegates to the Earth Summit. Cleveland, OH: United Church of Christ.

United Church of Christ. (1993). Resolution of respect for animals. Cleveland, OH: United Church of Christ.

United Church of Christ. (1983). Resolution on Christian environmental stewardship. Cleveland, OH: United Church of Christ.

United Church of Christ. (1989). Resolution on environment, solid waste and ecologically sound lifestyle. Cleveland, OH: United Church of Christ.

United Church of Christ. (1999). Resolution on global warming. Cleveland, OH: United Church of Christ.

United Church of Christ. (1991). Resolution on justice in the Maquiladoras. Cleveland, OH: United Church of Christ.

United Church of Christ. (1967). Resolution on leisure. Cleveland, OH: United Church of Christ. United Church of Christ. (1974). Resolution on the energy crisis. Cleveland, OH: United Church of Christ. 
United Church of Christ. (1967). Resolution on population control. Cleveland, OH: United Church of Christ.

United Church of Christ. (n.d.). Short course: Congregationalism. Retrieved from http://www.ucc.org/aboutus/shortcourse/congo.htm

United Church of Christ. (n.d.). Short course: German Evangelical churches. Retrieved from http://www.ucc.org/aboutus/shortcourse/move.htm

United Church of Christ. (n.d.). Short course: German Evangelical synod. Retrieved from http://www.ucc.org/aboutus/shortcourse/evan.htm

United Church of Christ. (n.d.). Short course: German Reformed Church. Retrieved from http://www.ucc.org/aboutus/shortcourse/reformed.htm

United Church of Christ. (n.d.). Short course: Moves toward unity. Retrieved from http://www.ucc.org/aboutus/shortcourse.ecum.htm

United Church of Christ. (n.d.). Short course: Not the final chapter. Retrieved from http://www.ucc.org/aboutus/shortcourse/ucc.htm

United Church of Christ. (n.d.). Short course: Reformation in England. Retrieved from http://www.ucc.org/aboutus/shortcourse/england.htm

United Church of Christ. (n.d.) Short course: Reformation roots. Retrieved from http://www.ucc.org/aboutus/shortcourse/roots.htm

United Church of Christ. (n.d.). Short course: The Christian churches. Retrieved from http://www.ucc.org/aboutus/shortcourse/christia.htm

United Church of Christ. (n.d.). Short course: The Congregational Christian churches. Retrieved from http://www.ucc.org/aboutus/shortcourse/ 
United Church of Christ. (n.d.). Short course: The Evangelical and Reformed Church.

Retrieved from http://www.ucc.org/aboutus/shortcourse/e\&r.htm

United Church of Christ. (n.d.) Short course: The first centuries. Retrieved from http://www.ucc.org/aboutus/shortcourse/intro.htm

United Church of Christ. (n.d.). Short course: Westward expansion and social vision.

Retrieved from http://www.ucc.org/aboutus/shortcourse/educ.htm

United Church of Christ. (1970). Statement on a decent environment. Cleveland, OH: United Church of Christ.

United Church of Christ. (n.d.). The Association of United Church Educators. Retrieved from http://www.aucc-educators.org/

United Church of Christ. (n.d.). The educational mission of the United Church of Christ. Retrieved from http://www.ucc.org/education/mission/index.html

United Church of Christ. (n.d.). The United Church of Christ: A family of faith for a global community. Retrieved from http://www.ucc.org/aboutus/family.htm

United Church of Christ. (1975). What is the United Church of Christ? In L. Rosten (Ed.), Religions of America: Ferment and faith in an age of crisis (pp. 277-292). New York, NY: Simon \& Shuster, Inc.

United Presbyterian Church in the U.S.A. (1984). Christian faith and economic justice. Louisville, KY: Office of the General Assembly of the Presbyterian Church (U.S.A.). United Presbyterian Church in the U.S.A. (1982). The theology of stewardship. Louisville, KY: Office of the General Assembly of the Presbyterian Church (U.S.A.). Valliere, W. (1994). Environmental ethics, attitudes and behaviors: An empirical study (Unpublished master's thesis). University of Vermont, Burlington, VT. 
Van Matre, S. (1972). Acclimatization: A sensory and conceptual approach to ecological involvement. Martinsville, IN: American Camping Association.

Van Matre, S. (1974). Acclimatizing: A personal and reflective approach to a natural relationship. Martinsville, IN: American Camping Association.

Van Matre, S. (1979). Sunship earth: An acclimatizing program for outdoor learning. Martinsville, IN: American Camping Association.

Van Slyck, A. A. (2006). A manufactured wilderness: Summer camps and the shaping of American youth. Minneapolis, MN: University of Minnesota Press.

Venable, M.E. (1955). God at work in his world: A program guidance manual for leaders in church day camps or resident camps for juniors. Nashville, TN: Abingdon Press.

Venable, S.F., \& Joy, D.M. (1998). How to use camping experiences in religious education: Transformation through Christian camping. Birmingham, AL: Religious Education Press.

Wackernagel, M, \& Rees, W. (1996). Our ecological footprint: Reducing human impact on the earth. Gabriola Island, B.C., Canada: New Society Publishers.

Warren, K., Sakofs, S., \& Hunt, J.S., Jr. (Eds.), The theory of experiential education. Dubuque, IA: Kendall/Hunt Publishing Company.

White, L., Jr. (1967). The historic roots of our ecologic crisis. Science, 155 (3767), 12031207.

White, L., Jr. (1973). Continuing the conversation. In I.G. Barbour (Ed.), Western man and environmental ethics. Reading, MA: Addison-Wesley Publishing Co.

Wilkinson, R.E. (1981). Camps: Their planning and management. St. Louis, MO: The C.V. Mosby Company. 
Witt, T.R. (1979). Responsible with creation: A camp counselor's manual for leaders of junior high youth. Atlanta, GA: John Knox Press.

Woodgates, G.M. (1963). Is nature study Christian education? International Journal of Religious Education, 39.5, 4-6, 18-19.

World Council of Churches. (1990). Now is the time: The final document and other texts from the World Convocation on Justice, Peace and the Integrity of Creation (p. 18). Geneva, Switzerland: WCC Publications.

World Resources Institute. (2000). World resources 2000-2001: People and ecosystems, the fraying web of life. Washington, DC: World Resources Institute in association with the United Nations Development Programme, the United Nations Environment Programme, and the World Bank.

Wuthnow, R. (1990). The restructuring of American Presbyterianism: Turmoil in one denomination. In M.J. Coalter, J.M. Multer, \& L.B. Weeks (Eds.), The Presbyterian predicament: Six perspectives (pp. 27-29, 35-39, 46-48). Louisville, KY:

Westminster/John Knox Press.

Yaple, C.H. (1985). Merging at the crossroads: New vehicles for environmental education. In L. Mattson (Ed.), God's good earth: Christian values in outdoor education (pp. 113-121). Duluth, MN: Camping Guideposts.

Zikmund, B.B. (1990). Empowerment and embodiment: Understandings of ministry in the United Church of Christ. In D.L. Johnson \& C. Hambrick-Stowe (Eds.), Theology and identity: Traditions, movements, and polity in the United Church of Christ (pp. 79-89). Cleveland, OH: United Church Press.

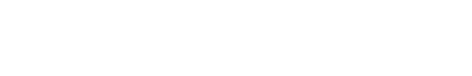 Vu=Acquisitions Department
oustions Hagen}

